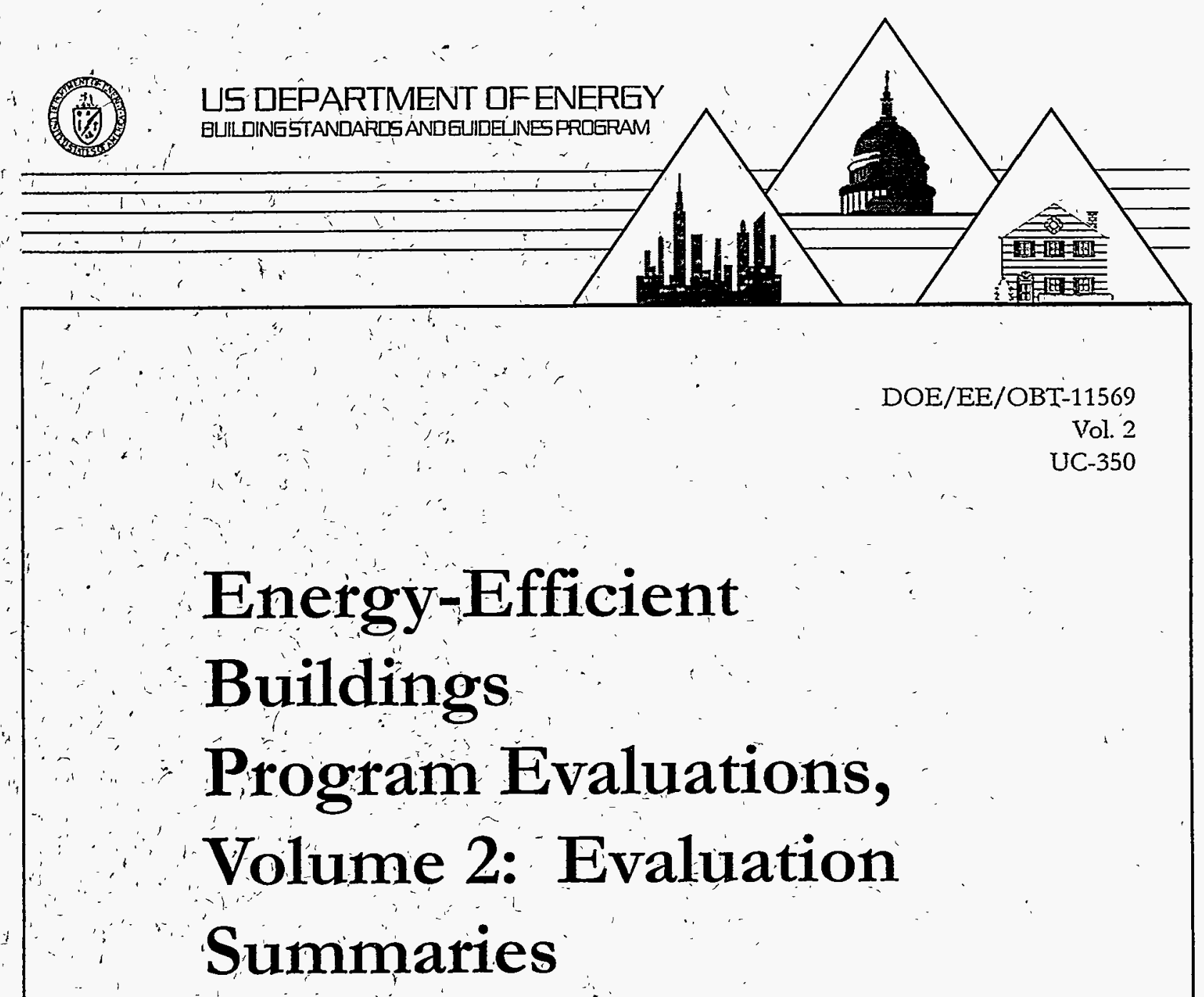
A. D Lee
D. Mayi
S.D. Edgemon

April 1997

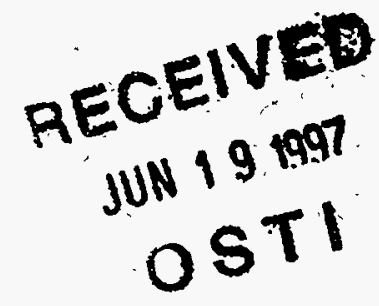

MASTER 
This report was prepared as an àceount of work sponsored by an agency of the United States Government. Neither the United States Government nor any agency thereof, nor any of their employees, makes any warranty, express or implied; or assumes any legal liability of responsibility for the accuracy, ${ }^{-}$ completeness, ot usefulness of any information, apparatus, product or process disclosed, or represents that its tise would not infringe privately owned rights. Reference, herein to any specific commercial product process ot service by trade name, trademarl, manufacturer, or otherwise does not necessarily 'constitute or imply its endorsement, recommendations, or favoring by the United States Government or any agency thereof. The views and opinions of aúthors expressed herein do not necessarily state or refléct those of the United States Goyernment or anyagency thereof.

For more information about the Building Standards and Guidelines Program; call the Hot Line at 800-270-CŌDE:

PACIFIC NORTHWEST NATIONAL̈ LABORATORY

Operated by
BATELEE
for the

UNITED STATES DEPARTMENT OF ENERCYY ENERGY EFFICIENCY \& RENEWABLE ENERGY

'OFFICE OF BUILDING TECHNDLOGIES STATE' \& COMMUNITY GRINT PROGRAMS under Contract DE-ACOG-76RLO 183̦. 


\section{ENERGY-EFFICIENT BUILDINGS PROGRAM EVALUATIONS, VOLUME 2: EVALUATION SUMMARIES}
A. D. Lee
D. Mayi
S. D. Edgemon

April 1997

Prepared for the U.S. Department of Energy under Contract DE-AC06-76RLO 1830

Pacific Northwest National Laboratory Richland, Washington 99352 


\section{DISCLAMIER}

Portions of this document may be illegible in electronic image products. Images are produced from the best available original document. 


\section{SUMMARY}

This document presents summaries of code and utility building program evaluations reviewed as the basis for the information presented in Energy-Efficient Buildings Program Evaluations, Volume 1: Findings and Recommendations. This study was conducted for the U.S. Department of Energy (DOE) by Pacific Northwest National Laboratory (PNNL). 


\section{CONTENTS}

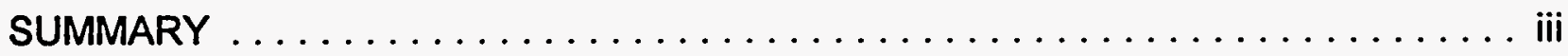

ACRONYMS $\ldots \ldots \ldots \ldots \ldots \ldots \ldots \ldots \ldots \ldots \ldots \ldots \ldots \ldots \ldots \ldots \ldots \ldots \ldots$

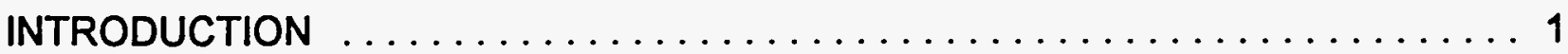

EVALUATION SUMMARIES .......................... 2

Home Builder Survey Report: Super Good Cents Evaluation . . . . . . . . 4

Super Good Cents Program Evaluation Interim Report ............ 5

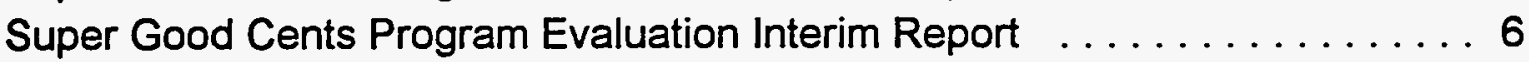

Follow-Up Homebuilder Survey: Super Good Cents Evaluation $\ldots \ldots \ldots 7$

Second Interim Report: Super Good Cents Program Evaluation . . . . . . . 8

Third Homebuilder Survey: Super Good Cents Evaluation $\ldots . \ldots \ldots \ldots .9$

Super Good Cents Performance Analysis: A Progress Report ........ 10

Super Good Cents Program Evaluation Final Report . . . . . . . . . . 11

Process Evaluation of the Super Good Cents Program: 1989-90 . . . . . 12

Evaluation of Portland General Electric Company's Super Good Cents Program

Evaluation of a New Home Construction Program: Combining Load Research, Billing Data, and Engineering Estimates in a Consolidated Framework

Development and Implementation of a Multi-Utility Residential New Construction

Program: The Energy Crafted Home Program ........... 15

Memphis Light, Gas and Water's Marketing Program Guarantees Heating and

Cooling Costs in New Homes . . . . . . . . . . . . . . . 16

PG\&E Residential New Construction (RNC) Program impact Evaluation . . 17

Promoting Energy-Efficient Home Construction: The Impacts of Alternative

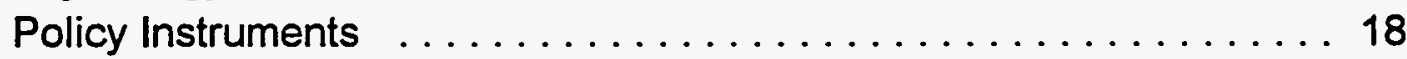

Impact Evaluation of the NYSE Star Program $\ldots \ldots \ldots \ldots \ldots \ldots \ldots$

"Lessons Learned" - Using Building Simulation Models in the Impact Evaluation

of Boston Edison's Energy Crafted Home and Home Energy Rebate

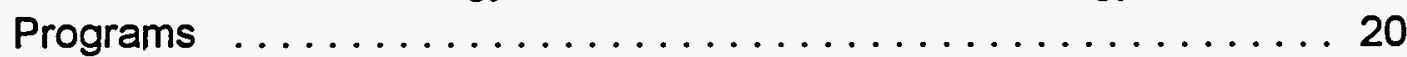

Energy Savings in New, Low-Rise Multifamily Buildings: Model Conservation

Standards in Tacoma, Washington ................. 21

An Evaluation of Energy Conservation Programs for New Residential Buildings 
First Year Load Impacts of Southern California Gas Company's Residential New Construction Program $\ldots \ldots \ldots \ldots \ldots \ldots \ldots \ldots \ldots \ldots \ldots \ldots \ldots$

Process Evaluation of BPA's Energy Smart Design Assistance Program . . 24 Energy Smart Design Program Second Process Evaluation . . . . . . . 25

Evaluation of Energy Smart Design Optional Services Program . . . . . . 26

The Energy Edge Project Building Design Process $\ldots \ldots \ldots \ldots \ldots \ldots 27$

Energy Edge Process Evaluation $\ldots \ldots \ldots \ldots \ldots \ldots \ldots \ldots \ldots \ldots$

Energy Edge Impact Evaluation-Findings and Recommendations from the

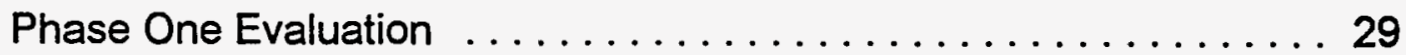

Energy Edge Impact Evaluation-Early Overview ............. 30

Energy Edge Impact Evaluation-Middle Overview ............. 31

In the Trenches with Large Commercial/Industrial Energy-Conscious New

Construction Programs: What Delivery Features Work Best? . . . . 32

Commercial New Construction Practices in Georgia--Findings From 480 On-Site

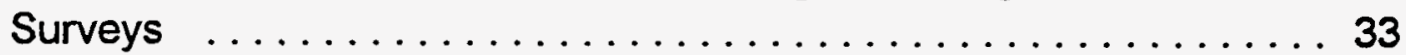

How Can We Do This Better? Redesigning RG\&E's Commercial/Industrial New

Construction Program ...................... 34

The Integrated Approach to Evaluating New Commercial Buildings: Does it

Work? . . . . . . . . . . . . . . . . . . . . . . . 35

An Energy Responsive Building Application for New Commercial Construction

The Performance of the Energy Edge Buildings: Energy Use and Savings . 37

Evaluating Actual Performance of New Commercial Buildings: The Energy Edge

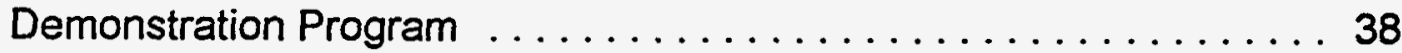

Design Assistance for New Commercial Buildings: Case Study Evaluation . 39 Mandating Energy Efficient Commercial Buildings: San Francisco's Commercial

Energy Conservation Ordinance $\ldots \ldots \ldots \ldots \ldots \ldots \ldots \ldots . \ldots 40$

A Utility Program for Improving the Energy-Efficiency of New Non-Residential Construction ..........................4 41

Savings by Design: A Customer Driven Electrical Efficiency Program for Commercial Buildings . . ................... 42

Evaluation of the Non-Residential Energy Conservation Building Standards of the State of Colorado. . . . . . . . . . . . . . . . . 43

Site and Building Energy-Conservation Study: Survey of Building $435 \ldots 44$ Energy Efficiency Building Performance Standards Study ........... 45 Impact Evaluation of Boston Edison's Commercial/Industrial New Construction

Program ........................ 46

Evaluation of Gross Savings Impacts of B.C. Hydro's New Building Design 
Program

Net Impact Evaluation of a Non-Residential New Construction Program in the

Pacific Northwest ....................... 48

Billing Analysis for New Construction Programs: What Are Realization Rates

Really Capturing? . . . . . . . . . . . . . . . . . . . 49

Commercial New Construction Impact Evaluation--A Comprehensive Approach

to Analyzing New Construction Incentive Program Results . . . . . 50

An Application of ASHRAE 90.1 as a Baseline for Evaluating Commercial New

Construction Programs $\ldots \ldots \ldots \ldots \ldots \ldots \ldots \ldots \ldots \ldots \ldots$

Results of NU ECC Comprehensive Program Evaluation: Lessons Learned

From Using Building Simulation as an Evaluation Technique . ..... 52

Energy Savings of Commercial Energy Code Compliance in Washington and

Oregon ........................... 53

Impact Evaluation of Northeast Utilities' Energy Conscious Construction Program

Comprehensive Area: Findings, Methods, and Avenues for Further

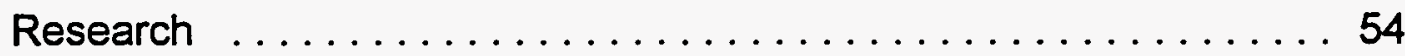

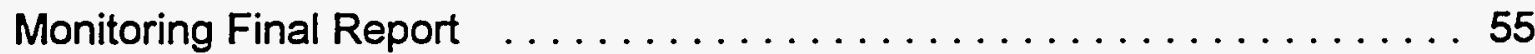

Multifamily Metering Study . . . . . . . . . . . . . . . . . . . 56

Design for Excellence--Commercial New Construction Incentive Program Impact

Evaluation .......................... 57

Non-Residential New Construction/Major Renovation Program Baseline Survey

Commercial New Construction Review of Engineering Assumptions . . . . 59 Lighting Code Compliance Training Through the Use of Interactive Video Tapes

First Year Load Impacts of Southern California Gas Company's Commercial New

Construction Program for Program Years 1990, 1991, and 1992. . . . 61

First Year Load Impacts of Southern California Gas Company's Commercial

Demand-Side Management Programs--Program Years 1990, 1991, and 1992 . . . . . . . . . . . . . . . . . . . . . . . . . . . . . . 62

Non-Residential New Construction Impact Evaluation Program . . . . . . . 63

Evaluation Design for MCS Code Adoption Demonstration ...........6 64

Energy Use in Homes Built to Model Conservation Standards: Outcomes

Evaluation of the Tacoma Early Adopter Program . . . . . . . . . 65

Evaluation of California's Energy Efficient Building Standards: The Residential

Building Monitoring Project $\ldots \ldots \ldots \ldots \ldots \ldots \ldots 6$

A Knowledge-Based System for Automated Evaluation of Energy Standards

Compliance

Evaluation of Compliance with Model Conservation Standards in Spokane, 
Washington $\ldots \ldots \ldots \ldots \ldots \ldots \ldots \ldots \ldots \ldots . \ldots 6$

Searching for an Implementation Strategy for the Model Conservation Standards

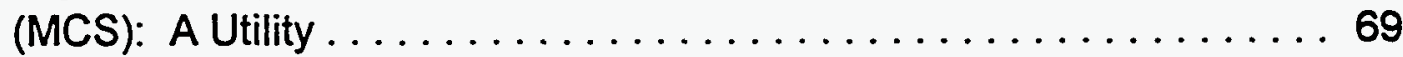

Florida State-Wide Energy Code Enforcement Study ............ 70

Evaluation of Implementation, Enforcement and Compliance Issues of the

Bonneville Model Conservation Standards Program, Volume 1 ... 71

Process Evaluation of the Tacoma MCS Adoption Part $1 \ldots \ldots \ldots \ldots 72$

Local Building Code Administration Survey Results . . . . . . . . . . . 73

Energy Use in Homes Built to Model Conservation Standards: A Follow-Up of

the Tacoma MCS Evaluation ..................... 74

1994 Washington State Nonresidential Energy Code Report: Baseline

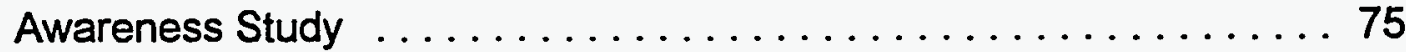

Evaluation Design for MCS Code Adoption Demonstration ......... 76 Increasing Energy Efficiency Through Improved Enforcement of Building Energy

Codes .............................. 77

Establishing a Baseline in Commercial New Construction DSM Impact

Evaluation - Comparison of Three Approaches ........... 78 Integration of a Utility New Construction Program with Provincial and National

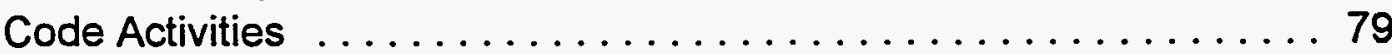

Con Edison's New Construction Design Assistance Program ........ 80 No Before, Only After - The Importance of Establishing a Baseline for New

Construction ........................... 81

Changing the Efficiency in New Buildings: California's Perspective . . . . 82

A Comparison of Statistical and Engineering Modeling in Residential New

Construction Program Evaluation $\ldots \ldots \ldots \ldots \ldots \ldots \ldots . \ldots 3$

Lessons Learned from New Construction Utility DSM Programs and Their

Implications for Implementing Building Energy Codes . . . . . . . . . 84

Evaluating Educational Effects in Pacific Gas and Electric's Energy Savings Plan

Do Education, Training and Code Enforcement Support Programs Translate Into

Stronger Energy Code Enforcement? Results from the Washington State

Energy Code Monitoring Program ................ 86

The Evolution of a Program for Commercial New Construction . . . . . . 87

Lighting Program Design: New Opportunities for Profits $\ldots \ldots \ldots \ldots 88$

New Process, New Program, New Beginning . . . . . . . . . . . . . . . 89

Design Assistance: How Effective Is It in the Long Run? ........... 90

Analysis of Commercial Model Conservation Standard Study ......... 91 
Florida Building Energy-Efficiency Rating Systems: Progress and Remaining Issues . . . . . . . . . . . . . . . . . . . . . . . . 92

Measured DSM Energy Savings in New Multifamily Buildings ........ 93 Evaluating the Impacts of Model Conservation Standards on Single-Family

Construction Practices in the Northwest .............. 94

Straight from the Horse's Mouth: Feedback from Design and Construction

Professionals on Commercial New Construction Efficiency Programs ................................ 96

Making a Connection Between Commercial New Construction Codes and Utility

New Construction Programs: A Means of Market Transformation . . . 97

Design Assistance: What's Been Learned from the Early Years . . . . . . . 98 Utility Programs: Supporting Adoption and Enforcement of Energy Codes for New Building Design and Construction ................ 99

The Role of Utility DSM Programs in Promoting Building Energy Codes . . 100 Issues and Results from the Evaluation of the Adoption and Enforcement of

Model Conservation Standards ... . . . . . . . . . . . . . . . . . . 101

Commercial Building Energy Code Compliance in Washington and Oregon

102

MCS Clearinghouse for Code Officials . ................ 103

Progress Evaluation of the Washington State Energy Code Program . . . . 104 Implementation and Enforcement or Bonneville's Model Conservation Standards

within Early Adopting Jurisdictions . . . . . . . . . . . . . . . . 105

New Residential Construction Compliance: Evaluation of the Washington State

Energy Code Program ...................... 106

An Evaluation of the New York State Energy Construction Code Program . 107 A Study of Compliance with the Lighting Provisions of the Minnesota State

Building Code for Small Commercial Buildings ............ 108

Evaluation Results for MCS Code Adoption Demonstration Project, Vol. I . 109 Getting to Code: Economic Costs and Benefits of Developing and Implementing

Washington State's Residential Energy Code ............. 110

Evaluation of the Enforcement Costs of the Washington State Commercial

Energy Code .............................. 111

Capturing Lost Opportunities in Residential New Construction . . . . . . 112 Reviewing the Past and Refining the Future: Evaluations in Resource Planning

PG\&E's 1992 Residential New Construction Program (RNC) Impact Evaluation

Moving the New Construction Baseline? A Regional Approach to Assessing the

Market Impacts of the Energy Crafted Home Program . . . . . . . . 115 
The Demise of Residential New Construction Programs: Is there Life After

Death?

A Cross Sectional Analysis of Commercial New Construction Impact Evaluations

..................................... 117

Process Evaluation of the Non-Integrated Areas Pilot Program . . . . . . 118

Energy Code Compliance ......................... 119

Evaluation of Commercial Code Enforcement Costs, Current Practices within the

State of Oregon . . . . . . . . . . . . . . . . . 120

Cost-Effectiveness of the 1986 Washington State Energy Code: Report to the

Legislature ........................ 121

A Plan for Evaluating Alternative Approaches to Financing Energy Improvements

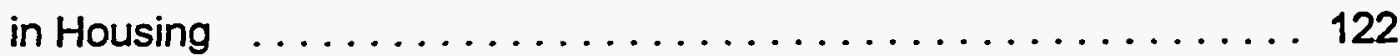

New Home Construction Research Project: Findings, Results \&

Recommendations ......................... 123

Utility Residential New Construction Programs: Going Beyond the Code . . 124 


\section{ACRONYMS}

AAHX: Air-to-air heat exchanger

AC: $\quad$ Air conditioner

$\mathrm{ACH}$ : $\quad$ Air changers per hour

ADM: $\quad$ ADM Associates, Inc.

aMW: $\quad$ Average megawatts

ASHRAE: American Society of Heating, Refrigerating and Air-Conditioning

Engineers

ASP: $\quad$ Alternative service provider

AWC: $\quad$ Association of Washington Cities

B.C.: $\quad$ British Columbia

BCA: $\quad$ Building Code Agency (Oregon)

BDL: $\quad$ DOE-2 Building Description Language

BECo: Boston Edison Company

BESP: DOE/PNNL Building Energy Standards Program (now called the Building Standards and Guidelines Program)

BPA: $\quad$ Bonneville Power Administration

BSGP: DOE/PNNL Building Standards and Guidelines Program

CABO-MEC: Council of American Building Officials' Model Energy Code

CAD: $\quad$ Computer Aided Design

CALPAS3: Computer program used in California for residential code compliance

CALRES: Computer program used in California for residential building analysis

CCAP: $\quad$ Clinton Administration's Climate Change Action Plan

CCCP: Baltimore Gas and Electric's Comprehensive Commercial Construction

Program

$\mathrm{CCH}$ : Pacific Gas \& Electric's California Comfort Home program

CDA: $\quad$ Conditional Demand Analysis

CEC: $\quad$ California Energy Commission

CECO: San Francisco's Commercial Energy Conservation Ordinance

CFL: $\quad$ Compact fluorescent light

CFR: $\quad$ Code of Federal Regulations

CMP: $\quad$ Central Maine Power

CVPS: $\quad$ Central Vermont Public Service Corporation

CZ: $\quad$ Climate zone

DCA : Department of Community Affairs

DEEP: Database on Energy Efficiency Programs

DFE: $\quad$ Southern California Edison's Design for Excellence new construction 
DHW: program

DNEE: Designated national evaluation entity

DOE: $\quad$ U.S. Department of Energy

DPS: Vermont's or Minnesota's Department of Public Service

DSM: $\quad$ Demand-side management

DVA: $\quad$ Department of Veterans Affairs

EA (EAP): BPA's Early Adopter Program

ECC: $\quad$ Northeast Utilities' Energy Conscious Construction program

ECH: Energy Crafted Home program

ECM: $\quad$ Energy conservation measure

EEM: $\quad$ Energy-efficiency mortgage

ELCAP: End-Use Load and Consumer Assessment Program

EMC: $\quad$ Energy Management Committee

EPAct: $\quad$ The National Energy Policy Act of 1992

EPI: Florida's Energy Performance Index, which is the ratio of as-built points to base points

ES-IDT: Energy Standards Intelligent Design Tool

ESCO: Energy services company

ESD: $\quad$ Energy Smart Design

E\$P: $\quad$ Energy Savings Program

EUI: $\quad$ End-use intensity

EUM: $\quad$ End-use metering

EWG: $\quad$ Evaluation Working Group

FHA: $\quad$ Federal Housing Administration

FmHA: $\quad$ Farmers Home Administration

FPL: $\quad$ Florida Power \& Light

FSEC: $\quad$ Florida Solar Energy Center

GPC: $\quad$ Georgia Power Company

GWh: $\quad$ Gigawatt-hour

HPW: $\quad$ High performance window

HRU: Heat recovery unit

HUD: $\quad$ U.S. Department of Housing and Urban Development

HVAC: Heating, ventilation, and air-conditioning

ICBO: International Conference of Building Officials

IEAL: International Energy Associates Limited

IES: Illuminating Engineering Society

IOU: Investor-owned utility

IRP: Integrated resource plan or planning

ISAAC: Integrated System for Analysis of Acquisitions 


\begin{tabular}{ll} 
kW: & Kilowatt \\
kWh: & Kilowatt-hour \\
LCP: & Least-cost utility plan or planning \\
LPD: & Lighting power density \\
LTCAP: & Long-term Commercial Acquisition Process \\
MAP: & Manual of Accepted Practices \\
MAP: & BPA Manufactured Housing Acquisition Program \\
MCS: & Model Conservation Standards \\
MEC: & Model Energy Code \\
MF: & Multi-family \\
MICROPAS: & A computer model for analyzing energy use \\
MLGW & Memphis Light, Gas and Water \\
MPR: & Major Projects Rule \\
MW: & Megawatt \\
MWh: & Megawatt-hour \\
NAC: & Normalized annual consumption \\
NBC: & New building construction \\
NBD: & New building design \\
NCSBCS: & National Conference of States on Building Codes and Standards \\
NEES: & New England Electric Service Co. \\
NIA: & Non-Integrated Areas Pilot Program \\
NPPC: & Northwest Power Planning Council \\
NREL: & National Renewable Energy Laboratory \\
NRNC: & PG\&E's Non-Residential New Construction program \\
NU: & Northeast Utilities \\
NWEC: & Northwest Energy Code \\
NWPPA: & Northwest Public Power Association \\
NYSE- & \\
STAR: & New York State Energy STAR program \\
NYSEO: & New York State Energy Office \\
O\&M: & Operations and maintenance \\
ORNL: & Oak Ridge National Laboratory \\
OSU: & Oregon State University \\
OTTV: & Overall thermal transmissivity value \\
PEPCo: & Potomac Electric Power Company \\
PFT: & Perfluorocarbon tracer \\
PGE: & Portland General Electric \\
PG\&E: & Pacific Gas \& Electric \\
PNNL: & Pacific Northwest National Laboratory (formerly Pacific Northwest \\
& Laboratory) \\
\hline
\end{tabular}


PRISM: $\quad$ Princeton Scorekeeping Method

PSCo: $\quad$ Public Service Company of Colorado

RCDP: Residential Construction Demonstration Program

REEP: $\quad$ Residential Energy-Efficiency Program

RMI: Resource Management International, Inc.

RNC: $\quad$ Residential new construction

RSDP: Residential Standards Demonstration Program

SAE: $\quad$ Statistically-adjusted engineering model

SCE: $\quad$ Southern California Edison

SDG\&E: San Diego Gas \& Electric Co.

SEER: Seasonal Energy Efficiency Ratio

SEO: $\quad$ State energy office

SF: $\quad$ Single-family home

SFD: $\quad$ Single-family detached home

SGC: $\quad$ Super Good Cents

SRC: $\quad$ Synergic Resources Corporation

TCL: $\quad$ Tacoma City Light

TMY: $\quad$ Typical meteorological year

TRC: $\quad$ Total resource cost

U-value: Thermal transmittance per unit area

UA-value: Overall thermal transmittance

UWCTP: University of Washington Component Test Program

WSEC: Washington State Energy Code

WSEO: Washington State Energy Office 


\section{INTRODUCTION}

This document presents summaries of code and utility building program evaluations reviewed as the basis for the information presented in Energy-Efficient Buildings Program Evaluations, Volume 1: Findings and Recommendations, DOE/EE/OBT11569 , Vol. 1: This study was conducted for the U.S. Department of Energy (DOE) by Pacific Northwest National Laboratory (PNNL).

DOE operates the Building Standards and Guidelines Program (BSGP) to increase the effectiveness of building energy codes, standards, and guidelines. PNNL provides technical support to DOE in the BSGP. Numerous activities have been conducted by DOE and PNNL under the program for more than a decade and, although DOE has reported on these activities to Congress and has conducted numerous assessments of the program, no large-scale program evaluation has yet occurred.

The main purpose of this volume is to summarize information from prior evaluations of similar programs that may be useful background for designing and conducting an evaluation of the BSGP. Another purpose is to summarize an extensive set of relevant evaluations and provide a resource for program designers, managers, and evaluators.

This volume presents information from 121 evaluations that have been conducted of both utility and code programs related to energy efficiency in new residential and commercial buildings. ${ }^{\text {(a) }}$ We used the information in these evaluations to identify major themes and lessons learned from utility and code programs. We also used the information to gain insights into appropriate evaluation methodologies and establish guidelines for designing future evaluations and an evaluation of the BSGP. This information is presented in Volume 1. A floppy disk containing the summaries is available through the BSGP hotline at 1-800-270-CODE as a useful resource for retrieving specific information.

(a) Note that 121 studies were reviewed and are summarized here, but only 119 were directly relevant to new building programs. 


\section{EVALUATION SUMMARIES}

This section presents the evaluation summaries. The information is presented in the fields described on the following page. For reference, key acronyms are presented in the list at the beginning of this document. If no information is present in a field, the evaluation did not include it or the field was not relevant. Information presented represents the conditions observed at the time of each study. 
Document Number: A reference number assigned to each document Study Title: Title of the report

Date: Publication date of the report in the format $\mathrm{mm} / \mathrm{dd} / \mathrm{yy}$. If no month or day was identified, the date is shown as 00/00/yy.

Study Sponsor: Name(s) of the study sponsors or organization carrying out the study Authors: Name(s) of individual or organizational authors

Building Type: Type of building covered by the program evaluation-R (residential), $\mathrm{C}$ (commercial), or both $\mathrm{R}$ and $\mathrm{C}$

Program Type, Code (C) or Utility (U): Type of program studied-either building code or utility demand-side management

Evaluation Type, Process (P) or Impact (I): Type of issues addressed by evaluation Evaluation Purpose, Formative (F) or Summative (S): Purpose of the evaluation-to help improve the program in early stages (formative), or draw conclusions about the program after implementation and before major program decisions (summative) Part of Process Addressed: Phase of the program that is the focus of the evaluationD (Development), A (Adoption), I (Implementation), C (Compliance), E (Enforcement) Stakeholders Targeted: Stakeholders targeted by the program

Program Description: Brief description of program characteristics

Process Evaluation Method: Brief description of the process evaluation method (if applicable)

Impact Evaluation Method: Brief description of the impact evaluation method (if applicable)

Program Findings: Brief description of the major program findings and lessons learned

Methodology Findings: Brief description of the major findings about the methodologies used in the study

Program Recommendations: Summary of the evaluation's recommendations about the program

Methodology Recommendations: Summary of the evaluation's recommendations about the methodologies employed

Comments: The reviewers' comments about the study

The remainder of this document consists of the summaries prepared for each evaluation study. 
Document Number: 0001

Study Title: Home Builder Survey Report: Super Good Cents Evaluation

Date: $10 / 16 / 86$

Study Sponsor: Bonneville Power Administration (BPA)

Authors: Columbia Information Systems

Building Type: $R$

Program Type, Code (C) or Utility (U): $U$

Evaluation Type, Process (P) or Impact (I): $P$

Evaluation Purpose, Formative $(F)$ or Summative $(S)$ : $F$

Part of Process Addressed: I

Stakeholders Targeted: Builders

Program Description: $S G C$ is a residential new construction program designed to promote the Model Conservation Standards (MCS). It is hoped that the MCS will become a widely adopted building practice and eventually, adopted as building code. Its features include utility promotion and certification of new homes built to the MCS. The primary tools during the first few years were marketing and technical assistance. Participating utilities work with local builders, code officials, and other key members of the shelter industry to encourage construction and purchase of Super Good Cents homes. Utility personnel review house plans, inspect homes, offer assistance to customers and builders in the construction of new SGC housing, and ensure that MCS specifications are being met. BPA assists the utilities with support programs, such as training, financial support for local advertising, and a region-wide marketing and advertising program to create consumer awareness and interest in purchasing a Super Good Cents home. BPA's role in the SGC program was planned to be reduced and eventually phased out, depending upon success in attaining implementation of the MCS as code in state and local jurisdictions. The five major elements of the SGC program are 1) advertising, 2) local promotion, 3) certification, 4) shelter industry assistance promotion, and 5) financial incentives. Financial incentives were added to the 1986 program and are available retroactively to builders or buyers of SGC homes built after January 1,1986 . Single family homes are eligible for $\$ 2,000$.

Process Evaluation Method: A baseline survey of builders was conducted as one component of BPA's SGC program. The survey was conducted prior to the regional advertising campaign in early 1986 . The sample frame included all home builders in the areas of the utilities participating in the SGC program: 319 surveys were completed, but this sample was weighted to get to a target of 586 total. This target sample was obtained by multiplying the actual data from each state by weighting factors so the final result would be the same proportions by state as the Census. An assumption made here is that the proportion of builders in participating utility territories is the same as the proportion in the general population. Federal Census figures were used as the reference for determining the appropriate sampling target of home builders from each state. Builders must have built SF homes in 1986 and could not build exclusively in counties not covered by utilities participating in SGC program. Objectives of the survey were 1) develop an evaluation baseline, 2) determine home builder perceptions regarding energy efficiency, 3) determine builder reaction to the SGC program and willingness to participate, and 4) develop suggestions for an appropriate strategy for stimulating future participation.

Impact Evaluation Method:

Program Findings: 1) Contrary to current belief, surveyors found a high degree of interest in and support for energy efficiency among builders, 2) energy efficiency was not one of the most important selection criteria for home buyers, according to builders, 3 ) half the builders were familiar with MCS/RSDP standards, $48 \%$ had heard of Super Good Cents, and less than 7\% had actually participated in the SGC program, 4) financial concerns were both a disadvantage and an advantage of SGC program, and 5) trade journals were the most commonly used source of general information on energy efficiency.

Methodology Findings:

Program Recommendations: A multi-sector strategy seems appropriate as the best method for stimulating program participation by builders, which would include working with code officials in all states as well as working through utilities. This strategy should be able to satisfy informational needs and should offer incentives as planned by BPA.

Methodology Recommendations:

Comments: 
Document Number: 0002

Study Title: Super Good Cents Program Evaluation Interim Report

Date: $02 / 01 / 87$

Study Sponsor: Bonneville Power Administration (BPA)

Authors: Columbia Information Systems

Building Type: $\mathbf{R}$

Program Type, Code (C) or Utility (U): U

Evaluation Type, Process (P) or Impact (I): P I

Evaluation Purpose, Formative (F) or Summative (S): F

Part of Process Addressed: I

Stakeholders Targeted: Builders, Consumers, Utilities

Program Description: See description for "Home Builder Report: Super Good Cents Evaluation."

Process Evaluation Method: This interim report was produced midway through the evaluation period that began in 08/85 and ends in 12/87. Findings in this report present a snapshot of a program that is constantly in transition. It's designed to assess the effectiveness of BPA-sponsored efforts to market, promote, and implement the SGC program. There are both process and impact components. The report includes baseline and follow-up consumer and builder surveys, on-going data collection on the number of new housing starts and SGC home certifications, an incentive analysis, and utility implementation analysis.

Impact Evaluation Method: Analysis of program benefits and costs.

Program Findings: 1) Program awareness objectives were met and exceeded, 2) $48 \%$ of potential home buyers in the service area of participating SGC utilities are now aware of the program, 3 ) the level of utility participation increased; 75 utilities are participating (65\%), and 4) overall percentage of trained builders is low, but this progress has led to several hundred trained builders in each state.

Methodology Findings:

Program Recommendations: 1) Redirect media campaign with emphasis placed on motivating the "aware" consumer to act, 2) take steps to reduce the costs of SGC homes, 3) redirect the advertising to attract a higher income audience, 4) emphasize the added value of SGC homes in promoting SGC homes, 5) hire a roving implementation specialist that can meet the utilities on their own turf and work with their specific problems, and 6) conduct a region-wide, coordinated effort to guarantee consistency, as well as a degree of certainty. Methodology Recommendations:

Comments: 
Document Number: 0003

Study Title: Super Good Cents Program Evaluation Interim Report

Date: $08 / 01 / 87$

Study Sponsor: Bonneville Power Administration (BPA)

Authors: Columbia Information Systems

Building Type: $R$

Program Type, Code (C) or Utility (U): U

Evaluation Type, Process (P) or Impact (I): $P$

Evaluation Purpose, Formative (F) or Summative (S): $F$

Part of Process Addressed: AI

Stakeholders Targeted: Consumers, Builders, Utilities

Program Description: See description for "Home Builder Survey Report: Super Good Cents Evaluation."

Process Evaluation Method: There are three major surveys: the Baseline Consumer survey, the Baseline Builder survey, and the Mid-Term Consumer Tracking survey. The overall evaluation contains both process and impact components. Specific elements of the evaluation include baseline and follow-up consumer and builder surveys, on-going data collection on the number of new housing starts and SGC home certifications, an incentive analysis, an analysis of the performance of SGC homes, and a utility implementation analysis.

Impact Evaluation Method:

Program Findings: It appears that general awareness goals have been met. This awareness has not led to much of an increase in concern over energy efficiency nor has it led to action towards building SGC homes.

Methodology Findings:

Program Recommendations: 1) Redirect the media campaign with emphasis placed on motivating the "aware" consumer to act; 2) take steps to reduce the costs of SGC homes to compete with standard homes; 3) redirect the advertising to attract a higher income audience; 4) emphasize the added value to make the promotion more effective; 5) hire a roving implementation specialist that can meet the utilities on their own turf and work with their specific problems should be hire; 6) BPA should maintain some coordination role as it reduces its role beyond 1988 and transfers responsibility to the utilities making it truly a "local" utility program.

Methodology Recommendations:

Comments: 
Document Number: 0004

Study Title: Follow-Up Homebuilder Survey: Super Good Cents Evaluation

Date: $11 / 17 / 87$

Study Sponsor: Bonneville Power Administration (BPA)

Authors: Columbia Information Systems

Building Type: $R$

Program Type, Code (C) or Utility (U): $U$

Evaluation Type, Process (P) or Impact (I): $P$

Evaluation Purpose, Formative (F) or Summative (S): $F$

Part of Process Addressed: I

Stakeholders Targeted: Builders

Program Description: See description for "Home Builder Survey Report: Super Good Cents Evaluation."

Process Evaluation Method: A total of 320 interviews were conducted. Federal Census figures on the number of home builders by state were used. The objective was to follow up on measuring building practices and attitudes toward energy efficiency in general and toward the SGC program. Primary screening criteria for the follow-up survey were identical to the baseline survey. It used a stratified random sample of homebuilders who build primarily in territories of utilities participating in the SGC program. A follow-up survey sample was controlled to include sufficient numbers of builders participating in the SGC program.

Impact Evaluation Method:

Program Findings: 1) Builders' perceptions of consumer attitudes on energy efficiency have not changed since baseline survey, 2) most builders (55\%) project their building practices will not change in terms of energy efficiency during the forthcoming year, 3) builders clearly support the SGC standards and energy-efficient building codes, 4) typical building practices for new home construction were reported to be more energy efficient for the follow-up survey in comparison to the baseline survey, 5 ) the SGC program is more visible to builders since 1986,6 ) only half of the SGC participants attended a SGC training session, 7) cooperative advertising offered to builders does not seem to have had much of an impact, 8) it appears that consumer demand is critical in generating builder willingness to build SGC homes and the incentive provides the needed encouragement.

Methodology Findings:

Program Recommendations:

Methodology Recommendations:

Comments: 
Document Number: 0005

Study Title: Second Interim Report: Super Good Cents Program Evaluation

Date: 09/01/88

Study Sponsor: Bonneville Power Administration (BPA)

Authors: Columbia Information Systems

Building Type: $R$

Program Type, Code (C) or Utility (U): U

Evaluation Type, Process (P) or Impact (I): $P$

Evaluation Purpose, Formative $(F)$ or Summative $(S)$ : $F$

Part of Process Addressed: I

Stakeholders Targeted: Utilities, Builders, Consumers

Program Description: See description for "Home Builder Survey Report: Super Good Cents Evaluation." 1987

program changes include modification of the specifications and the incentives. Incentives are now specifically tailored to each climate zone instead of being uniform across the region. A new development program implementation option has been developed for small utilities - they will be eligible to contract out the plan review, qualification and site inspections to a state energy office, another nearby utility, or a private contractor. These changes result from findings from Bonneville's MCS Cost-Effectiveness Analysis and the 1987 amendments to the MCS.

Process Evaluation Method: Builder and consumer surveys done to date. Impact Evaluation Method:

Program Findings: 1) Over $2 / 3$ of consumers in the program area are aware of the program and $3 / 4$ of nonparticipating builders, 2) $3 / 4$ of eligible utilities are participating, 3) $43 \%$ of those who built SGC homes had actually attended SGC training, 4) there is a steady increase in the number of both builder and utility training sessions, 5) Bonneville had paid nearly $\$ 2.5 \mathrm{M}$ in incentives at the end of $F Y 1987,6$ ) consumer awareness of the incentives is low in general and shows no change from the last year, 7) energy efficiency is not one of the major selection criteria for new homes among consumers, 8 ) there is a positive impact on builders in terms of the perceived value of a SGC home, 9) only about half as many builders cited disadvantages of SGC homes, 10) over half of the consumers continue to feel that current building codes don't guarantee an "acceptable" level of energy efficiency, 11) over $3 / 4$ of the builders feel codes should include energy-efficiency standards.

Methodology Findings:

Program Recommendations: 1) Focus efforts on helping the home buyer close the deal, 2) develop builder promotions that highlight the high level of program awareness and interest in purchasing a SGC home among consumers, 3) explore ways to persuade those planning to buy an existing home to consider a newly built home, 4) continue efforts to promote the program to utility management to obtain full support and operation of the program, 5) work closely with the large private utilities in the program to bring them up to speed quickly, and learn from past lessons, 6) continue builder training, particularly in territories served by newly participating private utilities, 7) increase efforts to raise consumer awareness incentives, 8) consider the increased use of non-monetary incentives for builders, and 9) provide additional education and public relations efforts to address perceived problems with indoor air quality and moisture.

Methodology Recommendations:

Comments: 
Document Number: 0006

Study Title: Third Homebuilder Survey: Super Good Cents Evaluation

Date: $12 / 01 / 88$

Study Sponsor: Bonneville Power Administration (BPA)

Authors: Columbia Information Systems

Building Type: $R$

Program Type, Code (C) or Utility (U): U

Evaluation Type, Process (P) or Impact (I): $P$

Evaluation Purpose, Formative (F) or Summative (S): $F$

Part of Process Addressed: I

Stakeholders Targeted: Builders

Program Description: See description for "Home Builder Survey Report: Super Good Cents Evaluation" and "Second Interim Report: Super Good Cents Program Evaluation."

Process Evaluation Method: The sample frame was essentially the same as that for the two previous surveys and consisted of a stratified random sample of homebuilders who build primarily in territories of utilities participating in the SGC program. The final sample achieved 395 respondents of which 101 were SGC builders.

Impact Evaluation Method:

Program Findings: There were no large changes in attitudes or practices among builders in general between the 1987 and 1988 surveys. The importance of energy efficiency to consumers and their own feelings about the value of energy efficiency have stayed roughly the same, though still high. Most builders still feel there will be higher demand for energy efficient homes than other homes. Utilities appear to be making a greater effort to contact builders. Negative findings included 1) nearly $21 \%$ fewer builders plan to increase the level of energy efficiency in their new construction, 2) there was a decrease in builders who support codes set to or above SGC/MCS levels, 3) nearly twice as many non-participants this year as last year said they had no interest in participating in the program, and 4) even fewer SGC builders attended SGC training in 1988 than in 1987.

Methodology Findings:

Program Recommendations:

Methodology Recommendations:

Comments: 
Document Number: 0007

Study Title: Super Good Cents Performance Analysis: A Progress Report

Date: $04 / 13 / 89$

Study Sponsor: Bonneville Power Administration (BPA)

Authors: Columbia Information Systems

Building Type: $R$

Program Type, Code (C) or Utility (U): U

Evaluation Type, Process (P) or Impact (I): I

Evaluation Purpose, Formative (F) or Summative (S): $F$

Part of Process Addressed: I

Stakeholders Targeted: Utilities, Builders, Consumers

Program Description: See description for "Home Builder Survey Report: Super Good Cents Evaluation" and "Second Interim Report: Super Good Cents Program Evaluation."

Process Evaluation Method:

Impact Evaluation Method: The evaluation was designed to examine the feasibility and limitations of using an evaluation approach based on PRISM as well as to provide a preliminary estimate of the performance of SGC residences. Data sources included billing history provided by over 30 utilities, submetered sites for estimation of the adjustment model for SF homes, occupant survey and hook-up card data, and weather data.

Program Findings: Preliminary estimates of the levelized cost performance of SF dwellings by climate zone are, by climate zone (CZ), 1) $C Z 1=3.5$ to $4.3 \mathrm{kWh} / \mathrm{sq}$. ft., $n=69,2) C Z 2=2.6$ to $4.8 \mathrm{kWh} / \mathrm{sq}$. ft., $n=9,3) C Z 3=2.6$ to 7.2 $\mathrm{kWh} / \mathrm{sq}$. ft., $\mathrm{n}=8$. For MF residences, levelized costs are 3.9 to $5.5 \mathrm{kWh} / \mathrm{sq}$. $\mathrm{ft}$. in $\mathrm{CZ1}$.

Methodology Findings: Results were subject to uncertainty due to 1) small final sample size upon which the estimate of space heat consumption is based, 2) short billing histories (sometimes less than one year in length), 3) few sub-metered sites available for estimation of the adjustment model for SF homes, and 4) no sub-metered data available for estimation of an adjustment model for MF residences.

Program Recommendations:

Methodology Recommendations: Results of this evaluation haven't resolved any of the controversy surrounding the use of PRISM as an evaluation tool for MCS/SGC residences. It is important to examine several methodologies for assessing the space heat energy use of SGC homes including 1) an enhanced PRISM model, 2) cross-sectional regression models, 3 ) combined cross-sectional regression and engineering simulation models, and 4) submetered data.

Comments: 
Document Number: 0008

Study Title: Super Good Cents Program Evaluation Final Report

Date: $07 / 01 / 89$

Study Sponsor: Bonneville Power Administration (BPA)

Authors: Jennings, J G

Building Type: $\mathbf{R}$

Program Type, Code (C) or Utility (U): U

Evaluation Type, Process (P) or Impact (I): P I

Evaluation Purpose, Formative (F) or Summative (S): $F$

Part of Process Addressed: 1

Stakeholders Targeted: Utilities, Builders, Consumers

Program Description: See description for "Super Good Cents Program Evaluation Interim Report." 1988 program changes included 1) BPA proposed (in February) that incentives not be eliminated, but phased out on a gradual timeline, 2) the 2 largest lOUs (Puget Power and PacifiCorp) signed on, 3) manufactured homes became eligible in 1988, although few were expected until 1989, 4) in August, Bonneville released its Final Environmental Impact Statement on new energy-efficient homes programs, 5) HUD Region 10 added "certified energy efficient" to its utility cost schedules used in determining eligibility for FHA loans, 6) state energy offices began providing the utility technical training which had been conducted by the NWPPA and the Columbia Group in previous years, 7 ) an Implementation Workbook was prepared for utilities at the end of 1988 for release in 1989, and 8) no fall ad campaign occurred in 1988 (the contract expired and Gerber advertising was selected as the new ad agency).

Process Evaluation Method: Consumer surveys, builder surveys, a survey of the SGC home owners, data collection on housing starts and certifications, and utility process analysis were used. All survey samples except the SGC Occupant Survey were drawn randomly from the combined territory of participating SGC utilities.

Impact Evaluation Method: Preliminary performance analysis. See "Super Good Cents Performance Analysis: A Progress Report" including an analysis of performance of SGC home and an analysis of the costs of the SGC homes.

Program Findings: The program achieved the following: 1) raised region-wide awareness of both energy efficiency and SGC, 2) trained builders and utilities all over the region and familiarized them with MCS, 3) achieved a high level of participation among utilities, 4) created over 6,200 SGC housing units 5) created or sustained jobs and contributed to local economics through related spending, 6) developed support for the Northwest Energy Code, and 7) increased regional capability to offer energy efficient new construction. Drawbacks of the program included 1) it has been costly to operate, 2) labor and training put into each builder are not being spread over many jobs, 3) unknown level of compliance is leading to a degree of uncertainty about the acquired resources, and 4) there appears to be a limitation as to the level of penetration achievable within current program design.

Methodology Findings:

Program Recommendations: 1) Work with volume builders and builders of MF buildings, 2) work with and encourage less committed and poorly performing utilities, 3) encourage greater utility staffing along with efforts to enhance productivity of staff, 4) focus efforts on professional builders who have built only one SGC home, 5) continue offering financial incentives, 6) continue builder training and offer refresher courses, 7) focus advertising on active buyers and position ads where these buyers would most likely see them.

Methodology Recommendations:

Comments: 
Document Number: 0009

Study Title: Process Evaluation of the Super Good Cents Program: 1989-90

Date: 07/01/91

Study Sponsor: Bonneville Power Administration (BPA)

Authors: Jennings, JG and AJ Block

Building Type: $R$

Program Type, Code (C) or Utility (U): $U$

Evaluation Type, Process (P) or Impact (I): $P$

Evaluation Purpose, Formative (F) or Summative (S): $S$

Part of Process Addressed: I

Stakeholders Targeted: Utilities, Consumers, Builders

Program Description: See description for "Home Builder Survey Report: Super Good Cents Evaluation," "Second interim Report: Super Good Cents Program Evaluation," and "Super Good Cents Program Evaluation." Program changes in 1989 and 1990 include 1) Gerber Advertising was hired to launch a SGC campaign, 2) technical specifications for the program were revised as a result of a long process of discussion among utility representatives, the state energy offices, Bonneville headquarters and area office staff, and representatives of the Northwest Power Planning Council, 3) WATTSUN building energy analysis software was revised under the auspices of the Washington State Energy Office, and 4) manufactured housing was added to the SGC program in the fall of 1989 and to the regional SGC advertising campaign in the spring of 1990.

Process Evaluation Method: The method was essentially qualitative and relied on in-depth discussions with Bonneville headquarters staff involved in program management, Bonneville Area office staff in regional implementation, SGC representatives from 50 participating utilities, state energy office representatives, and consultants/contractors. In addition, background materials were obtained along with program outcomes data such as certifications, housing starts, utility and builder participation levels, and training program attendance.

Impact Evaluation Method:

Program Findings: 1) There were few problems with program implementation, and all utilities were highly favorable toward the program, 2) the SGC name and logo established a reputation of quality, 3) no conclusion can be drawn at this time regarding the program's goals of increasing consumer and builder awareness and acceptance because surveys were not part of this evaluation, 4) there were dramatic increases in the number of single and multi-family homes certified, 5) more medium and large utilities are achieving penetration rates over $40 \%, 6$ ) more builders built SGC homes in 1989-90 than in all prior years combined, 7 ) the biggest influence was the widespread adoption of the MCS-level codes, 7) oversight and monitoring reviews found significant levels of deviations from specifications.

Methodology Findings:

Program Recommendations: 1) Remove environmental requirements such as radon monitoring and the distribution of indoor air quality brochures, 2) keep the SGC program as a tool for ensuring continuity and to provide an extra mark of quality over all other code homes, 3) monitoring efforts should be improved by focusing on significant performance-related measures and linking to training and technical assistance activities for better compliance, 4) peer training among and particularly within utilities should be encouraged to help maintain consistent program implementation in the face of changing staff and management, 5) if the existing SGC program and a future long-term SGC program are to be offered at the same time, the ad campaign should be reduced to a continuation of the name and logo recognition, 6) training, monitoring, and technical assistance should be continued, 7) data tracking continuity should be emphasized as the program changes.

Methodology Recommendations:

Comments: 
Document Number: 0010

Study Title: Evaluation of Portland General Electric Company's Super Good Cents Program

Date: 01/05/94

Study Sponsor: Portland General Electric

Authors: Ecker, LK

Building Type: $\mathbf{R}$

Program Type, Code (C) or Utility (U): $U$

Evaluation Type, Process (P) or Impact (I): I

Evaluation Purpose, Formative (F) or Summative (S): $S$

Part of Process Addressed: I

Stakeholders Targeted: Utilities, Builders, Consumers

Program Description: Operated from 1990 through 1992, PGE's SGC program provided financial incentives and design assistance to builders and home owners of newly constructed residential dwellings which were built in compliance with MCS of the Northwest Power Planning Council. With the State of Oregon's adoption of more stringent building codes on 01/01/92, the majority of measures included in this program became code. SGC contained 3 separate components: SF, MF, and manufactured homes. Each program component provided builders and home owners with financial or design assistance to offset the incremental cost of meeting the MCS. Builders or home owners executed an agreement with PGE that signaled their intentions to comply with SGC standards. For manufactured homes, dealers marketed the program to the customer, and informed the customer that, upon siting of the home, PGE would provide the home owner with a rebate. PGE inspected the unit after it was sited.

Process Evaluation Method:

Impact Evaluation Method: A quasi-experimental design using a treatment group and a non-participant group was used. There were seven basic steps: 1) drawing a stratified sample of participants and non-participants, 2) designing and implementing a telephone survey, 3) performing a market penetration analysis, 4) weather-normalizing sample billing histories, 5) developing a multivariate regression model to estimate energy savings, 6) performing energy savings analysis, and 7) performing a cost-effectiveness analysis.

Program Findings: 1) SF penetration rates ranged from 11\% (1990) to $31 \%$ (1991); MF penetration rates ranged from $7 \%$ (1990) to $83 \%$ (1992); manufactured housing penetration rates ranged from $3 \%(1990)$ to $33 \%(1992)$, 2) for SF, the program achieved 53\% of the LCP goal (1991) and $32 \%$ of 1992 goal; for MF, it achieved $120 \%$ of 1991 goal and $64 \%$ of 1992 goal; for manufactured housing, it achieved $12 \%$ of the $1991 \mathrm{goal}$ and $98 \%$ of the 1992 goal, 3) cumulative annual program energy savings were estimated to be 14.1 million $\mathrm{kWh}$, with 11.2 million occurring in the MF residences, 1.7 million in SF, and 1.2 in manufactured housing, 4) total resource program costs were $\$ 12 \mathrm{M}$, with PGE's share at $\$ 4.6 \mathrm{M}$, and 5) SF and MF components are cost-effective while the manufactured home component is not.

Methodology Findings:

Program Recommendations: 1) Improve communication between planners and implementors to increase program success both internally and externally, 2) conduct a follow-up study of the manufactured home market to ensure that comparable results do not occur in PGE's Manufactured Home Acquisition Program, and 3) revamp databases for the Long-Term SGC program to reflect the needs of all users.

Methodology Recommendations:

Comments: 
Document Number: 0011

Study Title: Evaluation of a New Home Construction Program: Combining Load Research, Billing Data, and Engineering Estimates in a Consolidated Framework

Date: $08 / 01 / 90$

Study Sponsor: Central Maine Power (CMP)

Authors: Starry, GP, M Ozog, G Wear, DM Violette, and L Michelson

Building Type: $R$

Program Type, Code (C) or Utility (U): $U$

Evaluation Type, Process (P) or Impact (I): P I

Evaluation Purpose, Formative (F) or Summative (S): $F$

Part of Process Addressed: I

Stakeholders Targeted: Homeowners, Builders, Utilities, Real-estate Agents, Bankers/Lenders

Program Description: This is a residential single-family and multi-family new home construction energy conservation program instituted in 1986. For a home to be certified as a Good Cents Home, it must meet the thermal performance standard of $15 \mathrm{Btu} / \mathrm{hr} / \mathrm{square}$ foot by having recommended measures installed to reduce heat loss. If the home has met these criteria and passed CMP inspections, it may be certified as a Good Cents Home and a Good Cents certificate is awarded to the home owner. (This applies to all space-heating types.) Implementation of the program has focused predominately on the building community, with CMP customer service advisors devoting most of their time to contacting builders and promoting Good Cents to them. Home buyers were targeted primarily through television and newspaper advertising.

Process Evaluation Method: Phase one utilized surveys of participating and non-participating home builders, participating and non-participating home owners, and surveys and interviews with CMP employees involved with the implementation of the program to address qualitative issues about the Good Cents Home Program. The evaluation team conducted four focus group discussions - two consisting of new home and condo owners and two of new home and condo builders. These discussions identified several issues, which were subsequently included on the questionnaires. Three surveys designed to assess program implementation and administration issues, customer satisfaction, and aspects of program impacts were implemented. A mail survey collected responses from over 1,300 participating and non-participating home owners, a mail survey collected responses from 220 home builders, augmented by a follow-up telephone survey of about 50 additional builders, a combination of mail and in-person surveys of $26 \mathrm{CMP}$ employees, and telephone interviews with 12 realtors and 12 bankers/enders. Impact Evaluation Method: The study applied a quantitative program impact analysis involving the estimation of discrete-choice participation model and a conditional demand model of home energy use to estimate program-induced energy savings. Phase two involved the estimation of the discrete choice participation models and preliminary energy savings models which used billing data. PRISM was used to normalize the billing data. The primary purpose of the discrete choice participation models is to control for self-selection and free ridership in the energy savings models. Phase three of the project is still underway and involves the collection of additional information to be used in estimating energy savings resulting from the Good Cents Program, which incorporates information from energy audits performed by the evaluation team and a load research experiment being conducted by CMP.

Program Findings: 1) The program was successful in achieving high levels of satisfaction among home builders and owners, 2) builders were very satisfied with program, 3) builders' opinions of CMP improved as a result of the program, 4) non-participants reported that the program had an impact on the energy use of non-Good Cents Homes because it has increased the awareness of efficient construction techniques among non-participating builders and non-participating home buyers, 5 ) it may have a subtle impact on the entire construction market and customer behavior, 6 ) it provided participating builders with valuable design tools and analyses, 7 ) builders believed the informational aspects of the program were important, 8) the quality of interaction between builders and CMP personnel was important, 9) early results indicate that GC oil-heated homes consumed approximately 47 fewer gallons of oil throughout the heating season.

Methodology Findings: The survey instrument should have included more specific questions relating to supplemental heating fuel; builders reported that surveys aimed at them would be best implemented during the slowest building season; and data used in the statistical model should include the average price of electricity across households.

Program Recommendations:

Methodology Recommendations:

Comments: 
Document Number: 0012

Study Title: Development and Implementation of a Multi-Utility Residential New Construction Program: The Energy Crafted Home Program

Date: $08 / 01 / 92$

Study Sponsor: NEES and NU

Authors: Fryer, LR and NA Schalch

Building Type: $R$

Program Type, Code (C) or Utility (U): U

Evaluation Type, Process (P) or Impact (I): P I

Evaluation Purpose, Formative (F) or Summative (S): F

Part of Process Addressed: DI

Stakeholders Targeted: Builders, Consumers, Utilities

Program Description: The Energy Crafted Home $(E C H)$ Program encourages the construction of homes that are substantially more energy efficient than those required by state building codes in Massachusetts (MA), Rhode Island (RI), and New Hampshire (NH). It includes training and technical assistance for builders, an energy analysis, quality assurance inspections during the construction phase, financial incentives for each house completed and certified, marketing of ECHs to home buyers, and promotion to real estate agents and lending institutions. The goal is to make the program one in which builders want to participate both because the training is valuable and because ECHs will be easier to sell due to their superior quality and the general marketing appeal.

Process Evaluation Method: The process evaluation was completed in April 1992. Its objective was to understand the current status of the ECH Program and to determine the future direction of the program. Phase 1 consisted of qualitative semi-structured interviews with 18 utility staff and contractors, 14 participating builders, $12 \mathrm{ECH}$ home owners, 13 mortgage lenders, and 13 real estate agents. Phase 2 consisted of structured telephone interviews of 200 builders who have not yet built ECH homes and 200 recent or potential home buyers. Impact Evaluation Method: End-use metering of six homes, four ECH and two non-ECH, is underway in MA. Five of the homes were built by the same builder and all homes have similar floor plans and occupancy patterns. End-uses monitored included heating, cooling, ventilation, water heating, oven/stove, microwave, dishwasher, refrigerator, washer and dryer; the whole building load and indoor and outdoor temperatures were also measured. Monitoring was planned to continue for two heating seasons.

Program Findings: Builders are positive about their experience. Home buyer awareness of the program is still quite low. Another barrier to participation other than education is the slow economy. Other barriers include fear of doing something new for the builders or buying something experimental for the buyers and cost. There is no indication that the program is encouraging builders to switch to electric heat.

Methodology Findings:

Program Recommendations: 1) Increase marketing and education for home buyers, 2) increase the incentive for electric heat homes and eliminate the incentive for fossil heat homes, 3 ) include more post-training follow-up with builders, and 4) develop a simplified prescriptive path and a special segment for multi-family construction. Methodology Recommendations:

Comments: 
Document Number: 0013

Study Title: Memphis Light, Gas and Water's Marketing Program Guarantees Heating and Cooling Costs in Now Homes

Date: 10/01/93

Study Sponsor: Memphis Light, Gas and Water (MLGW)

Authors: Delich, RL

Building Type: $R$

Program Type, Code (C) or Utility (U): U

Evaluation Type, Process (P) or Impact (I): I

Evaluation Purpose, Formative (F) or Summative (S): $F$

Part of Process Addressed: D

Stakeholders Targeted: Consumers, Builders, Utilities

Program Description: MLGWs Comfort Plus Home program demonstrates a systems approach to construction, accommodating the interaction of many components: people, structure, weather, and the mechanical system. This unique marketing program incorporates energy efficient building standards, quality assurance inspections, and design assistance for heating and cooling systems. Not only is there a set of energy-efficient building standards for the envelope, but heating and air conditioning sizing specifications are provided for the builder and the heating and air conditioning contractor. The builder provides a set of house plans and pays $\$ 150$ for design assistance. After plan evaluation, at least 3 on-site inspections are performed to ensure that the home is built as the builder agreed. Extensive marketing targets the builder and trade allies as well as the consumer. Homes can be advertised by indicating a guaranteed monthly heating and cooling costs. Training is offered to builders and installation crews on-site, to realtors on how to sell energy efficiency, and to consumers.

Process Evaluation Method:

Impact Evaluation Method: In the home design process, an energy technician enters actual R-values and other specific building information into a computerized load calculation program to determine the actual furnace and air conditioner size for a specific floor plan. Air flow requirements for each room are also provided by the software program. From this information, the technician can draw a duct system for the builder to use during construction. Expected energy costs for heating and cooling can be estimated. Since $99 \%$ of all newly constructed homes in Memphis use natural gas, end-use metering is not necessary. Monitoring heating and cooling costs is relatively simple.

Program Findings: From data obtained from billing records, the homes that have been certified during the past four years are well within the limits of their guaranteed amounts.

Methodology Findings:

Program Recommendations: Builder follow-up needs to be increased. The final inspections should be performed before homes are occupied to make sure they are certified. Coordination needs to be improved.

Methodology Recommendations:

Comments: Tennessee adopted the 1992 CABO-MEC effective Jan. 1,1994. MLGW is evaluating its effect on the Comfort Plus Home program, but the evaluation is just beginning. 
Document Number: 0014

Study Title: PG\&E Residential New Construction (RNC) Program Impact Evaluation

Date: 08/01/94

Study Sponsor: Pacific Gas and Electric

Authors: Caulfield, TO and AG Lee

Building Type: $R$

Program Type, Code (C) or Utility (U): U

Evaluation Type, Process (P) or Impact (I): I

Evaluation Purpose, Formative (F) or Summative (S): F

Part of Process Addressed: I

Stakeholders Targeted: Consumers, Builders, Utilities

Program Description: It consisted of 2 components: the PG\&E California Comfort Home (CCH) and High Performance Window (HPW) Programs. The RNC was designed to deliver significant summer energy savings and peak reduction. It offered incentives to builders for installing energy-efficient features that exceeded Title 24 standards by at least $10 \%$ of the cooling budget.

Process Evaluation Method:

Impact Evaluation Method: The study was based on extensive data collected from participants and nonparticipants including billing, site audit, tracking system, and end-use and whole-premise load data. These data allowed development of baseline and enhanced engineering simulation models from participant and nonparticipant characteristics and energy usage. Both baseline and enhanced MICROPAS3 models (including installed Energy Efficiency Measures) were calibrated. Using these models, customer-specific engineering adjustment factors were developed by running minimum and maximum parameter values for key selected parameters. Combining the participant data with the adjusted factors allowed site-specific and measure-specific impacts to be calculated. Net-to-gross savings issues were also addressed. The statistically adjusted engineering analyses have produced realization rates by customer segments and climate zone.

Program Findings: 1) Air conditioner SEER improvement had a dominant effect on the electric energy and demand program impacts, 2) the differences in impacts between climate zones illustrated the variety of new home construction practices used by builders, and 3) the RNC Program's net-to-gross ratio provides an indication of how the program changed builders' actual compliance with Title-24 efficiency standards ( 1.0 signifies a significant effect; RNC's was 0.97 overall).

Methodology Findings: Ex ante energy estimates overstated the ex post electric results by over one-third. The ex ante peak load estimate is comparable to the ex post impact due principally to the limited amount of load data available for the 1992 evaluation.

Program Recommendations:

Methodology Recommendations: The summer 1993 load data analysis will support specification of a more robust SAE model so reliability of the impacts can be better assessed.

Comments: There are at least three conference versions of this report as well as the original full report (and appendices) that consultants did. 
Document Number: 0015

Study Title: Promoting Energy-Efficient Home Construction: The Impacts of Alternative Policy Instruments

Date: 01/01/91

Study Sponsor: Bonneville Power Administration (BPA)

Authors: Brown, MA, P Brandis, B Cody, and P Degens

Building Type: $R$

Program Type, Code (C) or Utility (U): CU

Evaluation Type, Process (P) or Impact (I): P I

Evaluation Purpose, Formative (F) or Summative (S): $S$

Part of Process Addressed: IC

Stakeholders Targeted: Builders, Consumers, Utilities

Program Description: The SGC program was instituted in 1984 to promote home construction consistent with the Model Conservation Standards. It is a marketing program conducted through private and public utilities in Bonneville's region. Home buyer and builder participation is encouraged through the use of information and financial incentives. Bonneville funds are provided to utilities to support local advertising and to make incentive payments to builders or buyers of certified homes. The Early Adopter (EA) Program was initiated on a pilot basis in 1984 and on a region-wide basis in 1986 to help jurisdictions within Bonneville's region adopt the Model Conservation Standards as codes for new home construction. Two types of financial incentives were provided to promote the EA program: 1) incentive payments to builders or buyers of certified homes to offset increased construction costs for MCS-related measures and 2) reimbursement to EA jurisdictions for incremental adoption, implementation, and enforcement costs including costs for technical assistance to local contractors, material suppliers, and others in the shelter industry who can be important to the acceptance of new code requirements. Process Evaluation Method: A telephone survey of 1,092 households was conducted with the sample drawn from lists of 1987 hook-ups provided by utilities.

Impact Evaluation Method: On-site audits of 203 homes were conducted. This paper focuses on the telephone survey data. Twelve months of electric billing histories were collected for 854 of the 1,092 households that completed the occupant survey. PRISM was used to estimate the normalized annual consumption of each home. A multivariate least-squares regression analysis was used to isolate the influence of a single segmentation (or explanatory) variable.

Program Findings: 1) Energy efficiency of residential construction practices in Bonneville's region was significantly improved by its two MCS programs, 2) SGC had a bias toward more "up-scale" households, while EA homes included a more representative cross-section, 3) annual savings of both programs are 1,900 kWh/home, which is less than the Northwest Power Planning Council predicted; the shortfall was due partly to the greater-thananticipated energy efficiency of non-MCS homes. The fact that the EA and SGC programs have penetrated different market niches has significant energy-consumption implications.

Methodology Findings:

Program Recommendations:

Methodology Recommendations:

Comments: 
Document Number: 0016

Study Title: Impact Evaluation of the NYSE Star Program

Date: 03/26/95

Study Sponsor: Long Island Lighting Company (LILCo)

Authors: Gandhi, D and W Steigelmann

Building Type: $R$

Program Type, Code (C) or Utility (U): $U$

Evaluation Type, Process (P) or Impact (I): 1

Evaluation Purpose, Formative (F) or Summative (S): F

Part of Process Addressed: 1

Stakeholders Targeted: Utilities, Builders, Consumers

Program Description: The New York State Energy STAR (NYSE) Program is a new construction energy-efficiency program that was developed by the New York (NY) State Energy Office in collaboration with the NY State Builders Association, and electric and gas utilities in the state. This coalition worked to ensure that the program not only reflects the latest thinking with regard to building homes that are both efficient and healthy to live in, but also recognizes the complexities of the housing market. LILCo offers this program through its Residential New Construction (RNC) program and has two other components: 1) rebates, offered to home builders or new-home purchasers who install energy-efficient ACs, electric water heaters, or refrigerators and 2) CFLs, which are given to new-home purchasers and renters during a "house-warmer" visit by a LILCo representative. The NYSE program requires builders to 1) increase the thermal insulation levels in the homes, 2) reduce air-infiltration levels, and 3) use efficient space-heating equipment. Plan reviews, inspection of the home during construction, and a final air-infiltration measurement test are used to ensure that technical requirements are satisfied.

Process Evaluation Method:

Impact Evaluation Method: The average annual space-heating and space-cooling energy-requirements were compared for samples of three groups of homes: 1) NYSE STAR homes, 2) homes occupied by participants in the rebates component of the RNC Program, and 3) new homes occupied by LILCo customers who did not participate in any component of the RNC Program. Annual energy-use data for these comparisons were obtained from computer simulation modeling of all the homes in the three sample groups. On-site data collection was used to obtain the data needed for the simulation models. The telephone survey that was performed to obtain the data needed to characterize the new home segment was also used to guide the selection of homes in the participant and non-participant group samples. Three activities were performed in sequence: 1 ) sample selection ( 6 homes in each group which closely matched the NYSE STAR homes in terms of type, size, geographic location), 2) on-site data collection (survey/interview; data pertaining to the physical characteristics of the home and equipment/appliances; data pertaining to occupancy and equipment/appliance operating schedules), and 3) simulation modeling (data from on-site data-collection used to generate the DOE-2 Building Description Language (BDL) input files.

Program Findings: Results show that the average heating-energy EUI of the NYSE STAR group is $18 \%$ less than that of the participant group, and $38 \%$ less than that of the non-participant group.

Methodology Findings:

Program Recommendations:

Methodology Recommendations:

Comments: 
Document Number: 0017

Study Title: "Lessons Learned" - Using Building Simulation Models in the Impact Evaluation of Boston Edison's Energy Crafted Home and Home Energy Rebate Programs

Date: 03/26/95

Study Sponsor: Boston Edison Company (BECo)

Authors: McCray, J and E Guinee

Building Type: $R$

Program Type, Code (C) or Utility (U): U

Evaluation Type, Process (P) or Impact (I): 1

Evaluation Purpose, Formative (F) or Summative (S): $S$

Part of Process Addressed: I

Stakeholders Targeted: Utilities, Builders, Developers, Consumers

Program Description: Both the Energy Crafted Home $(E C H)$ and Home Energy Rebate (HER) program encourage energy-efficient new home construction by providing builders with training, promotional marketing materials, and financial incentives. The program is targeted toward builders and developers of single and multi-family residences, and some owner/builders have also participated. Residences heated with either electricity or fossil fuels are eligible for the program. Under the performance-based ECH program, registered builders submit architectural plans to BECo for approval based on the results of a building energy performance simulation. Plan evaluators review submitted plans and conduct three quality control inspections of the participating sites as construction progresses. These staff verify compliance with program requirements and provide technical assistance to builders in meeting these standards.

Process Evaluation Method:

Impact Evaluation Method: Four tasks were included: 1) Implementation analysis and database review for 1993 program participants. 2) impact evaluation including energy and demand impacts. The primary analysis technique for the impact evaluation was building simulation modeling of participating new residential buildings and their HVAC systems. The evaluation generated 1992 savings estimates for 1992 participants and 1993 savings estimates for 1993 participants. Annualized savings and measure lifetime savings were also estimated for 1992 and 1993 participants. 3) Site visits and data collection were conducted at $41992 \mathrm{ECH}$ participant sites, $111993 \mathrm{ECH}$ participant sites, and 31993 HER participant sites. Short-term lighting metering was conducted at the sites receiving incentives for high efficiency lighting. 4) A post-period billing analysis was conducted on a 1992 fossil-fuel-heated MF participant in Canton, Mass. This analysis had the advantage of being conducted at a site which had a very closely matched control group in a building in the same complex constructed prior to participation in the program. Detailed engineering simulations were completed using MICROPAS 4.2, and savings estimates were then calibrated to DOE-2.1D using hourly regression calibration factors. Final savings estimates were disaggregated to the program year, residence type, and rate/revenue code. A simpler and less input-intensive 8,760 hour simulation program, MICROPAS 4.2, enabled them to move beyond the use of "prototype" buildings, into a methodology where all program participants could be evaluated.

Program Findings: Actual program year savings are significantly less than annualized savings for the 1993 year. The 1992 program shows only $5,683 \mathrm{kWh}$ in actual savings and $8,111 \mathrm{kWh}$ in annualized savings. The 1993 evaluation of the 1992 program estimated program savings at $3,112 \mathrm{kWh}$ for the engineering estimate and 9,048 $\mathrm{kWh}$ for the billing analysis. The current estimate of 1992 program savings is within those bounds and should be considered BECo's best estimate because of its use of actual 1992 weather data instead of the TMY data used for the previous evaluation.

Methodology Findings:

Program Recommendations:

Methodology Recommendations:

Comments: A key challenge was sorting through the project documentation and results of multiple design simulation runs to determine the "base-case" model. Since the base-case in some projects went beyond existing code, the information in the project files ultimately led us to assume that the earliest design runs provided the base-case buildings. 
Document Number: 0018

Study Title: Energy Savings in New, Low-Rise Multifamily Buildings: Model Conservation Standards in Tacoma, Washington

Date: Unknown

Study Sponsor: Bonneville Power Administration (BPA)

Authors: Tonn, BE, DI White, and C Currier

Building Type: $R$

Program Type, Code (C) or Utility (U): C

Evaluation Type, Process (P) or Impact (I): I

Evaluation Purpose, Formative (F) or Summative (S): $S$

Part of Process Addressed: C

Stakeholders Targeted: Utilities, Builders

Program Description: The Northwest Power Planning Council (NPPC) and Bonneville have worked to design and implement a comprehensive portfolio of conservation programs. In 1983, the NPPC developed the Model Conservation Standards (MCS) to complement building codes in order to guide construction of energy-efficient buildings. Numerous projects to promote and evaluate MCS have been funded by Bonneville. The MCS will not be mandatory region-wide until Jan. 1, 1991, but jurisdictions adopting the standards before this date are considered "Early Adopters" and qualify for incentive payments. Tacoma, Wash., became the first adopter in 1984, using the MCS to replace the 1980 Washington State Energy Code, as amended in 1983. Thus, Tacoma was then responsible for the enforcement of three codes: the existing building code, the WSEC as it related to buildings heated by fuel oil or natural gas, and the MCS for buildings heated by electricity.

Process Evaluation Method:

Impact Evaluation Method: The method focuses on both unit-level (apartment) and building-level data. In order to obtain estimates of weather-adjusted/normalized annual space heating electricity use, electric utility bills were normalized using PRISM. Occupant surveys were used in both the unit-level and building-level analyses to control for non-climate influences on energy use. Multivariate regression models were developed from these data to identify the amount of electric space heating savings that can be attributed to the MCS.

Program Findings: 1) MCS buildings are nearly twice as large as 1983 current practice buildings but MCS units are $20 \%$ smaller. 2) MCS units have $46 \%$ less window area than 1983 current practice units. 3) MCS household heads are 18 years younger on average, with a mean age of 30 , and earn slightly less money than their 1983 current practice counterparts. 4) The sites of MCS developments are larger, have more buildings, and offer more social amenities. 5) Unit-level analysis of energy savings suggests that MCS saved $2.4 \mathrm{kWh} / \mathrm{sq}$. ft./year of space heat, or about $25 \%$ for each unit (this estimate represents the average amount of savings derivable from six econometrically estimated models). 6) Building-level analysis of energy savings yields an estimate of $0.8 \mathrm{kWh} / \mathrm{sq}$. $\mathrm{ft} . /$ year of space heat (savings of about $15 \%$ for each building). 7) Vacant units confound PRISM estimates of baseload and space heating for analysis conducted at both the unit- and building-level. 8) In addition to the vacancy/occupancy, the best predictors of electric space heating savings are the MCS, the use of additional electrical appliances for supplemental space heating, the orientation of the unit/building relative to the sun, and the similarity among building occupants in their conservation attitudes and practices.

Methodology Findings: PRISM overestimates space heating in the SF sector, and it's also likely that it overestimates space heating among the buildings analyzed in this study, particularly when occupied units are losing heat to vacant units. Also it cannot be concluded from the data whether air-to-air heat exchanger (AAHX) use/non-use results in over-or under-estimates of MCS savings.

Program Recommendations:

Methodology Recommendations: Additional research should be conducted to complement the work presented in this report using electricity savings estimates developed here and estimates developed by the City of Tacoma on MCS MF sector construction costs to determine cost-effectiveness. The program would benefit from a better understanding of the effects of vacancy on unit-and building-level energy consumption. Submetering of unit end-use loads would facilitate the calibration of PRISM parameter estimates. Work is needed to synthesize the engineering and econometric approaches to savings analyses.

Comments: 
Document Number: 0019

Study Title: An Evaluation of Energy Conservation Programs for New Residential Buildings

Date: $12 / 01 / 88$

Study Sponsor: DOE

Authors: Vine, E and J Harris

Building Type: R C

Program Type, Code (C) or Utility (U): C U

Evaluation Type, Process (P) or Impact (I): $P O$

Evaluation Purpose, Formative (F) or Summative (S): $F$

Part of Process Addressed: CE

Stakeholders Targeted: Utilities, State Regulatory Commissions

Program Description: This paper evaluates the implementation of programs promoting energy efficiency in new residential construction, and is one of a series of program-experience papers that seeks to synthesize current information from both published and unpublished sources to help utilities, state regulatory commissions, and others to identify, design, manage, and evaluate demand-side programs. The focus is on non-mandatory programs that are designed to complement/substitute for mandatory energy-efficiency requirements in local and state building codes such as technology demonstrations, pilot demonstration programs, financial incentive programs, consumer information and marketing programs, technical information programs, and site and community planning.

Process Evaluation Method: In selecting programs for reviews, extensive literature searches were conducted, and key organizations and knowledgeable individuals in the field were contacted. Program descriptions from state energy offices were sought through an announcement in Conservation Update. The focus was on programs that promote the design and construction of energy-efficient buildings with a particular emphasis on the building shell or envelope. Forty-eight programs were selected for review (37 for new residences, 11 for both residential and commercial buildings). These were reviewed based on telephone interviews with individuals knowledgeable about the program and on written materials. Topics addressed during the interview were program objectives, key participants, dates of implementation and current status, marketing methods, type of monitoring and evaluation, key results, related programs, and the interviewee's overall assessment of the program. After program descriptions were written, they were sent to the interviewees, who corrected any inaccuracies, updated the status of the program, and provided new information on specific questions raised during review of program writeups. Impact Evaluation Method:

Program Findings: 1) Many different types of non-mandatory programs appeared to be successful in a) overcoming barriers to promoting energy efficiency in new buildings, b) complementing and facilitating the adoption of future energy conservation building standards, and c) promoting compliance with existing standards.

2) Few program evaluation studies exist, resulting in a paucity of quantitative data on program effectiveness especially beyond the pilot or demonstration stages. 3) No program strategy was clearly dominant. 4) Only a few programs were designed as part of a long-term strategy to promote energy-efficient construction. 5) Successful programs were often characterized by intervention early in the building design and planning process in order to minimize delays in the project design, approval, financing, and construction process. 6) Education, training, and design assistance activities were especially important. 7) Non-mandatory programs can reinforce and pave the way for codes. 8) Most programs focused on the early design stages of a building without addressing issues normally arising later. 9) Utility rate designs were typically not used as conscious reinforcement for promoting energy-efficient construction. 10) Many programs considered successful were judged to be so on the basis of both energy and non-energy reasons. 11) Most of these programs could be easily implemented in other areas around the country and in other countries.

Methodology Findings:

Program Recommendations: A comprehensive and long-term perspective is needed to design and choose programs. Program strategies that should be considered as part of a well-integrated package of programs include design assistance, financial incentives, quality control, training and education of design professionals and the building community, simple and easy-to-use design tools, rating and labeling of buildings, effective marketing and promotion, energy awards for buildings and for design and building professionals, operations and maintenance activities, building commissioning, process and impact evaluation, monitoring, and feedback activities.

Methodology Recommendations:

Comments: 
Document Number: 0020

Study Title: First Year Load Impacts of Southern California Gas Company's Residential New Construction Program

Date: $10 / 01 / 93$

Study Sponsor: Southern California Gas Company

Authors: Chaudhury, IS and K Parris

Building Type: $\mathbf{R}$

Program Type, Code (C) or Utility (U): U

Evaluation Type, Process (P) or Impact (I): I

Evaluation Purpose, Formative (F) or Summative (S): F

Part of Process Addressed: I

Stakeholders Targeted: Builders, Utilities

Program Description: The Five Star Program is designed to encourage builders to build and sell single-and multi-family homes which use the latest energy-conserving construction techniques and energy-efficient gas equipment. Under this program, builders are offered cash incentives to build homes featuring qualifying appliances and insulation measures that exceed Title 24 building and appliance efficiency standards. For the two years studied, the program included 1) high-efficiency space heaters, 2) high-efficiency water heaters, and 3) wall insulation upgrades.

Process Evaluation Method:

Impact Evaluation Method: The analysis included Five Star single-family program participants from program years 1990 and 1991. A Conditional Demand Analysis (CDA) technique was used to estimate the load impacts. Using actual customer-specific consumption data, the CDA technique can statistically estimate average energy savings from specific conservation measures. In addition to actual customer-specific consumption information, the CDA technique utilizes weather data, customer-specific demographic information, dwelling unit characteristics, and Five Star Program element implementation data to develop the conditional demand load impact estimates. Program Findings: For all Five Star Program elements, the ex post load impact estimates are generally lower than the ex ante estimates.

Methodology Findings: Corrections for serial correlation and heteroscedasticity were made to get consistent estimated standard errors of the coefficients. The model with no corrections for serial correlation and heteroscedasticity produced higher load impact estimates for high-efficiency space heaters and improved wall insulation, when compared with the corrected mode.

Program Recommendations:

Methodology Recommendations:

Comments: 
Document Number: 0021

Study Title: Process Evaluation of BPA's Energy Smart Design Assistance Program

Date: 09/19/89

Study Sponsor: Bonneville Power Administration (BPA)

Authors: Heidell, JA and KM Lorberau

Building Type: $\mathrm{C}$

Program Type, Code (C) or Utility (U): $U$

Evaluation Type, Process (P) or Impact (I): $P$

Evaluation Purpose, Formative (F) or Summative (S): $F$

Part of Process Addressed: 1

Stakeholders Targeted: Utilities, Commercial Building Designers, Commercial Building Developers

Program Description: BPA works with utilities to provide technical design assistance to building owners, developers, architects, engineers, and other building design team members. The utilities work with the design team to develop design alternatives and provide assistance to quantify cost and energy savings associated with different conservation strategies. Participation is voluntary and no financial incentives were provided initially. Customers are not required to adopt recommended measures, but they are expected to make a good faith effort to implement technically and economically feasible measures. ESD provides free design assistance and analysis, awards for highly efficient buildings (exceeding the Model Conservation Standards), and the benefits of energy savings. Program objectives are to 1) exceed MCS levels by $30 \%$ in at least half the participating buildings, 2) provide site-specific services, 3) increase the acceptance of energy-efficient design, and 4) provide design assistance to $25 \%$ of new commercial buildings in participating areas within 3 years. Utility staff provide technical assistance in some cases and alternative service providers (ASPS) do in other cases. The utility and client agree to a set of measures to be analyzed. An hourly simulation model or prescriptive method are used to analyze energy savings. Economic analysis estimates payback periods. The utility provides a report summarizing the energy savings and economics of the measures. ESD started in late-1988.

Process Evaluation Method: This is the first of three planned process evaluations. It covers the first 6 months of the program. It relies on interviews with staff from 5 utilities (on-site) and 11 participating building owners, designers, and architects (by phone).

Impact Evaluation Method:

Program Findings: 1) The flexibility of the program has been well received. 2) Utilities and designers were enthusiastic about the program; designers felt that it allowed them to consider design options they would not have had the resources to explore.

Methodology Findings:

Program Recommendations: 1) Training provided by BPA to utilities needs to be tailored to staff skill levels. 2) Development of promotional support and tools needs to be accelerated. 3) Utilities need to increase conservation option promotion during building design conceptual phase. 4) Measure cost information needs to be improved. Methodology Recommendations:

Comments: 
Document Number: 0022

Study Title: Energy Smart Design Program Second Process Evaluation

Date: 6/1/91

Study Sponsor: Bonneville Power Administration (BPA)

Authors: W Gavelis

Building Type: $\mathrm{C}$

Program Type, Code (C) or Utility (U): $U$

Evaluation Type, Process (P) or Impact (I): $P$

Evaluation Purpose, Formative (F) or Summative (S): F S

Part of Process Addressed: I

Stakeholders Targeted: Utilities, Commercial Building Designers, Commercial Building Developers

Program Description: See Process Evaluation of BPA's Energy Smart Design Assistance Program

Process Evaluation Method: Three process evaluations were planned; this is the second. It covers the 14 months since the first evaluation. Staff from 11 utilities were interviewed along with 6 alternative service providers and 6 participating and 8 non-participating clients. This evaluation focuses on changes from the first evaluation, the role of ASPs, cases where utilities relied on BPA to provide all the assistance, long-term impacts on designers, non-participants, and other technical issues.

Impact Evaluation Method:

Program Findings: 1) Many of the problems identified in the first evaluation had been corrected. 2) Involvement in the project is most effective if it occurs at an early stage. 3) Follow-up on the buildings to see if measures are installed needs to be expanded. 4) Some of the clients were repeat participants. 5) Some potential clients had concerns about involving outsiders in their design process and felt that they already addressed energy efficiency. 6) Cost was often more of a concern than possible energy savings.

Methodology Findings: None.

Program Recommendations: 1) The program should be marketed emphasizing dollar, rather than energy savings. 2) Marketing should target designers likely to know about buildings in the early design stage. 3) Follow-up on adoption of measures should be improved.

Methodology Recommendations:

Comments: 
Document Number: 0023

Study Title: Evaluation of Energy Smart Design Optional Services Program

Date: $11 / 01 / 91$

Study Sponsor: Bonneville Power Administration (BPA)

Authors: Moe, R, W Gavelis, LA Skumatz, and C Breckinridge

Building Type: $C$

Program Type, Code (C) or Utility (U): $U$

Evaluation Type, Process (P) or Impact (I): $P$

Evaluation Purpose, Formative (F) or Summative (S): $F$

Part of Process Addressed: I

Stakeholders Targeted: Utilities, Commercial Building Designers, Commercial Building Developers

Program Description: See Process Evaluation of BPA's Energy Smart Design Assistance Program. The basic ESD was modified in response to utility feedback on the original program and because of regional electricity demand growth. In 1991, utilities began offering to pay building owners and developers to install particular energy conservation measures. Utilities also may provide expanded design assistance and inspections after measure installation (including building commissioning).

Process Evaluation Method: This evaluation covers the first 5 months of the revised program. On-site and phone interviews were conducted with staff from participating and non-participating utilities. Case studies of 12 of the first 24 buildings in the program were conducted. Case studies consisted of interviews with design team members (20) and project utilities.

Impact Evaluation Method:

Program Findings: 1) Incentives were effective in motivating participation and installation of recommended measures. 2) No utilities had implemented the building commissioning option. 3) Program marketing continues its reliance on newsletters, mailings, etc.; word of mouth usage increased. 4) Administrative burdens and time required to determine prescriptive compliance were problems. 5) Building professional responses were positive. Methodology Findings:

Program Recommendations: 1) Incentives should be continued. 2) Outreach to architects and engineers should be encouraged to increase influence in the early design process.

Methodology Recommendations:

Comments: 
Document Number: 0024

Study Title: The Energy Edge Project Building Design Process

Date: $03 / 21 / 88$

Study Sponsor: Bonneville Power Administration (BPA)

Authors: Lisee, EJ, GB Coleman, A Willman, et al

Building Type: $\mathrm{C}$

Program Type, Code (C) or Utility (U): $U$

Evaluation Type, Process (P) or Impact (I): $P$

Evaluation Purpose, Formative (F) or Summative (S): $F$

Part of Process Addressed: I

Stakeholders Targeted: Building Design Professionals, Developers

Program Description: Energy Edge provides technical assistance and financial incentives for the design and construction of energy-efficient commercial buildings. BPA, state energy offices, a private utility, and a consultant sponsor the program. The program was marketed as a design competition. Design teams consider a wide range of energy conservation measures (ECMs) and select a design that uses no more than $70 \%$ as much energy as a building built to the Model Conservation Standards. The added measures must save energy at a cost of no more than $4.5 \mathrm{k} / \mathrm{kWh}$. All designs are analyzed using an hourly simulation model. After being chosen for the program, the design team negotiates a contract with the sponsor to cover incremental design, construction, and administrative costs. In return, the owner agrees to install the ECMs and permit BPA to instrument and monitor the building.

Process Evaluation Method: Surveys were sent to 147 design team participants; 81 usable responses were received. Ninety structured interviews were also conducted with participants. The design processes for the 22 program buildings approved before September 30,1987 , were assessed. Both qualitative and quantitative results were reported.

Impact Evaluation Method:

Program Findings: The two primary reasons ECMs were selected were energy savings and payback period. Successful past experience with an ECM was the third most common reason for selecting it. Virtually all respondents said they would use the same ECMs again in future buildings. This suggested that an initial investment in demonstrating an ECM would pay off in future usage in other buildings. Comfort and ease of maintenance were also important factors. High initial cost was a primary reason certain ECMs were rejected. Participants generally responded favorably to the use of simulation models, especially for comparison of one ECM to others. The program effectively broadened the involvement of various professionals in the design process from the traditional reliance on architects. It increased the involvement of engineers/modelers in the early stages. The design process was more complex and time-consuming, but participants felt the designs were better.

Methodology Findings:

Program Recommendations: No recommendations were presented.

Methodology Recommendations:

Comments: This study is more of a description of the design process and changes to it under the program than an evaluation. 
Document Number: 0025

Study Title: Energy Edge Process Evaluation

Date: $12 / 01 / 88$

Study Sponsor: Bonneville Power Administration (BPA)

Authors: Lisee, EJ, GB Coleman, AJ Willman, et al.

Building Type: $\mathrm{C}$

Program Type, Code (C) or Utility (U): U

Evaluation Type, Process (P) or Impact (I): $P$

Evaluation Purpose, Formative (F) or Summative (S): $S$

Part of Process Addressed: I

Stakeholders Targeted: Building Design Professionals, Developers

Program Description: See The Energy Edge Project Building Design Process

Process Evaluation Method: The evaluation was designed to answer the following research questions: 1) Did the program build capability for constructing efficient buildings? 2) Did it lead to buildings designed to meet the performance target? 3) What energy conservation measures (ECMs) were used, in which buildings? 4) Did the design teams and process change? Historical documents describing the origins and purpose of the program were reviewed. Participant applications were used to obtain information on ECMs, costs, and energy savings. Over 90 in-person interviews were conducted with winning and non-winning design team members and program sponsors. Impact Evaluation Method:

Program Findings: 1) Energy Edge has been effective in increasing the experience of building professionals with energy-efficient design. 2) The importance of early involvement by engineers has been demonstrated and the design process has been modified effectively. 3) The program expanded the menu of design alternatives considered. 4) Design team familiarity and comfort with ECMs was increased. 5) The program has had little effect on design innovation. 6) The lack of knowledge and skill of program sponsors in the building design area was a constraint, but these were enhanced by the program. 7) The program delayed the building process an unacceptable amount in many cases, largely as a result of the time it took for the sponsors to respond to the design teams. 8) Two-thirds of participants would do it again; main benefits were getting a better building, learning about energy efficiency, and professional recognition. 9) The computer modeling was beneficial but mostly as a design tool and not as a predictor of energy use.

Methodology Findings:

Program Recommendations: 1) Future programs should bring industry professionals into the program design process early. 2) Future programs should not be publicized or implemented before agreement is reached on goals. 3) BPA should have had more continuity in the program and maintain staffing more consistently.

Methodology Recommendations:

Comments: 
Document Number: 0026

Study Title: Energy Edge Impact Evaluation-Findings and Recommendations from the Phase One Evaluation Date: $05 / 01 / 90$

Study Sponsor: Bonneville Power Administration (BPA)

Authors: Harris, J, R Diamond, O de Buen, A Hatcher, B Nordman, and MA Piette

Building Type: $\mathrm{C}$

Program Type, Code (C) or Utility (U): U

Evaluation Type, Process (P) or Impact (1): I

Evaluation Purpose, Formative (F) or Summative (S): S

Part of Process Addressed: $C$

Stakeholders Targeted: Building Design Professionals, Developers

Program Description: See The Energy Edge Project Building Design Process Evaluation

Process Evaluation Method:

Impact Evaluation Method: Billing data for 26 program buildings are compared with simulation model predictions. The billing data are also compared with the corresponding data for non-program buildings. The performance and cost-effectiveness of the first four buildings were analyzed in detail. The DOE-2 simulation model was used and calibrated using consumption data for each of the four buildings. The calibrated model was then used to compare the Energy Edge building with one built to meet the Model Conservation Standards (MCS) to estimate energy savings.

Program Findings: The comparison of the Energy Edge building with the building built to meet the MCS estimated the total savings to be within $10 \%$ of the predicted savings at the design stage. These savings are correct assuming the entrance vestibule was a significant factor for the energy savings. (The entrance vestibule parameter was studied subsequently.) Furthermore, there were differences between the results of the design-stage model and the actual model building. These differences are in terms of the absolute magnitude of energy use and the specific measures taken that are attributed to the energy savings.

Methodology Findings: This study showed both advantages and limitations of a calibrated building simulation model. It is always advantageous to have a real life model to gain experience in all aspects of the design since the model allows one to see if the design is suitable for the application as well as problems that were not predicted at the design stage. Yet if the model is not used with on-site testing, the model has limitations. The main limitation is future design modifications. Without on-site testing, the performance of the design model is unknown and therefore what needs to be changed is also unknown.

Program Recommendations:

Methodology Recommendations: Future studies will include studies on the entrance vestibule for its impact on the total energy savings. Also, results from the model will be compared with design predictions. Discrepancies will be taken into account on the basis of changed input assumptions, model accuracy, and other factors. Furthermore, additional attention will be given to the net impact of the program in both savings and costs. Better input data will be required. These data include data from site visits, one-time measurements, and controlled testing. In addition, documentation of building features and operating characteristics should be a continual process and not a one-time effort. Finally these data should be promptly and continually reviewed rather than having a delay of several months to a year or more before review.

Comments: 
Document Number: 0027

Study Title: Energy Edge Impact Evaluation-Early Overview

Date: $12 / 01 / 90$

Study Sponsor: DOE and Bonneville Power Administration (BPA)

Authors: Diamond, R, J Harris, MA Piette, $O$ de Buen, and B Nordman

Building Type: $C$

Program Type, Code (C) or Utility (U): $U$

Evaluation Type, Process (P) or Impact (I): 1

Evaluation Purpose, Formative (F) or Summative (S): $S$

Part of Process Addressed: I

Stakeholders Targeted: Utilities, Commercial Building Designers, Commercial Building Developers

Program Description: See The Energy Edge Project Building Design Process Evaluation.

Process Evaluation Method:

impact Evaluation Method: The data from 28 Energy Edge buildings were brought together to present what is currently known about the Energy Edge project. By comparing the data to other buildings as well as to other Energy Edge buildings and the computer simulated design, the performance of the Energy Edge buildings will be analyzed to determine energy-efficiency and cost-effectiveness.

Program Findings: Of the many new design technologies used in the Energy Edge project, many designers said they would continue to use these features in future building designs. Another finding involves the predicted building consumption rate. As a whole the Energy Edge buildings are using $10 \%$ more energy than predicted. But when a building does not meet the test of using 0.7 of the energy estimated for MCS buildings, it is often known why. Finally, there are some things that can be done to increase the market for energy-efficient buildings. One is to provide feedback to the current participants. Second, one could target new participants. Third, one could provide incentives that are flexible enough to deal with different sub-markets and differing technical opportunities.

Methodology Findings: There were three key methodology findings from this study. First, there is a need to provide clear guidelines and definitions for calculating predicted savings. Second, proper ranking of energy-efficient measures, operations, and maintenance is critical to ensure delivery of energy savings. Finally, monitoring and analysis techniques used in the Energy Edge project are very expensive and time-consuming.

Program Recommendations: A good design does not always assure good performance. The Long-Term Commercial Acquisition Process (LTCAP) and changes to the Model Conservation Standards (MCS) must go beyond the "building design" to incorporate construction quality, ongoing $O \& M$, and tenant improvements. $A 0.7$ MCS goal is possible to achieve; however, in the future, cost-effective energy services should be emphasized instead of a fixed percentage of energy savings. To increase the market, it has been suggested that a survey of businesses be conducted to determine potential participants.

Methodology Recommendations: BPA should work with other organizations to determine the guidelines and definitions to calculate savings in the initial stages of an Energy Edge building project to ensure clarity. BPA could do this to properly rank energy-efficient measures too. Also, better specification of an analysis plan for each building-not just a monitoring plan--could reduce the amount of data collected, and thus time and cost.

Comments: 
Document Number: 0028

Study Title: Energy Edge Impact Evaluation-Middle Overview

Date: 05/01/92

Study Sponsor: DOE and Bonneville Power Administration (BPA)

Authors: Diamond, R, MA Piette, B Nordman, $O$ de Buen, and $J$ Harris

Building Type: $\mathrm{C}$

Program Type, Code (C) or Utility (U): $U$

Evaluation Type, Process (P) or Impact (I): I

Evaluation Purpose, Formative (F) or Summative (S): $S$

Part of Process Addressed: I

Stakeholders Targeted: Utilities, Commercial Building Designers, Commercial Building Developers

Program Description: See The Energy Edge Project Building Design Process Evaluation

Process Evaluation Method:

Impact Evaluation Method: Data on the Energy Edge buildings were collected for up to four years. These data included on-site monitored energy use as well as utility bills. The Energy Edge building data were then compared with previous energy consumption data, and end-uses were studied.

Program Findings: Based on the first five analyses, efficiency measures are saving $13 \%$ less than predicted. In fact, utility bills show $60 \%$ of the Energy Edge buildings have an increased energy usage. For end-uses, lighting measures are saving more than predicted but HVAC measures are saving less. The heat pumps are performing better than predicted, and an analysis shows that the performance could be improved. Economizers in the smaller buildings have been saving only a small amount of the predicted savings.

Methodology Findings: There were four methodology findings. They are 1) energy use is much easier to document than energy savings, 2) the actual model was much more useful than the design prediction model, 3) the MCS code does not provide a consistent baseline from which to calculate the savings of individual measures, and 4) it is difficult to compare predicted and actual savings due to the lack of detail in the documentation of the predicted models.

Program Recommendations:

Methodology Recommendations: The study should be continued so that the energy saving effects can be seen over time. Also new construction trends should be examined and the performance of other buildings should be studied to establish baselines for comparisons.

Comments: 
Document Number: 0029

Study Title: In the Trenches with Large Commercial/nndustrial Energy-Conscious New Construction Programs: What Delivery Features Work Best?

Date: $10 / 01 / 95$

Study Sponsor: Energy Investment, Inc.

Authors: Bjorklund, A

Building Type: $\mathrm{C}$

Program Type, Code (C) or Utility (U): U

Evaluation Type, Process (P) or Impact (I): P

Evaluation Purpose, Formative (F) or Summative (S): $F$

Part of Process Addressed: D

Stakeholders Targeted: Building Designers, Owners

Program Description: The Commercial/ndustrial (C/) Energy-Conscious New Construction Program has a goal to make energy-efficient improvements a routine and essential part of building design and construction processes. This program gives various types of financial assistance as well as technical assistance in hopes of promoting energy efficiency as a valuable resource.

Process Evaluation Method: These analyses included a review of design documents and identification of potential energy-saving enhancements. An analysis of incremental costs and energy savings associated with design enhancements was also included. In addition, there were meetings with owners and designers to discuss potential measures. Detailed equipment selection information was provided to the design team as needed. Finally, in some cases, review of final design drawings and inspection of installed equipment was done to ensure compliance with the recommended measures.

Impact Evaluation Method:

Program Findings: It was found that technical assistance was important to building designers and owners. The energy specialist served as a resource and an ally to the utility, owner, and design team. The energy specialist devoted the necessary time and provided the expertise to develop energy conserving design improvements that were compatible with the building's design, as well as project schedule and budget constraints.

Methodology Findings:

Program Recommendations:

Methodology Recommendations:

Comments: This study discussed why technical assistance was beneficial to energy-efficient building design and construction. The energy efficiency of the buildings was not studied and compared with the buildings built without this technical assistance. Some typical energy savings were tabulated, but these numbers are not specific to this program. The sponsor listed was the company that did the evaluation; the actual sponsor was not given. 
Document Number: 0030

Study Title: Commercial New Construction Practices in Georgia-Findings From 480 On-Site Surveys

Date: 10/01/94

Study Sponsor: Georgia Power

Authors: Reed, G

Building Type: $\mathrm{C}$

Program Type, Code (C) or Utility (U): $U$

Evaluation Type, Process (P) or Impact (I): P

Evaluation Purpose, Formative (F) or Summative (S):

Part of Process Addressed: D

Stakeholders Targeted: Commercial Building Designers, Owners

Program Description: This study does not address a specific program. It focuses on providing baseline construction practice information.

Process Evaluation Method: A survey of $\mathbf{4 8 0}$ new commercial buildings was conducted to determine an appropriate baseline. Eight different types of buildings were included in the survey and were chosen from a random sampling of new account billing files from Georgia Power. The building types are office, retail, grocery, schools, health care, restaurant, hotel/motel, and other. This survey encompassed over 12.7 million square feet of new building space and represents one of the most detailed and comprehensive efforts by a utility to characterize new building practices in the commercial sector. The survey was conducted from October 1991 to February 1992. These data included information on lighting equipment, space heating, air conditioning, ventilation equipment, building envelope, refrigeration systems, hot water systems, and cooking equipment.

Impact Evaluation Method:

Program Findings: For interior lighting, $52 \%$ of the luminaire wattage are four foot fluorescent, of which only $0.2 \%$ are high efficiency T8 luminaries. Incandescents comprise $21 \%$ of the installed lighting wattage, followed by other fiuorescents at $16 \%$ and high-intensity discharge (HID) luminaries at $13 \%$ The percentage of installed watts that were fluorescent ranged from 94.3 percent in offices to 24.9 percent in hotels and motels. Only $31 \%$ of the fluorescent lighting were energy-efficient, $69 \%$ were standard, and less than $1 \%$ were comprised of T8s. The average watts/sq. ft. ranged from 2.21 in grocery stores to 1.18 in retail stores and 1.05 in the other category. For HVAC systems, all building types surveyed had new air conditioning equipment. The electric heating category was subdivided into resistance and heat pump. Of all buildings surveyed, $11.3 \%$ had heat pumps; heat pumps were most common in schools and hotels/motels at $32.7 \%$ and $21.3 \%$, respectively. Among resistance-based systems, the most prevalent was baseboard at $26.8 \%$, followed by unit heaters at $21.0 \%$, and duct furnaces at $20.6 \%$. Some of the building envelope results included average $U$-values. The average $U$-value for all buildings surveyed was 0.12 for walls, 0.08 for roofs, and 0.68 for windows. The window-to-wall area ratios were highest in restaurants $(0.36)$ and offices $(0.30)$, and schools had the lowest ratio at 0.07 . The survey inventoried seven different service water heating equipment types. The most common equipment type, based on input capacity ratings, were self-contained residential type units representing nearly $75 \%$ of the installed electric systems. Finally, 21 different types of cooking equipment were surveyed. They were counted, and a total $\mathrm{kW}$ value was recorded based on useful equipment output capacity.

Methodology Findings: There were three main findings: 1) it is difficult to generate a stratified sample for new construction surveys since buildings are usually not operating at capacity, 2) not all building data can be readily collected on-site (e.g., chiller efficiencies and glazing shading coefficients), and 3 ) the types of data required should be clarified before they are collected.

Program Recommendations:

Methodology Recommendations: One recommendation is that the data should be verified through a post-survey follow-up with the project's architect or engineer. For some equipment, model numbers can be obtained and manufacturer catalogs used to obtain the required efficiency information. To ensure that the proper data are collected, data requirements may be dictated by proposed or existing DSM program designs.

Comments: 
Document Number: 0031

Study Title: How Can We Do This Better? Redesigning RG\&E's Commercial/nndustrial New Construction

Program

Date: $10 / 01 / 94$

Study Sponsor: Rochester Gas \& Electric

Authors: Birnbaum, I, G Davis

Building Type: $\mathrm{C}$

Program Type, Code (C) or Utility (U): U

Evaluation Type, Process (P) or Impact (I): $P$

Evaluation Purpose, Formative (F) or Summative (S): $F$

Part of Process Addressed: $P$

Stakeholders Targeted: Commercial Building Designers, Contractors

Program Description: This program is a redesign of an existing program to implement energy-efficient measures in non-residential buildings. The original program was modified in 1992 due to changes to the New York commercial building efficiency code. These revisions include eligible measures, incentive levels, program materials and forms, and use of better designs.

Process Evaluation Method: The process of determining the new program for energy-efficient buildings involved brainstorming sessions. The ideas were then compared with the new 1992 standards to determine which ideas were the most feasible.

Impact Evaluation Method:

Program Findings: There was a large response to the new program. RG\&E initially sought 25 projects for the new program, but received 66 by the end of 1990 and 122 more by the end of 1991 . The MWh savings were also more than expected. The program's annual goal was 1,185 MWh, but at the end of 1991 it achieved 12,896 MWh. Most of the participation was largely due to requirements of the standards. Also, many of the energy-efficient measures taken were just the minimum amount to meet the standards. A key factor is how and when the benefits of the energy-efficient measures are demonstrated to the owners. Timing is a critical factor that determines whether analysis and design costs are negligible or prohibitive. Meeting this time constraint requires the development of an effective program marketing effort, including frequent communication with architects and engineers. Analysis and design services or incentives as well as other services are also essential to overcome the significant barriers to participation. Owners and their design teams lack the time, budget, and sometimes the capability to analyze the options, to specify and procure unfamiliar equipment, and to ascertain proper performance.

Methodology Findings:

Program Recommendations:

Methodology Recommendations:

Comments: 
Document Number: 0032

Study Title: The Integrated Approach to Evaluating New Commercial Buildings: Does it Work?

Date: $04 / 01 / 93$

Study Sponsor: Pacific Gas and Electric Company (PG\&E)

Authors: Galawish, EO, AG Lee, D Mahone and E Makela

Building Type: $\mathrm{C}$

Program Type, Code (C) or Utility (U): U

Evaluation Type, Process (P) or Impact (I): C

Evaluation Purpose, Formative (F) or Summative (S): $F$

Part of Process Addressed: 1

Stakeholders Targeted: Commercial Building Designers, Engineers, Contractors, Developers

Program Description: PG\&E's NRNC (Non-Residential New Construction) program promotes the design, construction, and operation of energy-efficient new buildings that exceed California's Title 24 Standards. There is a particular focus on on-peak electric load reductions. This program offers a rebate based on compliance with this program over a five-year study period. The types of buildings eligible for the program include government, grocery, hospital, office, retail, school, restaurant, hotel/motel public areas, public assembly, correctional facility, and commercial and industrial work space. Compared with the Title 24 Standards baseline, electric consumption for lighting must be reduced by $15 \%$ or more, and other systems must be reduced at least $5 \%$ for a building to be eligible for a rebate.

Process Evaluation Method:

Impact Evaluation Method: There were 82 participants and 78 non-participants initially studied in this evaluation. Site surveys were conducted between November 1991 and March 1993. Data collection during this time included both measures information and information vital to determining whether a project met the program guidelines. Engineering analyses were then conducted using the on-site data collection. These engineering analyses were used to conduct an economic analysis of the billing data. Finally, 39 sites (20 participants and 19 non-participants) were selected for two-to four-week end-use monitoring. The end-use monitoring was done between June 1992 and March 1993. To allow for fult-load conditions, the air conditioning and refrigeration equipment were monitored in the late summer of 1992. The end-use data were used in an engineering analysis which was then used in an economic analysis to determine $\mathrm{kWh}$ savings.

Program Findings: At the time of publication, the final numerical results were not authorized for release by PG\&E.

Methodology Findings:

Program Recommendations:

Methodology Recommendations:

Comments: 
Document Number: 0033

Study Title: An Energy Responsive Building Application for New Commercial Construction

Date: $00 / 00 / 92$

Study Sponsor:

Authors: C Hepting

Building Type: $\mathrm{C}$

Program Type, Code (C) or Utility (U):

Evaluation Type, Process (P) or Impact (I): This is a design study and was not reviewed further.

Evaluation Purpose, Formative (F) or Summative (S):

Part of Process Addressed:

Stakeholders Targeted:

Program Description:

Process Evaluation Method:

Impact Evaluation Method:

Program Findings:

Methodology Findings:

Program Recommendations:

Methodology Recommendations:

Comments: 
Document Number: 0034

Study Title: The Performance of the Energy Edge Buildings: Energy Use and Savings

Date: 00/00/92

Study Sponsor: Bonneville Power Administration (BPA)

Authors: Diamond, R, MA Piette, B Nordman, O de Bued, J Harris, B Cody

Building Type: $\mathrm{C}$

Program Type, Code (C) or Utility (U): U

Evaluation Type, Process (P) or Impact (I): I

Evaluation Purpose, Formative (F) or Summative (S): $S$

Part of Process Addressed: C

Stakeholders Targeted: Building Developers, Owners

Program Description: See The Energy Edge Project Building Design Process Evaluation

Process Evaluation Method:

Impact Evaluation Method: Three comparisons were done in this evaluation. The first comparison analyzed the energy consumption based on utility bills and then compared the estimated design-stage consumption with actual consumption. The second analysis compared the Energy Edge buildings with other buildings in the region using monitored end-use data. The third analysis compared actual energy consumption with the MCS code baseline. A "baseline building" was defined to provide a basis for comparison.

Program Findings: These analyses showed that in the first year of operation 27 Energy Edge buildings used $10 \%$ more energy than predicted. In the second year, this figure rose to $23 \%$. For the third year, there were data for 21 Energy Edge buildings. These data indicated that these buildings used $31 \%$ more energy than predicted. Finally, four years of data were available for 10 buildings. They showed a $52 \%$ higher consumption than initially predicted. When these buildings were compared with other buildings in the region, they were found to consume less energy. When compared with the MCS baseline, five buildings averaged $24 \%$ less consumption in HVAC and lighting.

Methodology Findings: It was difficult to compare the Energy Edge buildings to the MCS code due to the lack of standard definitions for a baseline. The modeler was forced to make several assumptions in order to define baseline buildings. There were also ambiguities because the MCS do not apply to all end uses. It was also discovered that it was easier to predict energy use than energy savings.

Program Recommendations: Other baselines need to be explored, and factors and forces that affect their energy performance and measure savings need to be better determined.

Methodology Recommendations:

Comments: 
Document Number: 0035

Study Title: Evaluating Actual Performance of New Commercial Buildings: The Energy Edge Demonstration Program

Date: Unknown

Study Sponsor: Bonneville Power Administration (BPA)

Authors: Diamond, R, J Harris, O de Buen B Nordman, B Cody

Building Type: $\mathrm{C}$

Program Type, Code (C) or Utility (U): U

Evaluation Type, Process (P) or Impact (I): P

Evaluation Purpose, Formative (F) or Summative (S): $F$

Part of Process Addressed: C

Stakeholders Targeted: Building Designers, Developers, Owners

Program Description: See The Energy Edge Project Building Design Process Evaluation

Process Evaluation Method: Due to the significant discrepancies between design predictions and whole-building energy use in The Energy Edge Project Building Design Process Evaluation, a more detailed analysis was conducted using detailed monitored data, utility billing data for 26 buildings, hourly monitored data for four buildings, and the detailed "tuned model" results from one pilot study building. The purpose of these analyses was to determine if the results from The Energy Edge Project Building Design Process Evaluation were correct. Impact Evaluation Method:

Program Findings: Compared with the MCS, Energy Edge buildings are approximately 20 percent more efficient. The ratio of billed energy use to design predicted energy use for 26 energy-edge buildings is 1.11 . The analysis also showed that Energy Edge buildings are using more energy as time passes.

Methodology Findings: The use of calibrated building models is a very important tool to assess whole building performance.

Program Recommendations: Another evaluation of Energy Edge buildings should be done in the future to see the energy use trends.

Methodology Recommendations: The specific approach of using a tuned model might be refined with additional steps to validate the tuned model with a separate subset of data, use actual hourly values for loads and scheduled input to the model, and incorporate improved measurements for critical parameters in each building. Also, the model parameters should be changed so that the model calculates savings for each measure and for various combinations of measures.

Comments: 
Document Number: 0036

Study Title: Design Assistance for New Commercial Buildings: Case Study Evaluation

Date: 00/00/90

Study Sponsor: Bonneville Power Administration (BPA)

Authors: Kunkle, R, D Kilpatrick, S Simpson

Building Type: $C$

Program Type, Code (C) or Utility (U): $U$

Evaluation Type, Process (P) or Impact (I): $P$ and I

Evaluation Purpose, Formative $(F)$ or Summative $(S)$ : $S$

Part of Process Addressed: A

Stakeholders Targeted: Building Developers. Owners

Program Description: See Process Evaluation of BPA's Energy Smart Design Assistance Program.

Process Evaluation Method: This evaluation consisted of ten case studies of the original 26 participants. For each individual building, a six-step evaluation process was conducted. The first step was to contact the participants and collect utility data. The second step was to review the utility data as well as the energy-efficient measures installed in the building. The third step was an on-site visit. Its main purpose was to compare the design energy-efficiency measures with what was actually installed. The fourth step involved an as-built computer simulation. The fifth step included interviews with all the project participants. Finally, the impacts of the program were estimated and important process issues were identified for each case study.

Impact Evaluation Method: See process evaluation method discussion.

Program Findings: The program delivered cost-effective energy conservation. Participants reacted favorably to the simple nature of the program and the experience they gained. However, the program had limited impact on the efficiency of the buildings. None of the case study buildings was notably energy efficient. The case studies show that providing the client with economic information on energy-efficiency improvements early in the building design is not sufficient to ensure building energy efficiency. The accuracy of the original design assistance energy savings predictions was poor.

Methodology Findings:

Program Recommendations: The program needs to be more flexible and targeted to the specific needs of the client. A broader range of design services is needed. Services need to be available throughout the design process. Some form of building operator training and building commissioning need to be provided. Also, some form of incentives both to the designers and building owner/developers may be required if the program intends to have all cost-effective energy-efficiency improvements installed in the building.

Methodology Recommendations:

Comments: This evaluation is a combination of previous process and impact evaluations. 
Document Number: 0037

Study Title: Mandating Energy Efficient Commercial Buildings: San Francisco's Commercial Energy Conservation Ordinance

Date: $00 / 00 / 90$

Study Sponsor: City of San Francisco

Authors: Egel, K, J Cook, B Knox

Building Type: $\mathrm{C}$

Program Type, Code (C) or Utility (U): C

Evaluation Type, Process (P) or Impact (I): $P$

Evaluation Purpose, Formative (F) or Summative (S): $F$

Part of Process Addressed: D

Stakeholders Targeted: Building Designers, Owners

Program Description: San Francisco's Commercial Energy Conservation Ordinance (CECO) is the nation's only ordinance designed to require energy conservation for retrofits in commercial buildings. It took effect in 1989 and was developed by the City of San Francisco due to unsatisfactory energy consumption performance by commercial buildings, especially older buildings. Consequently, the intent of CECO was to promote the efficient use of energy in existing commercial buildings and to benefit the City's local economy by retaining utility bill savings and creating local jobs in the building industry.

Process Evaluation Method:

Impact Evaluation Method:

Program Findings:

Methodology Findings:

Program Recommendations: The three things that would benefit the program are 1) increased public awareness of the ordinance, 2) improved enforcement procedures by the city, and 3) access to management data by city staff.

\section{Methodology Recommendations:}

Comments: This is not an evaluation, but a description of CECO's development. It also discusses some initial suggestions for ways to improve the program. 
Document Number: 0038

Study Title: A Utility Program for Improving the Energy-Efficiency of New Non-Residential Construction

Date: $00 / 00 / 90$

Study Sponsor: Northeast Utilities

Authors: Wajcs, FF, Jr

Building Type: $\mathrm{C}$

Program Type, Code (C) or Utility (U): $U$

Evaluation Type, Process (P) or Impact (l): P I

Evaluation Purpose, Formative (F) or Summative (S): $S$

Part of Process Addressed: I

Stakeholders Targeted: Suppliers, Developers, Design Professionals, Contractors

Program Description: This program is an effort to implement energy-efficient measures during the construction of a commercial building instead of implementing the measures in a retrofit program. This program has features targeted at different categories of buildings: prescriptive, accelerated, and comprehensive. The prescriptive area of the ECC (Energy Conscious Construction) program is designed for nonresidential buildings, excluding grocery stores, under 10,000 square feet in any stage of design or construction. The accelerated area is for nonresidential buildings over 10,000 square feet where the design documents are complete or the building is already under construction. The comprehensive area of the program is for projects over 10,000 square feet and for all grocery stores in the early stages of design. For the prescriptive area, NU (Northeast Utilities) developed a menu of measures including lighting, HVAC, and motor items with fixed incentives. This method was selected because of the short design time and the limited efficiency options. The accelerated area uses the prescriptive menu along with the services of specialists who are able to offer customized incentives. Finally the comprehensive area of the program uses the actual design team to implement kilowatt-hour reduction techniques. The design team, which consists of the owner, the architect, the mechanical and electrical engineer and all other consultants that can influence the design, uses brainstorming to come up with energy-efficient measures. Once a suitable design has been proposed, the design team and NU do analysis of the design to determine which measures should be used. Together they decide on a final design.

Process Evaluation Method: The methodology is not described, but program process findings are reported. Impact Evaluation Method: No specific methodology is described, but estimated costs and energy savings are presented.

Program Findings: For the first 130 contracts signed in 1989 , estimated energy savings associated with the $\$ 2.8$ million of incentives for measures are 10.8 million annual kilowatt-hours and 159.0 million lifetime kilowatt-hours. Through March 1990, contracts for 190 projects had been signed producing estimated lifetime savings of 700 million $\mathrm{kWh}$. Design assistance is expected to have a large payoff as designers transfer to new projects what they learned in the program. A key program accomplishment was helping designers and their clients communicate effectively about energy efficiency.

Methodology Findings:

Program Recommendations: The author uses experiences from the program to recommend guidelines for future programs. The first recommendation is to build a good foundation by working closely with the building community, defining baseline construction practices through a survey, and training the people who will deliver the service. The second recommendation is to develop a clear message about the program to deliver to the participants. The third recommendation is to have a computerized tracking system in place when the program is implemented. It would allow easy tracking of data and would be a useful tool to immediately answer questions about the program status or where money is being allocated. This tracking system should also have the raw data from the initial survey to determine the baseline for the program. That way it can be referred to for a presentation on special projects or for reevaluation when challenged. The final recommendation is to establish professional credibility with the program participants. The primary technical area needing improvement was the lighting. A methodology that simply related levels of illumination and watts per square foot without doing a full lighting design would make NU's efforts and that of the design community a lot easier.

Methodology Recommendations:

Comments: 
Document Number: 0039

Study Title: Savings by Design: A Customer Driven Electrical Efficiency Program for Commercial Buildings

Date: $00 / 00 / 90$

Study Sponsor: Ontario Hydro

Authors: Jordan, SD, D Grafstein

Building Type: $\mathrm{C}$

Program Type, Code (C) or Utility (U): U

Evaluation Type, Process (P) or Impact (l): IP

Evaluation Purpose, Formative (F) or Summative (S): $F$

Part of Process Addressed: D

Stakeholders Targeted: Building Designers, Owners

Program Description: Savings by Design is a customer-driven incentive program. It is meant to incorporate energy-efficient ideas that do not fall into any specific category. The program starts with an energy-saving idea. A feasibility study is then conducted. Next, $\mathrm{KW}$ savings, avoided costs, and the incentive are determined. Once the energy-saving measures are in place, the full incentive is paid.

Process Evaluation Method: The process evaluation included a market research study that took into account applicants' and non-applicants' points of view. Telephone and personal interviews were conducted by Ontario Hydro's market research consultant. The information collected was given to Ontario Hydro in workshops for discussion. The consultants used Ontario Hydro's responses in the workshops for further discussion in focus groups of engineers and owners and developers. Finally, another staff workshop was led by research consultants, from which emerged a list of potential improvements to the program.

Impact Evaluation Method:

Program Findings: In 1989 Ontario Hydro had a goal of saving $6.8 \mathrm{MW}$. It beat that goal by saving $7.3 \mathrm{MW}$. In 1990 the target was 20.5 MW. By the end of May, their result was $16 \mathrm{MW}$ of committed demand reduction. The market research suggested that owners and developers had little awareness of the program. On the other hand, consulting engineers did know a lot about the program. Yet, consulting engineers did not know how it differed from current incentive programs offered by Ontario Hydro. The research also confirmed that consulting engineers can and do encourage clients to become innovative with their designs.

Methodology Findings:

Program Recommendations: It was recommended that Savings by Design be more user-friendly and simplified by allowing engineers to have access to Ontario Hydro's software at a lower cost, changing the amount of detail necessary for the feasibility study, and changing the amount of verification the engineers needed for their results. Methodology Recommendations:

Comments: All of the program recommendations have been addressed by allowing free access to the software, reducing the detail necessary for the feasibility study, and no longer requiring verification if a successful track record has been demonstrated already. 
Document Number: 0040

Study Title: Evaluation of the Non-Residential Energy Conservation Building Standards of the State of Colorado. Date: 05/01/81

Study Sponsor: U.S. Department of Commerce, National Bureau of Standards, National Conference of States on Building Codes and Standards Inc.

Authors: Cattany, RW, DE Croy, L Rup

Building Type: $\mathrm{C}$

Program Type, Code (C) or Utility (U): C

Evaluation Type, Process (P) or Impact (I): I

Evaluation Purpose, Formative (F) or Summative (S): $F$

Part of Process Addressed: I

Stakeholders Targeted: Building Designers, Owners

Program Description: The Colorado Model Energy Efficiency Construction and Renovation Standards for Nonresidential Buildings are based on the ASHRAE (American Society of Heating, Refrigerating and Air-Conditioning Engineers) Standard 90-75, with minor revisions to make the standards relative to Colorado. These standards establish specific, well-defined performance criteria for each element involved in building design that is related to energy usage.

Process Evaluation Method:

Impact Evaluation Method: This evaluation used information on 30 different buildings in three different geographic regions of Colorado. Half of these buildings were built before the standards were enforced (1974-1977) and the other half were built after the standards were enforced. Estimated energy savings were obtained by computer modeling 15 pre-code buildings on nationally recognized energy simulation programs then modifying results to reflect design requirements of State Standards. Thorough plan and specification checks of design documents were made on 15 post-code buildings to determine the degree of compliance with energy standards.

Program Findings: The standards were found to be effective in reducing annual energy consumption in all building types and locations studied. The average annual reduction was estimated to be $39.5 \%$ for office buildings three stories and under, $40.9 \%$ for office buildings over three stories, $6.1 \%$ for schools, $31.2 \%$ for retail stores, and $27.7 \%$ for warehouses. It was also found that very few post-code buildings were in compliance with the state standards. However, additional efforts to enforce the Standards would not make a significant change in the energy savings.

Methodology Findings:

Program Recommendations: The five recommendations made were 1) the state standards should be continued and improved as problem-area feedback is received and as the state-of-the-art advances, 2) the lighting portion of the standards should be completely revised to permit a more simplified approach, 3) standard forms should be developed by the State and made available to local building code officials for checking compliance, 4) the state program of training and technical assistance should be continued and improved, particularly for local enforcement officials, and 5) the state and the building industry should pursue additional energy and cost savings through a program of efficient operation and maintenance of existing nonresidential buildings.

Methodology Recommendations:

Comments: 
Document Number: 0041

Study Title: Site and Building Energy-Conservation Study: Survey of Building 435

Date: $10 / 01 / 79$

Study Sponsor: Kaiser Engineers

Authors: No authors were given

Building Type: $\mathrm{C}$

Program Type, Code (C) or Utility (U): Other

Evaluation Type, Process (P) or Impact (I): I

Evaluation Purpose, Formative (F) or Summative (S): $F$

Part of Process Addressed: D

Stakeholders Targeted: Building Owners

Program Description: Lawrence Livermore Laboratory requested an analysis of this and other buildings for opportunities to reduce energy consumption. This is a retrofit, rather than new building, study.

Process Evaluation Method:

Impact Evaluation Method: The survey of building 435 was based on a detailed review of design drawings, an on-site inspection, and discussions with the building manager and various operating personnel. Data were collected regarding the number of people occupying the building, operating schedules, and the energy equipment. The HVAC systems were investigated as well. The building energy systems were simulated using DOE-1 for the buildings performance for more efficient equipment compared to what is currently used in the building.

Program Findings:

Methodology Findings:

Program Recommendations:

Methodology Recommendations:

Comments: There was no specific program in this study. 
Document Number: 0042

Study Title: Energy Efficiency Building Performance Standards Study

Date: 02/00/93

Study Sponsor: Maine Office of Community Development

Authors: Maine Tomorrow.

Building Type: $\mathbf{R}$

Program Type, Code (C) or Utility (U): C

Evaluation Type, Process (P) or Impact (I): $P$

Evaluation Purpose, Formative (F) or Summative (S): $S$

Part of Process Addressed: CI

Stakeholders Targeted: Home Owners, Builders, Designers, Suppliers, Lenders, Real-Estate Agents

Program Description: In January 1989, Maine adopted Energy Efficiency Building Performance Standards

for residential, commercial, and industrial construction. All speculatively built single-family homes and all multi-family homes must comply. The standards require specific envelope insulation levels or equivalent thermal performance.

Process Evaluation Method: Mail questionnaires were used to gather information from home owners, contractors and builders, architects and designers, suppliers, lenders, and real-estate agents. The main purpose was to measure the compliance rate. Levels of awareness for the different audiences were measured. The surveys also obtained information about attitudes toward the standards and educational programs. On-site surveys of the homes were conducted when possible. Out of 1,245 surveys mailed, responses were received for 195 of them; the overall response rate was $14.5 \%$. The responses represented 927 residential structures.

Impact Evaluation Method:

Program Findings: Only $38 \%$ of respondents were aware of the standards law. Two-thirds of builders said they were familiar with the law, but only $14 \%$ of home owners said they were. Awareness about specific requirements of the standards was even lower. Compliance rates were the lowest for sloped ceilings (around $35 \%$ ) and highest for windows (about $95 \%$ ). Home owners have little understanding of the thermal characteristics of their homes. Owners rely mostly on contractors and supply stores for building practice information; supply store staff, however, have a relatively poor understanding of energy efficiency. Twothirds of respondents favored more consumer and builder education. Three-fourths of lenders and realestate agents supported more education.

Methodology Findings:

Program Recommendations: 1) Provide education on the standards to all participants in the housing market through several mechanisms. 2) Make selected regulatory changes. 3) Explore promotional activities including incentives to those meeting the standards, promotion of the home energy rating system (HERS), promotion of efficient appliances, and establishment of store discounts on efficient products.

Methodology Recommendations:

Comments: 
Document Number: 0043

Study Title: Impact Evaluation of Boston Edison's Commercial//ndustrial New Construction Program

Date: 07/01/94

Study Sponsor: Boston Edison Company

Authors: Wilcox, D, E Guinee

Building Type: $C$

Program Type, Code (C) or Utility (U): $U$

Evaluation Type, Process (P) or Impact (I): I

Evaluation Purpose, Formative (F) or Summative (S): $S$

Part of Process Addressed: I

Stakeholders Targeted: Building Owners, Designers

Program Description: The Commercial/nndustrial New Construction and Major Renovation Program began in 1990. The program provides both informational and financial assistance. Larger projects are provided with a report analyzing potential improvements to the initial building design. The financial incentive offered is equal to the incremental cost difference between the efficient equipment and the cost of the equipment proposed in the initial customer design. Once the incentives have been approved, $45 \%$ of the total incentive is paid at the start of construction, and the rest is paid upon project completion.

Process Evaluation Method:

Impact Evaluation Method: This evaluation used on-site data collection combined with engineering analysis on a representative sample of 12 of the 24 participant projects in 1992 and 15 of the 40 participant projects completed during 1993. The analysis calculated the connected demand, summer and winter coincident peak demand, and on-peak and off-peak energy impacts. The on-site visits included verification of measure installation and persistence, collection of metered data, and participant survey data which were used to establish operating characteristics and resulting measure savings. Results from these 27 on-site visits were extrapolated to the respective -participating population using statistical methods to determine the overall impacts of program participants. The baseline used was determined from site visits to 15 non-participant buildings.

Program Findings: In 1992 there were 24 completed projects, and in 1993 there were 40 total completed projects. The total annualized savings were $4,842,556 \mathrm{kWh}$. The lighting measures alone saved 2,426,204 $\mathrm{kWh}$. The net summer and winter coincident peak demands were 1,104 and $940 \mathrm{~kW}$, respectively. Lighting measure savings were 500 and $437 \mathrm{~kW}$ correspondingly.

Methodology Findings: The use of building simulation analysis using actual building operation data as verified through on-site visits can be an effective means to estimate new construction program impacts. In addition, it is important to collect service-area-specific baseline data. Finally, the methods used in this study to determine program impacts were able to achieve the requested precision of $\pm 10 \%$ for both 1992 and 1993 annualized kWh savings estimates.

Program Recommendations:

Methodology Recommendations: Future studies may want to consider increasing the sample size and data collected at the non-participant sample so that additional insight and higher confidence levels can be obtained.

Comments: 
Document Number: 0044

Study Title: Evaluation of Gross Savings Impacts of B.C. Hydro's New Building Design Program

Date: 00/00/95

Study Sponsor: B.C. Hydro

Authors: Fielding, D, C Chappell, M Abrishami

Building Type: $\mathrm{C}$

Program Type, Code (C) or Utility (U): U

Evaluation Type, Process (P) or Impact (I): I

Evaluation Purpose, Formative (F) or Summative (S): $S$

Part of Process Addressed: A

Stakeholders Targeted: Building Owners, Developers

Program Description: B.C. Hydro's New Building Design (NBD) Program has been designed to encourage commercial customers to design and construct energy-efficient buildings. The program offers financial incentives to customers constructing new buildings with equipment that exceeded the minimum efficiency requirements. The two types of rebates include Product Option and Custom Option rebates. Product Option provides fixed rebates on specific technologies; Custom Option rebates allow more flexibility of energy-efficient measures. The Custom Option is only available for buildings over 50,000 gross square feet.

Process Evaluation Method:

Impact Evaluation Method: First, data on the building, equipment characteristics, and the operational practices of the sample buildings were collected through on-site visits. There were 99 participants - 66 were NBD participants and 33 were non-participants. These 99 participants included colleges, elementary and secondary schools, supermarkets, convenience stores, hospitals, motels, high-rise buildings, low-rise buildings, recreation, restaurants, retail, and warehouses. For each building in the sample, the data collected on-site were used in a series of parametric simulation runs with the DOE-2 building energy analysis model to develop estimates of annual energy use under different sets of building conditions. The gross savings attributable to measures installed under the NBD program were then determined through comparisons of a building's whole-building and end-use energy use with and without the rebated measures installed.

Program Findings: The total achieved savings were significantly greater for the participants than for the non-participants for all types of buildings. Both types of participant grocery stores had the largest total achieved savings. Supermarkets saved $9.361 \mathrm{kWh} / \mathrm{sf} / \mathrm{yr}$, and convenience stores saved $6.390 \mathrm{kWh} / \mathrm{sf} / \mathrm{yr}$. Supermarkets also had the greatest demand reduction at $2.079 \mathrm{~W} / \mathrm{sf}$. The low-rise offices had the greatest energy savings and demand reduction at $1.306 \mathrm{kWh} / \mathrm{s} / \mathrm{f} / \mathrm{r}$ and $0.450 \mathrm{~W} / \mathrm{sf}$ respectively. The average energy savings for the participants were $2.654 \mathrm{kWh} / \mathrm{sf} / \mathrm{yr}$, and the average demand reduction was $0.73 \mathrm{~W} / \mathrm{sf}$. The total achieved savings by end-use was greatest for interior lighting for both participants and non-participants.

Methodology Findings:

Program Recommendations:

Methodology Recommendations:

Comments: 
Document Number: 0045

Study Title: Net Impact Evaluation of a Non-Residential New Construction Program in the Pacific Northwest

Date: $00 / 00 / 00$

Study Sponsor: Portland General Electric Company

Authors: Rittenhouse, B, D Dohrmann, S Noell

Building Type: $\mathrm{C}$

Program Type, Code (C) or Utility (U): U

Evaluation Type, Process (P) or Impact (I): 1

Evaluation Purpose, Formative (F) or Summative (S): $S$

Part of Process Addressed: I

Stakeholders Targeted: Building Developers, Owners

Program Description: See Process Evaluation of BPA's Energy Smart Design Assistance Program

Process Evaluation Method:

Impact Evaluation Method: This evaluation studies 78 participants in 1990 and 1991 . The main strategy for the study was to compare the savings for the program participants and a sample of non-participants. The participant data were used to estimate gross program savings through DOE-2 simulations, which were based on on-site survey data. The net-to-gross ratio, which is a measure of naturally occurring conservation, was used to adjust gross savings for estimating net program savings. This net-to-gross ratio was estimated through a telephone survey of building construction decision-makers and verified through an economic analysis.

Program Findings: The gross savings reduced EUl's an average of $3.15 \mathrm{kWh} / \mathrm{sf} / \mathrm{yr}$ and peak power densities by an average of $0.40 \mathrm{~W} / \mathrm{sf}$. Interior lighting and space cooling were the end-uses responsible for most of the energy savings and all of the peak load savings. The free-ridership rate was estimated to be $18 \%$ to $22 \%$ for the custom design assistance customers and approximately $10 \%$ for the specific technology customers. The average rebated measure realization rate for the custom design assistance customers was $89 \%$ and $121 \%$ for the prescriptive path customers.

Methodology Findings:

Program Recommendations: Six program recommendations were made: 1) measure installation should be verified by a third party; 2) projects involving renovations should be excluded from program; 3 ) hard to verify measures (like controls) should be excluded or subject to more conservative savings estimates; 4) savings estimates should be updated when measure installation is verified; 5) energy code compliance documentation should be required; and 6) decision-maker information should be collected with the program application.

Methodology Recommendations: Three methodology recommendations arose from this study. First, time lags should be accounted for when considering the timing of program evaluation. Second, end-use monitored data could be used selectively to increase the accuracy of key simulation input data, including utilization factors, off-hour operation, and installed load. Third, for addition and renovation projects, project documentation must identify new and existing areas, rebated measures and the areas they affect. The decision-maker analysis should be extended to include non-rebated measure savings for program participants and free-driver effects for non-participants.

Comments: 
Document Number: 0046

Study Title: Billing Analysis for New Construction Programs: What Are Realization Rates Really Capturing?

Date: 00/00/95

Study Sponsor: Potomac Electric Power Company

Authors: Gallahe, M, M Kumm, P Uirey

Building Type: $\mathrm{C}$

Program Type, Code (C) or Utility (U): U

Evaluation Type, Process (P) or Impact (I): I

Evaluation Purpose, Formative (F) or Summative (S): $F$

Part of Process Addressed: D

Stakeholders Targeted: Building Designers, Developers

Program Description: Pepco's NBD (New Building Design) Program provides design incentives and rebates for energy-efficient equipment to encourage building designers and developers to incorporate a higher level of energy efficiency in new commercial construction or in total renovation of existing commercial buildings. Rebate levels are based on the incremental cost of energy-efficient equipment, averaged over the size and types of equipment, and capped by Pepco's avoided cost.

Process Evaluation Method:

Impact Evaluation Method: A combined engineering simulation and statistical billing analysis was conducted to estimate the reduction in energy consumption for the NBD Program. The analysis used on-site surveys conducted for the 27 program participants and the 10 non-participants. The non-participating buildings were randomly selected from Pepco's new customer accounts file to match as closely as possible the participating buildings with respect to building type and size. Each participant building was modeled twice using the DOE-2 software. The building was first modeled "as built," including all high-efficiency measures for which the participant received rebates, to estimate total facility energy usage. The participant building was then modeled again using standard-efficiency baseline assumptions to estimate total facility energy usage in the absence of the NBD program. The difference between the simulations represents the energy reductions attributable to the program. Program Findings: The realization rate on energy savings is estimated to be close to but less than one. The realization rates are interpreted as the function of energy savings estimates that are realized in the customers' bills. Methodology Findings: The non-participants were key in determining an appropriate baseline.

Program Recommendations:

Methodology Recommendations: Statistical billing analysis should play an integral role in evaluating new construction programs, but caution should be used in automatically scaling engineering estimates as a result of estimated realization rates. The relative uncertainty of engineering estimates versus the uncertainty of regression results should be compared, as well as the sources and direction of potential bias associated with each method. Comments: This evaluation investigates the unique issues of statistical billing analysis for new construction programs and evaluates areas of potential bias. 
Document Number: 0047

Study Title: Commercial New Construction Impact Evaluation-A Comprehensive Approach to Analyzing New Construction Incentive Program Results

Date: 00/00/95

Study Sponsor: San Diego Gas and Electric

Authors: Cowles, D, A Besa, T Alereza, F Sebold

Building Type: $\mathrm{C}$

Program Type, Code (C) or Utility (U): U

Evaluation Type, Process (P) or Impact (I): I

Evaluation Purpose, Formative (F) or Summative (S): $S$

Part of Process Addressed: I

Stakeholders Targeted: Building Designers, Owners

Program Description: The 24 Plus Program was designed to encourage commercial customers to design and construct energy-eficient buildings. Financial incentives were offered to promote installation of building products and equipment that were at least $10 \%$ more efficient than the minimum requirements of Title 24 , California's Building Energy Efficiency Standards and Title 20, California's Appliance Efficiency Standards. Participants had to demonstrate the improved efficiency by documentation from analyses. The five end-uses which the program acknowledged were cooling, heating, fans/motors, lighting, and domestic hot water.

Process Evaluation Method:

Impact Evaluation Method: A building sample was established first. Of the 52 program participant buildings, 35 agreed to take part in this evaluation. For each participant and non-participant, a telephone interview and a high-resolution on-site survey were conducted. The data included building type (public assembly, education, manufacturing, office, fast food restaurant, retail, and health care) and end use data (space heating, space cooling, auxiliary HVAC, and interior lighting). From the data, DOE-2.1E simulation model inputs were developed and DOE2.1 runs were conducted. Finally, the gross savings were calculated, billing data were analyzed, and net-to-gross analyses were conducted.

Program Findings: The average gross energy savings by building type was $1.41 \mathrm{kWh} / \mathrm{sf} / \mathrm{yr}$ for the participants and $1.34 \mathrm{kWh} / \mathrm{sf} / \mathrm{yr}$ for the non-participants. Education facilities had the highest gross savings at 4.71 for the participants and 2.96 for non-participants. By end use the gross savings was 1.41 for the participants and 1.34 for the non-participants. For the participants more than half of gross savings by end use were due to interior lighting; for non-participants, more than half was attributed to space cooling.

Methodology Findings: The non-participants did not closely match the participants in building types, size, and other energy-affecting characteristics.

Program Recommendations: Non-rebated measures need to be verified to confirm that they meet Title 24 standards and do not offset program rebated measure savings.

Methodology Recommendations: There needs to be a larger sample as well as improved non-participant selection. The detail of the data could also be improved.

Comments: 
Document Number: 0048

Study Title: An Application of ASHRAE 90.1 as a Baseline for Evaluating Commercial New Construction Programs

Date: 03/26/95

Study Sponsor: Baltimore Gas and Electric

Authors: Twombly, E, C Hindes

Building Type: $\mathrm{C}$

Program Type, Code (C) or Utility (U): U

Evaluation Type, Process (P) or Impact (I): I

Evaluation Purpose, Formative (F) or Summative (S): F

Part of Process Addressed: $C$

Stakeholders Targeted: Building Architects, Designers

Program Description: The Comprehensive Commercial Construction Program (CCCP) provides incentives for architects and designers to develop buildings with a higher degree of energy efficiency. The program uses fixed values to characterize baseline energy consumption. Incentives are paid on the basis of reduced annual $\mathrm{kWh}$ and peak kW. The program is open to new buildings, additions, and major remodels for large commercial buildings. Process Evaluation Method:

Impact Evaluation Method: Eight buildings in each category (proposed, adjusted proposed and reference) were used in this evaluation. CCCP achieves compliance when the Proposed building has a lower energy cost than the ASHRAE Reference building. (A proposed building is one that has been recently constructed and was a CCCP participant. An adjusted proposed building is the same as the proposed building but with operating conditions defined by ASHRAE. A reference building is similar to a CCCP participant in geometry only.) Once the buildings were selected, an hourly simulation model was completed using the building data.

Program Findings: It was found that the proposed buildings had a much lower annual electricity use than the Reference buildings. The approximate difference between the two categories of buildings was $7 \mathrm{kWh} / \mathrm{sf}$. As a result it was concluded that ASHRAE was an appropriate baseline for the CCCP program.

Methodology Findings: The main findings were the following. First, another simulation should be completed as end-use data becomes available. Second, standardization of documentation for end-uses will be essential to determine the actual savings realized by a given building. Third, a more sophisticated computer model, such as DOE-2 should be considered due to the complexity of modern building designs.

Program Recommendations:

Methodology Recommendations:

Comments: 
Document Number: 0049

Study Title: Results of NU ECC Comprehensive Program Evaluation: Lessons Learned From Using Building Simulation as an Evaluation Technique

Date: 03/26/95

Study Sponsor: Northeast Utilities

Authors: Bjorklund, A, M Selig, D Bowles, P Spinney

Building Type: $\mathrm{C}$

Program Type, Code (C) or Utility (U): $U$

Evaluation Type, Process (P) or Impact (I): I

Evaluation Purpose, Formative (F) or Summative (S): F

Part of Process Addressed: I

Stakeholders Targeted: Building Architects, Designers

Program Description: See Impact Evaluation of Northeast Utilities' Energy Conscious Construction Program Comprehensive Area: Findings, Methods, and Avenues for Further Research.

Process Evaluation Method:

Impact Evaluation Method: To improve the accuracy of savings estimates and to assess the usefuiness of DOE2 re-simulations of as-built buildings as a program evaluation tool, two levels of analysis were conducted. The level one analysis consisted of brief site surveys (of 22 sites) to observe differences between as-built conditions and pro-construction assumptions, followed by simple proportional adjustments to the pre-construction savings estimates as appropriate. The level two analysis consisted of more detailed site surveys, including selected lighting and HVAC equipment end-use metering, followed by savings analysis utilizing the DOE2 building simulation program.

Program Findings: Both the level one and the level two analyses resulted in aggregate savings estimate that were $24 \%$ greater than the pre-construction estimate for the six sites analyzed under both levels. In addition, there were significant differences among pre-construction, level one, and level two savings estimates on a site-by-site and measure-by-measure basis.

Methodology Findings: The three main methodology findings are 1) incompleteness of documentation of pre-construction analyses and assumptions can hinder the efficiency and accuracy of post-construction evaluation analyses, 2) new construction savings analyses are very sensitive to differences between pre-construction assumptions and as-built conditions, and 3) the quality and accuracy of information used for the evaluation is greatty improved by on-site observations and metering of key operating parameters such as operating schedules. Program Recommendations:

Methodology Recommendations: Evaluation costs can be reduced by selecting impact analysis techniques that are measure specific.

Comments: 
Document Number: 0050

Study Title: Energy Savings of Commercial Energy Code Compliance in Washington and Oregon

Date: $08 / 14 / 92$

Study Sponsor: Ecotope

Authors: Kennedy, M, D Baylon

Building Type: $\mathrm{C}$

Program Type, Code (C) or Utility (U): U

Evaluation Type, Process (P) or Impact (I): I

Evaluation Purpose, Formative (F) or Summative (S): $P$

Part of Process Addressed: $C$

Stakeholders Targeted: Building Designers, Owners

Program Description: This evaluation does not involve any specific program. It provides estimates of energy savings attributable to full compliance with commercial buildings energy codes in Washington and Oregon.

Process Evaluation Method:

Impact Evaluation Method: The baseline used for this evaluation is Bonneville Power Administration's (BPAs new construction prototype (1989) for each sector. Energy use simulations were conducted using DOE2.1d for typical baseline prototypes and compared with the results of simulations for the same prototype adjusted to comply with the code. The difference in energy use between the complying and non-complying simulations was taken to be the savings that would result from code compliance. The energy estimates were normalized by prototype area and adjusted to reflect different heating fuel types and HVAC systems.

Program Findings: The overall total energy savings which would have resulted from full compliance in both states during 1990 was $8,900 \mathrm{MWh}$ of electricity and 98,000 therms of natural gas.

Methodology Findings:

Program Recommendations:

Methodology Recommendations:

Comments: 
Document Number: 0051

Study Title: Impact Evaluation of Northeast Utilities' Energy Conscious Construction Program Comprehensive Area: Findings, Methods, and Avenues for Further Research

Date: $00 / 00 / 00$

Study Sponsor: Northeast Utilities

Authors: Bowles, D, P Spinney, A Bjorklund

Building Type: $\mathrm{C}$

Program Type, Code (C) or Utility (U): U

Evaluation Type, Process (P) or Impact (I): I

Evaluation Purpose, Formative (F) or Summative (S): $F$

Part of Process Addressed: D

Stakeholders Targeted: Architects, Engineers, Developers, Owners

Program Description: See A Utility Program for Improving the Energy Efficiency of New Non-Residential Construction.

Process Evaluation Method:

Impact Evaluation Method: On-site surveys were conducted with 22 of the 24 participants in the Energy Conscious Construction Program to collect all field data necessary to support preparation of improved estimates of energy savings. Next, 23 of the 24 participants took part in a telephone survey of project decision-makers and design professionals to explain the design and equipment specifications. DOE-2 simulations were then conducted to compare as-built conditions with as-occupied. Finally, these results were analyzed.

Program Findings:

Methodology Findings:

Program Recommendations:

Methodology Recommendations:

Comments: Results from the DOE-2 simulation were not given. This document appeared to be an early publication without any results. 
Document Number: 0052

Study Title: Monitoring Final Report

Date: 06/01/94

Study Sponsor: California Energy Commission

Authors: Valley Energy Consultants

Building Type: C R

Program Type, Code (C) or Utility (U): C

Evaluation Type, Process (P) or Impact (I): $P$

Evaluation Purpose, Formative (F) or Summative (S): $S$

Part of Process Addressed: C

Stakeholders Targeted: Home and Building Owners

Program Description: Each year the Califomia Energy Commission conducts a monitoring program to determine the compliance and enforcement problems associated with the Building Energy Efficiency Standards. Its four main objectives are to collect building characteristic data for the purpose of standards development and forecasting energy consumption, to identify and summarize discrepancies between the energy code and the actual building documentation and construction, to train the building departments' staff on the energy regulations, and to recommend solutions to the Commission which will improve compliance and enforcement.

Process Evaluation Method: The monitoring procedure consisted of reviewing 116 buildings in 30 jurisdictions. Eighty-nine of these buildings are residential. Energy calculations, plan, and field reviews were conducted for each building. The building data where recorded on the energy code review form. Discrepancies and violations were recorded on the violation form.

Impact Evaluation Method:

Program Findings: The monitoring team found that some building departments did a thorough job of enforcing the standards. There was a wide range of enforcement levels encountered with no relationship to the size or location of the jurisdiction. Some displayed a lack of knowiedge or lack of motivation. Most did well with the limited resources available. The wide range of enforcement was due to the timing of the monitoring. The monitoring was done during a transition year of standards. In addition $44 \%$ of the buildings were permitted under 1988 standards. Methodology Findings:

Program Recommendations:

Methodology Recommendations:

Comments: 
Document Number: 0053

Study Title: Multifamily Metering Study

Date: 04/00/94

Study Sponsor: Bonneville Power Administration (BPA)

Authors: SBW Consulting

Building Type: $\mathbf{R}$

Program Type, Code (C) or Utility (U): U C

Evaluation Type, Process (P) or Impact (I): I

Evaluation Purpose, Formative (F) or Summative (S): $S$

Part of Process Addressed: I

Stakeholders Targeted: Utilities

Program Description: The Model Conservation Standards (MCS) is a voluntary regional energy code adopted by Tacoma. This study was designed to quantify energy savings of MCS buildings in Tacoma Public Utilities' (TPU) service area.

Impact Evaluation Method: The analysis was conducted through 8 steps. 1) Five test buildings were selected by TPU. Five reference buildings were selected in surrounding utility areas. Matched pairs of buildings were selected for study. 2) Energy audits, professional judgment, and one-time short measurements were used to provide data. Continuous consumption measurements also were made on selected end uses and total usage and selected temperatures and run times. 3) Data were cleaned and integrated with weather data. 4) Measured data and characteristics were integrated into a simulation model. The model was run and adjustments were then made to match consumption data. 5) Simulation results were adjusted for weather, tenant behavior, and physical properties. 6) Energy savings were disaggregated by individual conservation measure. 7) End use consumption data were used to adjust simplified analysis techniques, including PRISM. 8) Energy savings from the individual measure and simplified analyses were compared for two calibration years.

Program Findings: 1) Space heat consumption was the smallest end use in most buildings, representing $19 \%$ to $33 \%$ of total consumption. Most reference buildings were more efficient than required by existing standards. 2) Energy savings during the first year ranged from $12 \%$ to $-3 \%$. The presence of an AAHX in MCS buildings contributed to negative savings. 3) Efficiency improvements were not cost effective unless adjusted for the effects of the AAHX. 4) PRISM tended to overestimate space heat consumption. 5) Energy savings persisted into the second year. 6) Savings were notably higher when the reference building was built to just meet the existing code. Methodology Findings: 1) The analysis protocol was technically sound. 2) DOE-2 was a robust tool for estimating consumption and impacts. 3) The simplified analysis technique was inexpensive and easy to apply, but it could not account for individual measures or correct for non-program effects.

Program Recommendations:

Methodology Recommendations:

Comments: 
Document Number: 0054

Study Title: Design for Excellence-Commercial New Construction Incentive Program Impact Evaluation

Date: 11/12/93

Study Sponsor: Southern California Edison Company

Authors: ADM Associates, Inc.

Building Type: $\mathrm{C}$

Program Type, Code (C) or Utility (U): U

Evaluation Type, Process (P) or Impact (I): I

Evaluation Purpose, Formative (F) or Summative (S): $F$

Part of Process Addressed: A

Stakeholders Targeted: Commercial Design Professionals

Program Description: Retrofitting energy-efficient measures into existing buildings is often a difficult and expensive process. The Commercial New Construction incentive Program attempts to avoid this by including energy-efficient measures in the construction of new structures. Technical assistance is offered to the design community to promote energy efficiency for DFE (Design For Excellence) and other related programs. Financial incentives are offered to promote installation of higher efficiency building products and equipment that exceed the minimum efficiency requirements of Title 24, California's Building Energy Efficiency Standards. Awards are also given for recognition of superior energy-efficient building designs.

Process Evaluation Method:

Impact Evaluation Method: The study was based on a statistically derived sample of participants. A telephone survey of 176 decision-maker organizations and on-site surveys of 95 sites were conducted to collect detailed information about the sample buildings. Installation of measures was verified and used to develop engineering simulation models of the surveyed sites. Gross energy savings were calculated for the actual measures and efficiencies were compared to a baseline. The baseline was the California Title 24 Building Energy Efficiency Standards. Net energy savings were estimated based on calculations of free ridership. Results for the sample were projected back to the participant population to determine program impacts.

Program Findings: The results of this study were reported in terms of how many $\mathrm{kWh}$ were saved relative to the baseline. For lighting 40,146,000 kWh were saved. Similarty, 35,157,000 kWh were saved for heating and cooling systems. For fans and pumps, 10,599,000 kWh were saved. A miscellaneous category showed an increased use of $62,000 \mathrm{kWh}$. Therefore, the total savings is $85,839,000 \mathrm{kWh}$ for a two-year study period of approximately 100 study sample buildings. Overall, the program achieved $9 \%$ greater savings than what was expected.

Methodology Findings:

Program Recommendations: The 11 program recommendations specifically mentioned were 1) the program should address all energy used in the building, not just a few measures that are rebated; 2) avoid paying incentives for measures that cannot be verified; 3 ) estimates of savings should make more conservative assumptions for HVAC-related equipment, so as not to inflate expectations; 4) installation of measures should be verified by a third party whose only interest is to be sure the measures are in place and functional; 5 ) if the measures change during construction, the savings estimates should also be changed; 6) because it is frequently difficult to pinpoint exactly which equipment was rebated and where it is located at the customer site, this information should be explicitly captured in the tracking database and on a location sketch retained with the coupon records; 7 ) the Certificate of Compliance generated for the building should be collected and retained in program records at the time of verification; 8) information on different technologies should be recorded on a consistent basis in the database; 9) a less ambitious database should be developed (making it easier to understand) and it should be kept current by the people who are generating the information; 10) performance analysis results should be recorded by end-use to better tie incentives directly to measures; and 11) information should be collected from participants early in the program while it is fresh in their minds.

Methodology Recommendations: Eight recommendations were made for future studies: 1) time lags need to be recognized for non-residential new construction; 2) non-participants need to be included; 3) short-term end-use data should be obtained and analyzed; 4) make provisions for cleaning and maintenance of data; 5) establish a definition of "building;" 6 ) use the utility's customer number for sampling purposes since this number is more consistentty and accurately recorded; 7) sample sites should be selected taking account of the types of measures installed and their distribution; and 8) allow more time for evaluation.

Comments: 
Document Number: 0055

Study Title: Non-Residential New Construction/Major Renovation Program Baseline Survey

Date: $07 / 15 / 94$

Study Sponsor: Public Service Company of Colorado

Authors: Synergic Resources Corporation

Building Type: $\mathrm{C}$

Program Type, Code (C) or Utility (U): $U$

Evaluation Type, Process (P) or Impact (I): $P$

Evaluation Purpose, Formative (F) or Summative (S): $F$

Part of Process Addressed: D

Stakeholders Targeted: Design and Construction Industries

Program Description: This study supported the Start Smart! Energy By Design program.

Process Evaluation Method: A survey was developed by SRC and PSCo to establish if the standards provided in ASHRAE 90.1-1989 are used as common practice by the design and construction industry in PSCo's service territory. The survey was revised based on the findings from 14 pre-test participants. Finally, a total of 51 telephone surveys were completed with 10 architect participants, 26 engineering participants, 5 contractor participants, and 10 vendor participants. The five categories that the survey included were lighting, HVAC, electric power, building envelope, and service water heating.

Impact Evaluation Method:

Program Findings: It was found that less than $45 \%$ of the respondents used the standard, but more than $70 \%$ of them were familiar with it. The degree of familiarity and the usage percentages were respectively $70 \%$ and $43 \%$ for lighting, $77 \%$ and $40 \%$ for HVAC systems, $72 \%$ and $42 \%$ for electric power, $81 \%$ and $37 \%$ for building envelope characteristics, and all the participants indicated they followed the intent of ASHRAE's standards for service water heaters.

Methodology Findings:

Program Recommendations: It is recommended that the ASHRAE 90.1-1989 standard be used as the baseline for PSCo's Start Smart! Energy by Design program. One of the main reasons is that this standard has helpod to drive the design and installation "standard practice" toward compliance with the 90.1-1989 standard over the past five years.

Methodology Recommendations:

Comments: The program itself is not what is being evaluated; a potential baseline for the program is assessed instead. 
Document Number: 0056

Study Title: Commercial New Construction Review of Engineering Assumptions

Date: 12/01/91

Study Sponsor: Pacific Gas and Electric

Authors: ADM Associates, Inc.

Building Type: $\mathrm{C}$

Program Type, Code (C) or Utility (U): $U$

Evaluation Type, Process (P) or Impact (I): $P$

Evaluation Purpose, Formative (F) or Summative (S): $F$

Part of Process Addressed: I

Stakeholders Targeted: Building Designers, Owners

Program Description: See The Integrafed Approach to Evaluating New Commercial Buildings: Does it Work?

Process Evaluation Method: The first task was to determine those measures and parameter estimates that have the largest impact on energy savings calculations and that are most uncertain. To accomplish this, a matrix was set up that showed the estimated savings potential, magnitude of the energy savings potential, and degree of uncertainty for measures considered under the program. Next, an investigation was conducted of the engineering assumptions used to originally calculate energy savings. The parameters that were of particular interest were those used in the results from the matrix study. Finally, a sensitivity analysis was conducted to determine the sensitivity of those assumptions that were least certain but applied to a measure with high savings potential or high uncertainty.

Impact Evaluation Method:

Program Findings: The matrix analysis concludes that high potential energy savings measures with high uncertainty include adjustable speed drives, chiller reset controls, air cooled air conditioner units, oversized condensers and cooling towers, multiplex compressors and variable speed compressors. The engineering and sensitivity analyses found that the procedures, data and assumptions being used by PG\&E were consistent with the best engineering practice in Northern California. In one case, the gated pipe, the engineering analysis showed that PG\&E could not justify the savings they had previously claimed. This measure has been dropped from the rebate program.

Methodology Findings:

Program Recommendations:

Methodology Recommendations: Due to the newness of the program, only a small number of projects were complete at the time of the evaluation. It is recommended that on-site surveys be used in a future evaluation.

Comments: 
Document Number: 0057

Study Title: Lighting Code Compliance Training Through the Use of Interactive Video Tapes

Date: $00 / 00 / 00$

Study Sponsor: Oregon State University Extension Energy Program

Authors: Baker, W

Building Type: $\mathrm{C}$

Program Type, Code (C) or Utility (U): C U

Evaluation Type, Process (P) or Impact (I): $P$

Evaluation Purpose, Formative (F) or Summative (S): $S$

Part of Process Addressed: E

Stakeholders Targeted: Energy Code Officials

Program Description: The OSU Extension Energy Program is a training program for code officials. The program was developed because these officials have no lighting or electrical background, and to effectively enforce the new code, training was necessary.

Process Evaluation Method: The training consists of a technical reference manual and an accompanying 45minute interactive training video. The training program is done at one's own pace.

Impact Evaluation Method:

Program Findings: The use of a video tape proved to be a very cost effective method of training. The most receptive audience were architects and engineers. These professionals appreciated the document because it helped them submit plans that are less likely to have compliance problems. The overall response was favorable. The program will be continued.

Methodology Findings:

Program Recommendations:

Methodology Recommendations:

Comments: 
Document Number: 0058

Study Title: First Year Load Impacts of Southern California Gas Company's Commercial New Construction Program for Program Years 1990, 1991, and 1992.

Date: $11 / 01 / 93$

Study Sponsor: Southern California Gas Company

Authors: Analysis Group, Inc.

Building Type: $\mathrm{C}$

Program Type, Code (C) or Utility (U): $U$

Evaluation Type, Process (P) or Impact (I): I

Evaluation Purpose, Formative (F) or Summative (S): $F$

Part of Process Addressed: D

Stakeholders Targeted: Building Owners, Designers

Program Description: Southern California Gas Company's High Efficiency New Commercial Building Program provides financial incentives and technical assistance to builders of new commercial buildings. The incentives are provided to persuade builders to install more efficient equipment than they would have if the incentives were not provided. The measures covered under the program are space heating, water heating, and cooking equipment. Process Evaluation Method:

Impact Evaluation Method: Load impacts for the first year were determined through the conditional demand analysis (CDA) technique. This technique uses a separate equation for each end use. The CDA equations were estimated on a sample of customers that participated in the program for at least one of the end uses covered by the program. Participants that did not install a particular end use were used as a control group. In addition, statistical information from these equations is used to construct confidence intervals. The sample size was 90 .

Program Findings: The projected annual savings were 156 therms for space heating, 310 therms for water heating, and 2,566 therms for cooking equipment. The actual savings for the first year were $26,1,372$, and 492 therms respectively.

Methodology Findings: It was found that the savings estimates were not very reliable because the parameter estimates were much more sensitive than initially thought. The survey data was also found to be inconsistent and not reliable. Finally the survey data and what was needed for the program files did not always coincide.

Program Recommendations: Future evaluations should take into account free-driver effects.

Methodology Recommendations: For more reliable data in the future, data should be collected from the appropriate decision-maker as close to the point of the decision as possible. Also, to increase the data quality, it is recommended that the survey be limited to key questions. To have consistency between survey data and program files the same questions should be asked to all participants and non-participants.

Comments: 
Document Number: 0059

Study Title: First Year Load Impacts of Southern California Gas Company's Commercial Demand-Side Management Programs-Program Years 1990, 1991, and 1992

Date: $11 / 02 / 93$

Study Sponsor: Southern California Gas Company

Authors: Analysis Group, Inc.

Building Type: $C$

Program Type, Code (C) or Utility (U): U

Evaluation Type, Process (P) or Impact (I): I

Evaluation Purpose, Formative (F) or Summative (S): $S$

Part of Process Addressed: I

Stakeholders Targeted: Building Owners, Designers

Program Description: See evaluation of First Year Load Impacts of Southem Califomia Gas Company's Commercial New Construction Program for Program Years 1990, 1991, and 1992 (11/01/93).

Process Evaluation Method:

Impact Evaluation Method: The evaluation method is the same as reported in Document Number 0058, but other end-use measures were added. The additional measures are boilers, air conditioners, dryers, and weatherization measures. The number of participants also increased to a total of 5,514 in 12 business types.

Program Findings: The savings were poorly predicted. The cooking equipment was estimated to save 2,566 therms/year, but actually only saved 878 therms. The space heating savings was estimated at 159 therms/year and saved 142 therms. The boiler was estimated to save 4,693 therms/year, and it saved 12,295. The air conditioning was predicted to save 25,000 therms/year, but only saved 17,201 therms. The water heater saved 374 therms when predicted to save 314 therms in the first year. The dryer saved 812 therms when predicted to save 300 therms in the first year. Finally, the weatherization measures saved 215 therms compared to 157 predicted savings for the first year.

Methodology Findings: See Document Number 0058.

Program Recommendations: See Document Number 0058.

Methodology Recommendations: See Document Number 0058.

Comments: This evaluation is just a final version of Document Number 0058. 
Document Number: 0060

Study Title: Non-Residential New Construction Impact Evaluation Program

Date: $10 / 01 / 93$

Study Sponsor: Pacific Gas and Electric Company

Authors: Miller, WC

Building Type: $\mathrm{C}$

Program Type, Code (C) or Utility (U): $U$

Evaluation Type, Process (P) or Impact (I): 1

Evaluation Purpose, Formative (F) or Summative (S): F

Part of Process Addressed: I

Stakeholders Targeted: Building Designers, Owners

Program Description: See the evaluation entitled The Integrated Approach to Evaluating New Commercial

Buildings: Does it Work?

Process Evaluation Method:

Impact Evaluation Method: The first step to estimate the $\mathrm{KW}$ savings and the net-to-gross ratio was to collect data on the characteristics of the Non-Residential New Construction program participants and their buildings. Similar data was collected for non-participants. The data was collected through on-site surveys for lighting, air conditioning, refrigeration measures, electric motors, and glazing. There were 62 projects that had data taken on their lighting characteristics. Similarly there were 25 projects for air conditioning, 16 for electric motors, 4 for glazing, and 11 for refrigeration. Once all the data were collected, engineering and economic analyses were conducted.

Program Findings: The net-to-gross ratios for lighting, HVAC, and refrigeration were $0.622,0.965,0.986$, respectively. The average ratio was 0.762 for all end-uses. The energy savings were $7,919,774 \mathrm{kWh}$ from the program estimate and $6,064,415 \mathrm{kWh}$ by the on-site engineering simulation.

Methodology Findings:

Program Recommendations:

Methodology Recommendations:

Comments: 
Document Number: 0061

Study Title: Evaluation Design for MCS Code Adoption Demonstration

Date: 03/04/85

Study Sponsor: Bonnevilie Power Administration (BPA)

Authors: Synergic Resources Corporation

Building Type: R C

Program Type, Code (C) or Utility (U): C

Evaluation Type, Process (P) or Impact (I): $P$

Evaluation Purpose, Formative (F) or Summative (S): $F$

Part of Process Addressed: A

Stakeholders Targeted: Builders, Building Officials

Program Description: Bonneville is undertaking an effort to assist local governments in implementing the Model Conservation Standards (MCS) as part of its responsibilities for implementing the Regional Power Act. These efforts include 1) working with selected local communities that adopt the MCS during 1985 (prior to required adoption in 1986) to learn from their experience to help improve the MCS program and 2) providing reimbursement to local communities to defray the incremental costs of implementing and enforcing the MCS.

Process Evaluation Method: Objectives were 1) to develop estimates of the incremental cost and time requirements for enforcing MCS from the state coordinated studies, and 2) to develop an evaluation plan for the early adopters. Approaches: 1) to develop a description of current energy code enforcement practices, which was done by analyzing the results of the inventory of current practices and through discussions with building code officials. These results were used to develop typical building code enforcement processes; 2) to identify alternative approaches for implementing MCS and the impacts of these approaches on the current code enforcement process; and 3) to estimate the incremental time and costs associated with MCS enforcement. Simulation studies were completed by a sample of local building code officials.

Impact Evaluation Method:

Program Findings: The evaluation plan consists of both process and impact evaluations. An important issue in developing an evaluation plan is the wide variation among jurisdictions. There is a wide range of practices in enforcing current building codes among jurisdictions, reflecting in part differences in construction activity, local support for the code enforcement, sophistication of the local building community, and available resources. Code enforcement also entails a variety of activities. Finally, the MCS can be implemented through a variety of approaches. The evaluation plan must be flexible enough to be applicable to the various jurisdictions and possible enforcement approaches. The process evaluation will be conducted at two levels: 1) individual communities, to assess the implications of the particular characteristics of a jurisdiction upon costs and enforcement approach, and 2) community comparisons, to determine the resource requirements and management approaches that could achieve compliance at relatively lower costs than other arrangements. Four major activities are required to complete the process evaluation: profile of enforcement process, resource assessment, profile of jurisdiction, and inter-community assessment. The impact evaluation will follow a three-step process: 1) assess the degree of compliance with MCS requirements, through inspections of completed buildings, 2) determine the significance of non-compliance on $\mathrm{kWh}$ consumption using energy use calculations, and 3 ) identify where in the building process non-compliance could have been prevented.

Methodology Findings:

Program Recommendations:

Methodology Recommendations:

Comments: 
Document Number: 0062

Study Title: Energy Use in Homes Built to Model Conservation Standards: Outcomes Evaluation of the Tacoma Early Adopter Program

Date: $02 / 01 / 87$

Study Sponsor: Bonneville Power Administration (BPA)

Authors: Bronfman, BH, MW Horowitz, and DI Lerman

Building Type: $R$

Program Type, Code (C) or Utility (U): C

Evaluation Type, Process (P) or Impact (I): IP

Evaluation Purpose, Formative (F) or Summative (S): F

Part of Process Addressed: A IC

Stakeholders Targeted: Builders, Utilities

Program Description: See description for Energy Savings in New, Low-Rise Multifamily Buildings: Model Conservation Standards in Tacoma, Washington.

Process Evaluation Method: Overall data were collected from inspections of 159 dwelling units, inteviews with 113 home-owners/renters, interviews with 37 building department staff members, and interviews with 40 builders. Impact Evaluation Method: The Princeton Scorekeeping Method (PRISM) was used to estimate the normalized annual electric consumption for MCS and current practice homes. The control group used for this evaluation was selected from electrically-heated homes built during from 1982 to 1984 . There were 127 MCS participants and 480 control group homes. The data used for PRISM included actual energy use as shown on utility bills, weather data, and household-level demographic, behavioral, and attitudinal information to control for individual-level variations in energy usage. The data used was modified twice to take into account alternative specifications of billing histories and adjustments to heating estimates. PRISM was then used three times to arrive at a "best" estimate of energy savings. PRISM was used to estimate total energy consumption and space-heating consumption for both sets of homes. To adjust for misallocations of energy use between the heating and baseload components of PRISM estimates, four alternative adjustment factors were developed and applied to PRISM estimates using all bills, estimates using only one year of bills, and estimates using one year of bills but weather-normalized to the same time period.

Program Findings: Home inspections indicated that the level of code compliance had increased since 1980 in many areas. Building officials, inspectors, and plan examiners identified three major problem areas in enforcing Chapter 53: underfloor insulation, the amount of attic blow-in insulation, and vapor barriers. Ninety-five percent of the home owners said they were comfortable or very comfortable with their home. Also, 33\% of those interviewed said they considered the energy-efficient measures before buying or renting. Fifty-three percent of builders said they understood the provisions of Chapter 53. Yet when they were asked a series of technical questions, $77 \%$ answered fewer than $30 \%$ correctly. $41 \%$ of the builders said costly requirements are a major reason for non-compliance. MCS homes use about 18,000 kWh/year, compared with 23,500 kWh/year for homes built under current practice, but MCS homes were generally smaller in size. Over the long run, MCS homes will use about $3.6 \mathrm{kWh} / \mathrm{sq}$. ft./year for heating, while current practice homes will use about $6.3 \mathrm{kWh} / \mathrm{sq}$. ft./year. In Tacoma, the MCS home represents a $40 \%$ savings in space heating.

Methodology Findings: PRISM methodology misallocates a large fraction of energy use between baseload and heating load, probably because some portion of baseload consumption is season-dependent. It appears that this misallocation increases as residences are more energy-efficient. Overall, current practice homes performed better than expected, and MCS homes performed worse than expected.

Program Recommendations:

Methodology Recommendations: Further assessment is clearly warranted. MCS homes must be revisited in a year to determine whether the high heating energy use is due, in part, to "shakedown" effects in new construction. Revisiting Tacoma in one year will result in adequate data for analysis being available for many more MCS residences, eliminating questions regarding the size of the MCS sample used for this analysis. This exercise demonstrates the need for continued end use metering of a sample of residences in new programs.

Comments: 
Document Number: 0063

Study Title: Evaluation of California's Energy Efficient Building Standards: The Residential Building Monitoring Project

Date: 00/00/89

Study Sponsor: XENERGY, Inc

Authors: Warner, KL, M Messenger, B Wilkox

Building Type: $R$

Program Type, Code (C) or Utility (U): C

Evaluation Type, Process (P) or Impact (I): $P$

Evaluation Purpose, Formative (F) or Summative (S): $F$

Part of Process Addressed: D

Stakeholders Targeted: Engineers, Evaluators

Program Description: The California Energy Commission (CEC) has been a national leader in developing innovative energy standards for new residential buildings. The CEC has pioneered a number of building standards program features such as energy budgets and computer program certification. To complete this effort, the Commission has initiated an evaluation of its residential building standards program to assess its effect on energy use in new homes built throughout California.

Process Evaluation Method: A mail survey of approximately 2,400 new home owners and 380 on-site inspections were conducted. The on-site surveys monitored air infiltration, indoor and outdoor temperatures, and space and water conditioning appliance run-times. Next, a conditional demand analysis of the mail survey data was conducted to provide mean estimates of end-use energy consumption. Also, PRISM was used to analyze the data. A parametric simulation using CALPAS3 was done to estimate the appropriateness of modeling assumptions. Finally, cost estimation and cost-effectiveness calculations were done for the on-site sample homes. Impact Evaluation Method:

Program Findings:

Methodology Findings:

Program Recommendations:

Methodology Recommendations:

Comments: At the time of this publication the project had not been completed. Completion was set for June 1990. 
Document Number: 0064

Study Title: A Knowledge-Based System for Automated Evaluation of Energy Standards Compliance

Date: 00/00/92

Study Sponsor: DOE

Authors: Quadrel, RW, RC Stratton, MR Brambley

Building Type: $C R$

Program Type, Code (C) or Utility (U): C

Evaluation Type, Process (P) or Impact (I): $P$

Evaluation Purpose, Formative (F) or Summative (S): $F$

Part of Process Addressed: C

Stakeholders Targeted: Architects, Engineers

Program Description: The ES-1DT (Energy Standards Intelligent Design Tool) is a computer program designed to check compliance with the ASHRAE 90.1 Standard. Architects and engineers can also use it for choosing energy efficient equipment. The prototype integrates $C A D$ and building energy programs to accomplish this.

Process Evaluation Method:

Impact Evaluation Method:

Program Findings: Several advantages were found when using this program. First, it allows the design and analysis to be done at the same time. Immediate results help the engineer speed up the design process. In addition, the program is a form of technical assistance which allows the designer to choose from more energy-efficient options.

Methodology Findings:

Program Recommendations:

Methodology Recommendations:

Comments: 
Document Number: 0065

Study Title: Evaluation of Compliance with Model Conservation Standards in Spokane, Washington

Date: $02 / 11 / 89$

Study Sponsor: Bonneville Power Administration (BPA)

Authors: Kold, JO

Building Type: $R$

Program Type, Code (C) or Utility (U): C

Evaluation Type, Process (P) or Impact (I): $P$

Evaluation Purpose, Formative (F) or Summative (S): $F$

Part of Process Addressed: C

Stakeholders Targeted: Manufacturers, Utilities, Code Officials

Program Description: The City of Spokane was one of the early adopters of the Northwest Energy Code. This is described in the evaluation of Tacoma's early adoption of NWEC.

Process Evaluation Method: Twenty single-family homes were selected for the evaluation. The Perfluorocarbon Tracer (PFT) gas testing method was used for blower door testing and measurement of total ventilation rates. The tests were conducted according to the NORIS protocol.

Impact Evaluation Method:

Program Findings: It was found that the average air changes per hour (ACH) were approximately 0.26 for the MCS homes. In addition, all but one of the homes tested met the MCS code for ventilation systems. A quality control inspection resulted in no noticeable problems except for one home. Even so, when this home was tested it had a $0.42 \mathrm{ACH}$.

Methodology Findings:

Program Recommendations:

Methodology Recommendations:

Comments: 
Document Number: 0066

Study Title: Searching for an Implementation Strategy for the Model Conservation Standards (MCS): A Utility Perspective

Date: $00 / 00 / 88$

Study Sponsor: Public Power Council

Authors: Hammarlund, $J$

Building Type: $R$

Program Type, Code (C) or Utility (U): C

Evaluation Type, Process (P) or Impact (I): $P$

Evaluation Purpose, Formative (F) or Summative (S): $S$

Part of Process Addressed: 1

Stakeholders Targeted: Northwest Power Planning Council, Bonneville Power Administration (BPA), Utilities, State and Local Governments, Builders, Environmental Community

Program Description: On Mar. 15, 1985, the NPPC released an issue paper that proposed the adoption of a phased approach to implementing MCS. The principal effects of the proposed amendments were to extend the deadline for adopting the full standards for electrically heated residential buildings to January 1989 and to create a set of interim standards that would need to be met by January 1987. The reaction of utilities and BPA to the NPPC's proposal was hostile. By mid-Sept. of 1985, it was clear that the NPPC needed to revise the amendments. In its new proposal, the NPPC staff explained that the proposed cost-sharing ratios would be driven by the level of current building practices in the states compared to the residential MCS standard. Reaction from Bonneville and the utilities to this new proposal was mixed. There was widespread disappointment that the NPPC hadn't accepted more of the utility recommendations. But there was also a more widespread acceptance of the use of incentive payments as a short-term bridge to reach MCS through codes. New information was also emerging that challenged the costeffectiveness of MCS and ensured continued controversy. It became clear that several NPPC members had all but abandoned the goal of achieving the full MCS through the adoption of state or local building codes. They indicated that states should not be expected to pass codes that set standards beyond the "minimum life-cycle cost" level since this is the level that is presumed to be economically feasible for the home buyer. According to this view, the incremental savings between the consumer optimum and regionally cost-effective level should be paid for as long as there is variance between the consumer optimum level and the full regionally costeffective MCS. The NPPC not only set the incentives for the BPAvutility marketing program at a substantially higher level than the utilities or BPA wanted but also set the Early Adopter builder incentives at very high levels ranging from $\$ 5,000$ to $\$ 6,000$ depending on the climate zone. The utility community was disappointed with the NPPC's final amendments.

Process Evaluation Method: The paper chronicles the interplay between the NPPC, BPA, and the utilities as they searched for a mutually acceptable MCS implementation strategy.

Impact Evaluation Method:

Program Findings: There is little question that utility enthusiasm for MCS has been dampened as a result of the NPPC's decision to ignore the recommendations of the utility community. However, if the cost-effectiveness issue can be resolved, there is a good chance that substantial progress will resume in moving the region toward the MCS.

Methodology Findings:

Program Recommendations:

Methodology Recommendations:

Comments: 
Document Number: 0067

Study Title: Florida State-Wide Energy Code Enforcement Study

Date: 08/05/92

Study Sponsor: State of Florida, Department of Community Affairs

Authors: Tenah, KA

Building Type: R C

Program Type, Code (C) or Utility (U): C

Evaluation Type, Process (P) or Impact (I): $P$

Evaluation Purpose, Formative (F) or Summative (S): $F$

Part of Process Addressed: E

Stakeholders Targeted: Local Governments, Building Officials

Program Description: Florida's Energy Code

Process Evaluation Method: Two mail survey questionnaires (one for the building department and one for building department staff) were developed and distributed to all local jurisdictions. Responses were from received from 88 cities and counties and 247 building department personnel or building inspection services. In addition to the mail surveys, a focus group of selected building officials and building department personnel was conducted for an in-depth group discussion of the survey questions. The focus group discussion was designed to collect input on permitting and inspection procedures, enforcing personnel qualifications and level of understanding, department staffing and funding, problems associated with enforcing the code, and suggestions on how to improve state-wide enforcement. The final step involved data analysis and evaluation of the input from the field studies and submittal of a final report.

Impact Evaluation Method:

Program Findings: 1) A two-year code change cycle is too short for building departments to overhaul their systems, which typically takes 9 to 12 months, thus giving them only 1 year of smooth running with the code before it changes again. 2) Most building departments surveyed are not fully enforcing the energy code and are not requiring adequate information at the time of permitting to ensure full compliance. The level of review and enforcement decreases as plans get more technical. 3) Lack of knowledge and training within local government appears to follow through to builders, design professionals, and energy inspection service people.

Methodology Findings:

Program Recommendations: 1) Workshops for the building departments and the general public should be conducted at least one month before a new code becomes effective. 2) The energy code should be simplified and compact with instruction manuals and a simple handbook in common language with simple diagrams similar to other codes for use by construction field personnel. 3) Funding for additional staff and training is needed at the local level to improve enforcement of the energy code. 4) There is a need for education and training for building department personnel, design professionals, builders, and the general public. 5) Visual training aids should be provided to local jurisdictions at no or low costs. 6) The Department should increase the number of training programs on the energy code and tailor them to suit audiences at different levels of competency.

Methodology Recommendations:

Comments: 
Document Number: 0068

Study Title: Evaluation of Implementation, Enforcement and Compliance Issues of the Bonneville Model Conservation Standards Program, Volume 1

Date: $07 / 01 / 89$

Study Sponsor: Bonneville Power Administration (BPA)

Authors: Cantor, RA and SM Cohn

Building Type: $R$

Program Type, Code (C) or Utility (U): C

Evaluation Type, Process (P) or Impact (I): P I

Evaluation Purpose, Formative (F) or Summative (S): $F$

Part of Process Addressed: IE C

Stakeholders Targeted: Utilities, Local Governments, Code Officials, Builders

Program Description: in 1986, the Northwest Power Planning Council (NPPC) set a deadline for mandatory adoption of BPA's Model Conservation Standards by January 1, 1989. The MCS goal was to ensure that all new electrically heated buildings served by BPA utilities would be built to a standard of energy efficiency that was economically feasible to home owners and regionally cost-effective. To decrease adoption burdens and collect enforcement and inspection data, the Early Adopter Program offered financial assistance to jurisdictions adopting the MCS prior to the deadline. EAP was made available to all Northwest state and local governments, utilities, and Indian Tribes. Four of the 5 jurisdictions in this study participated in the EAP. Payments to jurisdictions are intended to reimburse incremental costs of implementing the MCS including adoption and start-up, training, technical assistance, implementation and enforcement, and builder incentive administration. Builder incentives are designed to help cover the additional construction costs of installing the MCS-related measures.

Process Evaluation Method: A process evaluation was conducted to evaluate implementation activities. Reporting and direct interviewing techniques were used to establish MCS effects including the incremental time and cost burdens arising from the enforcement activities. Early Adopters were selected for case study analysis and a smaller set of non-adopting jurisdictions (for comparative purposes). The approach focused on incremental time and costs, and major impediments to successful adoption of the MCS. Three techniques were used to gather information: 1) three data forms to monitor incremental time for enforcement activities; 2) a protocol to interview enforcement personnel in adopting and non-adopting jurisdictions to establish baseline values for enforcement and construction practice; and 3) a builder-interview protocol that was used for individual interviews with builders and for focus-group discussions with a limited number of builders.

Impact Evaluation Method: The impact evaluation measured the incremental time, incremental cost, compliance, and electricity savings. Three primary methods of analysis were used: 1) physical data were collected from on-site inspection of the housing units along with data from the building plans and interviews of the building inspectors; 2) blower door tests were performed; and 3) energy-use simulations were performed to estimate annual space heating energy use. The SUNDAY model was used to estimate the effects of MCS-related measures on annual electricity consumption for space heating in individual housing units.

Program Findings: 1) Reimbursement for multi-family buildings just exceeds the estimated costs for Washington and ldaho jurisdictions. 2) Reimbursement for single-family buildings is below the upper range of the estimated costs of enforcement activities in the Early Adopter sample in Washington and Idaho. 3) Early Adopters that used one of the interactive strategies to implement the MCS performed relatively well on infiltration and electricity savings. 4) Smaller jurisdictions may be discouraged from becoming adopters by the contracting process and preparation of the technical proposal. 5) One of the most important adoption obstacles for non-adopting jurisdictions may be their perception that the opportunity cost from MCS enforcement will be much larger than the accounting expenses.

Methodology Findings:

Program Recommendations: 1) To understand the MCS adoption decision better, the incremental cost analysis should focus on costs as perceived by the jurisdictions as opposed to accounting costs. 2) Enforcement efforts should be increased to comply with infiltration. 3) More empirical evidence in compliance and energy savings is called for to convince critics that MCS offer a worthwhile difference compared to the Washington State Energy Code. 4) Limit the changes in the code or program to occur at intervals several years in length to promote stability and credibility. 5) Correct deficiencies in enforcement tools like WATTSUN. 6) Devise a training tool to be used in technical assistance that meets the needs of subcontractor workers.

Methodology Recommendations:

Comments: 
Document Number: 0069

Study Title: Process Evaluation of the Tacoma MCS Adoption Part 1

Date: 06/01/85

Study Sponsor: Bonneville Power Administration (BPA)

Authors: Lerman, $\mathrm{Dl}$ and $\mathrm{BH}$ Bronfman

Building Type: RC

Program Type, Code (C) or Utility (U): C

Evaluation Type, Process (P) or Impact (I): $P$

Evaluation Purpose, Formative $(F)$ or Summative $(S)$ : $F$

Part of Process Addressed: AI

Stakeholders Targeted: Local Government, Code Officials, Contractors

Program Description: The Model Conservation Standards (MCS), designed to reduce electricity consumption in residential and commercial new construction and remodeled structures, took effect in Tacoma on June 1, 1984. As a result, Tacoma became the first political jurisdiction in the Northwest to adopt the MCS. Through changes in the City building code and in the plan review and inspection process, only those plans meeting the MCS for insulation, infiltration, glazing, and, in the case of commercial buildings, lighting and HVAC, would be approved. An augmented inspection process would ensure compliance with the MCS. The city council directed its municipal electric utility, Tacoma City Light (TCL), to enforce the MCS in those portions of the TCL service area outside the Tacoma city limits, and enforcement in Pierce County would be secured by requiring MCS compliance before electric senvice hookup. To offset the costs associated with early adoption of the MCS, Tacoma obtained a series of grants from the BPA to cover the incremental costs of adopting and implementing the code. Refer to Evaluation of Implementation, Enforcement and Compliance Issues of the Bonneville Model Conservation Standards Program, Volume 1 for more description of the Early Adopter Program.

Process Evaluation Method: A process evaluation was conducted for two functions: 1) to inform Bonneville of costs of adoption and the accomplishments and problems in implementing the MCS in Tacoma; and 2) to alert Bonneville of potential barriers to MCS implementation in other jurisdictions adopting the MCS. Information was gathered from the staff of the Tacoma Energy Office, the Tacoma Buildings Division, the Tacoma Office of Intergovernmental Affairs, the Pierce County Buildings Division, and a selected group of Tacoma building contractors. The evaluation looks at the achievements in Tacoma and Pierce County jurisdictions through March of 1985, the incremental costs to the city for implementing the MCS along with an estimate of the costs in Pierce County, and barriers to implementation in the city and the county.

Impact Evaluation Method:

Program Findings: 1) The city of Tacoma was able to integrate the MCS into its building permit and inspection processes by establishing a separate office for MCS information, builder consultation, energy plan reviews and inspections; 2) by contrast, MCS procedures at Pierce County were wholly external to the permit and inspection processes; 3) half of Tacoma's total MCS budget went to program development costs, and the other half went to the actual implementation and operation of the MCS in Tacoma; 4) for calendar year 1984, the cost of plan review and inspection for the average Tacoma building was approximately $\$ 135$, but once the MCS operations are incorporated in the routines of the Buildings Division, it is estimated that the incremental cost will be reduced to $\$ 61$ per structure; 5) builders reported that the additional cost of constructing to the MCS is in the $\$ 3,000$ to $\$ 4,000$ per house range ( $\$ 1.50$ to $\$ 2.00$ per sq. $\mathrm{ft} ; 6$ ) the barriers to MCS implementation in Tacoma were related to the lack of certain specified materials and difficulties in understanding the specifications. Delays in the marketing of MCS homes limited awareness and demand among both the home buying and building communities. A serious barrier to MCS implementation in Pierce County was the lack of integration of the MCS plan review and inspection processes into the County Buildings Division routines.

Methodology Findings:

Program Recommendations:

Methodology Recommendations:

Comments: 
Document Number: 0070

Study Title: Local Building Code Administration Survey Results

Date: 00/00/94?

Study sponsor: National Science Foundation

Authors: University of New Orleans

Building Type: R C

Program Type, Code (C) or Utility (U): C

Evaluation Type, Process (P) or Impact (I): $P$

Evaluation Purpose, Formative (F) or Summative (S): $S$

Part of Process Addressed: $E$

Stakeholders Targeted: Building Departments

Program Description: This study summarizes results from a survey investigating administration of building codes across the country.

Process Evaluation Method: A questionnaire was sent to 1328 local building departments. The response rate was $78 \%$. The survey addressed a wide range of questions about code administration. Energy codes were not a major component of the study.

Impact Evaluation Method:

Program Findings: Energy provisions were ranked as the lowest priority of 6 categories of provisions. Contractors were felt to make less effort to comply with residential building codes than commercial building codes. Insufficient knowledge was the main reason contractors were felt to violate commercial building codes. Building departments frequently provided technical assistance to the private sector. Many other general findings on code enforcement are presented.

Methodology Findings:

Program Recommendations:

Methodology Recommendations:

Comments: 
Document Number: 0071

Study Title: Energy Use in Homes Built to Model Conservation Standards: A Follow-Up of the Tacoma MCS

Evaluation

Date: 08/01/88

Study Sponsor: Bonneville Power Administration (BPA)

Authors: Haeri, MH

Building Type: $\mathbf{R}$

Program Type, Code (C) or Utility (U): C

Evaluation Type, Process (P) or Impact (I): I

Evaluation Purpose, Formative (F) or Summative (S): F

Part of Process Addressed: I

Stakeholders Targeted: Home Owners, Utilities

Program Description: See the evaluation Energy Use in Homes Built to Model Conservation Standards: Outcomes Evaluation of the Tacoma Early Adopter Program .

Process Evaluation Method:

Impact Evaluation Method: This evaluations objectives are 1) to analyze the energy performance through PRISM of MCS homes and deriving accurate and unbiased estimates of space heating energy use in these homes, 2) to analyze the occupant survey data on the MCS and control home practices and relating this information to energy consumption levels, and 3 ) to re-examine the findings of the original study. This evaluation method is the same as the original study except for the sample data. The data include two years of bimonthly billing for 62 MCS homes built and occupied prior to June 1985, and 312 comparable control homes; one year of billing histories for 395 new MCS homes built between June 1985 and mid-1986; daily temperature data from the Sea-Tac weather station; occupant survey data on structural and demographic characteristics for the MCS and control home practices; information on floor space for the two samples; and end-use metered data for a sample of 89 homes in the BPA Residential Standards Demonstrations Program (RSDP) used to correct for the misallocation of load components by the PRISM model.

Program Findings: Application of PRISM to the sample of end-use metered MCS and control homes in RSDP showed that PRISM overestimated the space heating component by about $30 \%$ in MCS homes and $18 \%$ in control homes. Yet on the average, the MCS homes used about 6,500 KWh/year (25\%) less energy than the control homes. For the original sample of MCS homes, comparison of space heating energy use during the first and second year showed no change in energy performance over time. Annual space heating energy use in the Tacoma MCS homes averaged $3.7 \mathrm{kWh} / \mathrm{sq} . \mathrm{ft}$. for the original sample, $3.4 \mathrm{kWh} / \mathrm{sq}$.ft. for the new MCS homes built between June 1985 and mid-1986, and slightly over $5.9 \mathrm{kWh} / \mathrm{sq} . \mathrm{ft}$. for the control homes.

Methodology Findings:

Program Recommendations:

Methodology Recommendations: It is recommended that this program be studied further.

Comments: 
Document Number: 0072

Study Title: 1994 Washington State Nonresidential Energy Code Report: Baseline Awareness Study

Date: 06/00/95

Study Sponsor: Washington Utility Code Group

Authors: Ecotope, Inc., Utility Code Group; Pacific Energy Assoc.; Market Trends

Building Type: $\mathrm{C}$

Program Type, Code (C) or Utility (U): C

Evaluation Type, Process (P) or Impact (I): $P$

Evaluation Purpose, Formative (F) or Summative (S): $S$

Part of Process Addressed: IC

Stakeholders Targeted: Utilities

Program Description: Washington revised its nonresidential building energy code (NREC) in 1994.

Process Evaluation Method: The purpose of this study was to assess awareness of the new NREC and elicit feedback on NREC marketing, training, and information products. A sample of 400 architects, engineers, building officials, sub-contractors, and contractors were interviewed by telephone.

Impact Evaluation Method:

Program Findings: Building officials $(86 \%)$ had the highest basic awareness of the NREC and engineers $(65 \%)$ had the lowest. Seventy two percent of all respondents had received information on the NREC. About one fourth had received information from their building department and a similar share received information from a trade association. Fifty three percent of all respondents had received a copy of the NREC. Training on the NREC had been received by $38 \%$ of respondents. The most desired new product mentioned was a reference manual $(41 \%)$, followed closely by code calculation software (37\%).

Methodology Findings:

Program Recommendations:

Methodology Recommendations:

Comments: 
Document Number: 0073

Study Title: Evaluation Design for MCS Code Adoption Demonstration

Date: $03 / 04 / 85$

Study sponsor: Bonneville Power Administration (BPA)

Authors: McCutcheon, L, G Cullen, C McDonald, M Weinstein

Building Type: $\mathbf{R}$

Program Type, Code (C) or Utility (U): C

Evaluation type, Process (P) or Impact (I): $P$

Evaluation Purpose, Formative (F) or Summative (S): $F$

Part of Process Addressed: C

Stakeholders Targeted: Home Owners, Builders

Program Description: There is no specific program, but BPA is undertaking an effort to assist local governments in implementing the MCS. To accomplish this BPA is working with local communities to learn from their experience and is reimbursing local communities for the incremental cost increase.

Process Evaluation Method: One of the objectives was to estimate the additional enforcement time and cost that would occur in plan reviews, inspections, and office time under the proposed MCS requirements. Since the MCS codes are to be implemented in four states, simulations were done for each state. The state organizations for each state were responsible for data collection. The second objective of this evaluation was to develop an evaluation plan for the early adopters of the MCS code. This was done through a meeting with building code officials.

Impact Evaluation Method:

Program Findings: The data from Oregon and Idaho was not available at the time of this evaluation. The data from Washington and Montana indicated that the incremental enforcement cost varied from $\$ 8$ to $\$ 674$, and the incremental time was from 25 minutes to 1,370 minutes. The methodology for evaluating the Early Adopters was not mentioned in this evaluation.

Methodology Findings:

Program Recommendations:

Methodology Recommendations:

Comments: 
Document Number: 0074

Study Title: Increasing Energy Efficiency Through Improved Enforcement of Building Energy Codes

Date: 09/03/92

Study Sponsor: Pacific Northwest National Laboratory

Authors: Shankle, D, A Lesperance, R Fowler

Building Type: RC

Program Type, Code (C) or Utility (U): C

Evaluation Type, Process (P) or Impact (I): $P$

Evaluation Purpose, Formative (F) or Summative (S): $S$

Part of Process Addressed: $E$

Stakeholders Targeted: Code Officials

Program Description: This evaluation does not involve a specific program but evaluates the knowiedge of code officials.

Process Evaluation Method: Information was gathered with a combination of telephone and mail surveys across the United States. Of the 66 mail surveys 14 were completed and returned, and 40 of the 42 telephone surveys were completed. The surveys focused on the types of training materials and programs used by building code officials and what types they would like to have access to in order to facilitate their enforcement of building energy codes.

Impact Evaluation Method:

Program Findings: To effectively enforce codes, building officials need training, tools, and a code that is understandable and easily enforced. Equally important is education on the importance of building energy codes to all groups involved in the design, construction and use of buildings.

Methodology Findings:

Program Recommendations: Survey results overwhelmingly show the need for increased staffing, initial and ongoing training, and enforcement tools. A national training plan is recommended.

Methodology Recommendations:

Comments: 
Document Number: 0075

Study Title: Establishing a Baseline in Commercial New Construction DSM Impact Evaluation - Comparison of Three Approaches

Date: 00/00/94

Study Sponsor: Heschong Mahone Group, ADM Associates, San Diego Gas and Electric, Pacific Gas and Electric, Portland General Electric

Authors: Mahone, DE, T Alereza, A Besa, AG Lee, SK Noell

Building Type: $C R$

Program Type, Code (C) or Utility (U): $U$

Evaluation Type, Process (P) or Impact (I): 1

Evaluation Purpose, Formative (F) or Summative (S): $F$

Part of Process Addressed: 1

Stakeholders Targeted: New Commercial Building Owners, Occupants

Program Description: There is no specific program in this evaluation. Instead this evaluation compares three commercial new construction impact evaluations to determine if Title 24 is a good baseline to use.

Process Evaluation Method:

Impact Evaluation Method: Three previous evaluations of Title 24 as a baseline were studied. Each review included a methodology and final results.

Program Findings: One evaluation found Title 24 to be too strict a baseline; another found it was not stringent enough. The final evaluation was not completed at the time of this study; therefore, no conclusions were drawn based on it.

Methodology Findings: Determining the actual efficiency baseline is a critical task for evaluating program impacts accurately. The use of Title 24 is convenient for program planning and implementation. However, studies have shown that the energy code does not reflect current levels of naturally occurring energy efficiency. Net-to-gross ratios were applied to compensate for this problem in the impact evaluations.

Program Recommendations:

Methodology Recommendations: A good baseline requires clear definitions of the participant and non-participant populations, good record keeping to keep the populations separate, and careful analysis of installed measures.

Comments: 
Document Number: 0076

Study Title: Integration of a Utility New Construction Program with Provincial and National Code Activities

Date: 00/00/94

Study Sponsor: Ontario Hydro

Authors: Lemoine, JRY, LE Reid

Building Type: $\mathrm{C}$

Program Type, Code (C) or Utility (U): U

Evaluation Type, Process (P) or Impact (I): I

Evaluation Purpose, Formative $(F)$ or Summative $(S)$ : $F$

Part of Process Addressed: I

Stakeholders Targeted: Designers

Program Description: There were three phases to Ontario Hydro's New Building Construction (NBC) Program. In the first phase, the NBC program provided incentives to owners/developers to both meet and excoed the minimum requirements of the ASHRAE 90.1 Standard. Incentives vary based on building size and are paid directly to the design team leader upon submission of a complete and approved program application form. The second phase of the program was the same as the first except that only incentives were paid for exceeding compliance. Phase three of the program was not completed at the time this evaluation was published.

Process Evaluation Method:

Impact Evaluation Method: An audit of over 1,000 commercial buildings and over 250 buildings that had participated in Ontario Hydro's DSM program was conducted.

Program Findings: By March 31, 1993, the program results included 205 submitted and approved applicants, $29 \%$ share of market penetration, $\$ 15.7$ million committed incentive pay-out, a $16 \mathrm{MW}$ estimated demand reduction, and $\$ 981 / \mathrm{kW}$ saved in its first year of operation.

Methodology Findings:

Program Recommendations: Cooperation among all stakeholders is required, as is a clear message. A threephase program was put in place by the Ontario Hydro that would eventually end in the province adopting a revised version of ASHRAE 90.1.

Methodology Recommendations:

Comments: To improve the usability of the 90.1 Standard into current design practices, training was offered to design professionals. From the target audience of engineering designers $70 \%$ were represented, but less than $10 \%$ of the targeted architects were represented. 
Document Number: 0077

Study Title: Con Edison's New Construction Design Assistance Program

Date: 00/00/94

Study Sponsor: Con Edison

Authors: Quinioned, G, P Blom

Building Type: $\mathrm{C}$

Program Type, Code (C) or Utility (U): $U$

Evaluation Type, Process (P) or Impact (I): $P$

Evaluation Purpose, Formative (F) or Summative (S): $S$

Part of Process Addressed: I

Stakeholders Targeted: Designers

Program Description: Consolidated Edison's New Construction Design Assistance program is a program intended to encourage the most efficient and productive use of energy resources in new commercial and industrial facilities by influencing the construction practices of developers and design teams. Incentives are offered that allow customers much fiexibility. Design assistance is also offered.

Process Evaluation Method: The program was qualitatively compared before and after design assistance was offered.

Impact Evaluation Method:

Program Findings: Design assistance eliminated difficulties in terms of the time and expense of evaluating the costs and benefits of energy-efficiency options. It also reduced risks and increased the knowledge of the design team about new and innovative efficient design approaches and technologies.

Methodology Findings:

Program Recommendations: Keep the program flexible.

Methodology Recommendations:

Comments: This paper is a discussion of the utility's program and improvements made to the program over time. 
Document Number: 0078

Study Title: No Before, Only After - The Importance of Establishing a Baseline for New Construction

Date: 00/00/91

Study Sponsor: XENERGY, Inc.

Authors: Glenn, $R$

Building Type: $C$

Program Type, Code (C) or Utility (U): U

Evaluation Type, Process (P) or Impact (I): $P$

Evaluation Purpose, Formative (F) or Summative (S): $F$

Part of Process Addressed: 1

Stakeholders Targeted: Designers

Program Description: There is no specific program evaluated in this paper. Instead, this paper examines the importance of accurately determining baseline construction practices when evaluating the performance of new construction DSM programs.

Process Evaluation Method: The paper explored interviews with design professionals and on-site surveys as two methods for determining baseline practice at best.

Impact Evaluation Method:

Program Findings:

Methodology Findings: It was found that interviews with design professionals hold the promise of obtaining both current and utility-specific data. Unfortunately, responses tend to be less quantitative than expected. Finally, on-site surveys offer the greatest degree of analytical rigor and definitions. Unfortunately, these come at a significant cost premium.

Program Recommendations:

Methodology Recommendations: Two altemative approaches are 1) to examine state and local building codes and 2) to review national standards.

Comments: 
Document Number: 0079

Study Title: Changing the Efficiency in New Buildings: California's Perspective

Date: 00/00/92

Study Sponsor: ADM Associates

Authors: Johnson, J

Building Type: $C R$

Program Type, Code (C) or Utility (U): CU

Evaluation Type, Process (P) or Impact (l): $P$

Evaluation Purpose, Formative (F) or Summative (S): $S$

Part of Process Addressed: I

Stakeholders Targeted: Utilities, Designers

Program Description: The report discusses several programs implemented by the State of California. It focuses on what those programs did well and what they did poorly. The programs addressed in this report include Title 24 programs and utility programs. Their histories, development, implementation, training and enforcement are discussed.

Process Evaluation Method:

Impact Evaluation Method:

Program Findings: It was found that in the development phase a balance between raising the minimum standard for new construction through regulation, and lowering the economic hurdle of achieving the maximum economic potential through utility incentive programs must be accomplished for success. There was one key point in the training phase. When a new regulation takes effect, there is a drop in compliance. This drop usually takes two to three years to overcome. By providing a thorough training program, the time frame for overcoming the drop in compliance ratio is reduced thereby increasing savings. Finally, in the category of enforcement, the main point was to focus on developing requirements that can be field checked first.

Methodology Findings:

Program Recommendations: Three recommendations were made for the implementation phase: 1) establish a partnership between the regulatory agency and enforcement agency, 2) establish a feedback loop between the design, enforcement community, and the state code officials, and 3) create a process that allows for exceptional methods and design to encourage creativity while maintaining a minimum standard of practice.

Methodology Recommendations:

Comments: 
Document Number: 0080

Study Title: A Comparison of Statistical and Engineering Modeling in Residential New Construction Program Evaluation

Date: 00/00/94

Study Sponsor: Boston Edison

Authors: Corvari, S, A Parece, G Reed

Building Type: R

Program Type, Code (C) or Utility (U): $U$

Evaluation Type, Process (P) or Impact (I): I

Evaluation Purpose, Formative (F) or Summative (S): $F$

Part of Process Addressed: I

Stakeholders: Residential building contractors

Program Description: Boston Edison's Energy Crafted Home (ECH) Residential New Construction Program was developed in 1990. It is very similar to the Super Good Cents program since consultants from that program helped with ECH. The program offers residential building contractors technical assistance and financial incentives to improve the thermal integrity of their structures.

Process Evaluation Method:

Impact Evaluation Method: Both statistical and engineering models were used to estimate weather-adjusted savings using energy bills for a sample of participant and non-participant customers. The engineering model used was CALRES, a residential building simulation software tool. The statistical model used regression analysis of actual customers' energy bills. The baseline used was the Massachusetts Building Code which was revised in 1988.

Program Findings: The test indicates a total savings of $64 \mathrm{kWh}$ per year per unit (with a $90 \%$ confidence interval) over the period between October 1991. and October 1992 . This number is lower than the estimated savings of $125 \mathrm{kWh}$ per year per unit due to substantially fewer cooling degree days for the period defined.

Methodology Findings: A comparison of the results showed consistency in the estimates of program savings produced by the two methods.

Program Recommendations:

Methodology Recommendations:

Comments: 
Document Number: 0081

Study Title: Lessons Learned from New Construction Utility DSM Programs and Their Implications for Implementing Building Energy Codes

Date: $07 / 01 / 94$

Study Sponsor: U.S. Department of Energy

Authors: Wise, BK, KR Hughs, SL Danko, TL Gilbride

Building Type: $C R$

Program Type, Code (C) or Utility (U): CU

Evaluation Type, Process (P) or Impact (I): $P$

Evaluation Purpose, Formative $(F)$ or Summative $(S)$ : $S$

Part of Process Addressed: I

Stakeholders Targeted: Engineers, Architects, Code Officials

Program Description: This was one research project conducted under the Building Energy Standards Program (BESP), now the Building Standards and Guidelines Program (BSGP).

Process Evaluation Method: A telephone survey was conducted of 27 utility DSM managers across the U.S. Impact Evaluation Method:

Program Findings: A number of findings were made in this study: 1) DSM covers a wide range of programs; 2) DSM programs can lead to better codes and standards; 3 ) builder and subcontractor training is an important step; 4) utilities need to form working relationships with the building community; 5 ) incentives can be cut without killing the program; 6) aggressive marketing to buyers can yield bigger market impacts; 7 ) energy codes are useless without adequate enforcement; 8 ) bankers and real-estate agents are important additions to the designer-builder-owner team; 9 ) utilities can collaborate to reduce costs and they need to reassess DSM programs for more cost-effective savings; and 10) utilities can work with state legislators to adopt energy codes.

Methodology Findings:

Program Recommendations: Recommendations for DOE include 1) collect utility DSM information for each state; 2) compile a DSM lessons-learned fact sheet; 3) promote interaction between state energy offices and utilities; 4) identify opportunities for collaborative marketing programs; 5) promote SEO-utility collaboration on projects that combine energy efficiency and environmental concerns; and 6) help states identify ways to encourage local enforcement of energy codes.

Methodology Recommendations:

Comments: 
Document Number: 0082

Study Title: Evaluating Educational Effects in Pacific Gas and Electric's Energy Savings Plan

Date: 00/00/94

Study Sponsor: Pacific Gas and Electric

Authors: O'Meara, KP, JA Flanagan

Building Type: $\mathbf{R}$

Program Type, Code (C) or Utility (U): $U$

Evaluation Type, Process (P) or Impact (I): I

Evaluation Purpose, Formative (F) or Summative (S): $S$

Part of Process Addressed: 1

Stakeholders Targeted: Consumers

Program Description: Residential customer education is a large part of many DSM programs; however, it is hard to evaluate how much impact this has within the DSM program itself. Small educational effects can make a large impact. Pacific Gas and Electric's Energy Savings Program is used as an example in this study.

Process Evaluation Method:

Impact Evaluation Method: Educational effects can be defined as energy-efficient actions taken by a utility customer for which the utility does not directly compensate the customer. The two kinds of educational effects reviewed were customer actions which change the household equipment stock and energy-efficient changes in customer behavior.

Program Findings: Some of the educational effects of the customers affected the equipment in their homes. Some of the measures customers took outside the program were cleaning of the refrigerator coils, installation of more efficient light bulbs, refrigerator change-outs, freezer change-outs, and dryer change-outs. There was not a clear pattern in the results that could prove or disprove the existence of behavioral effects other than those reflected in equipment replacement.

Methodology Findings: Participants in the portion of the ESP program that included on-site visits were more likely to replace their existing refrigerators and freezers than non-participants. Educational effects were found to represent $26 \%$ of the overall impact.

Program Recommendations:

Methodology Recommendations: The most reliable way to estimate impacts caused by behavioral factors other than equipment replacement is to run a controlled experiment, i.e, to create a control group that would receive the direct measures but not the educational materials.

Comments: 
Document Number: 0083

Study Title: Do Education, Training and Code Enforcement Support Programs Translate Into Stronger Energy Code Enforcement? Results from the Washington State Energy Code Monitoring Program

Date: $00 / 00 / 94$

Study Sponsor: Washington State Energy Office

Authors: Schueler, V, J Devine

Building Type: R

Program Type, Code (C) or Utility (U): C

Evaluation Type, Process (P) or Impact (I): I

Evaluation Purpose, Formative (F) or Summative (S): $F$

Part of Process Addressed: I

Stakeholders Targeted: Builders

Program Description: The Washington State Energy Code Program (WSEC) is a supplemental effort to provide training and financial support to the code enforcement community. The program includes a one-time start up payment, training allowances, technical assistance, and training on the code and inspection procedures.

Process Evaluation Method:

Impact Evaluation Method: Site visits were made to 216 sites in participating WSEC program jurisdictions. A sample was stratified by expected building activity. The lack of a control group made the study more complicated. Program Findings: Average rating for all structures was 1.7 on a 4-point scale (a 1 value meant that no variances were found from the code and a 4 meant that 2 major variances were found). Other ratings for various components are given. Residential energy code compliance levels in Washington appear to be higher than in other states.

Methodology Findings: Similar studies conducted by the State of California showed a lower level of compliance with the energy code. This may be due to stricter definitions of compliance used in California.

Program Recommendations: Both builder and code enforcement support are needed to make energy codes work over the long run.

Methodology Recommendations:

Comments: 
Document Number: 0084

Study Title: The Evolution of a Program for Commercial New Construction

Date: $3 / 26 / 95$

Study Sponsor: Central Vermont Public Service Corporation (CVPS)

Authors: Hunter II, G

Building Type: $C$

Program Type, Code (C) or Utility (U): $U$

Evaluation Type, Process (P) or Impact (I): $P$

Evaluation Purpose, Formative (F) or Summative (S): $F$

Part of Process Addressed: D A I

Stakeholders Targeted: Builders, Consumers

Program Description: In the earty 1990s, Central Vermont Public Senvice Corporation (CVPS), a regulated utility, introduced a program for Commercial New Construction which sought to integrate the utility DSM program with the State of Vermont's comprehensive land use and development control law (Act 250). In 1991, the Vermont Department of State Buildings and Department of Public Service, DPS, modified ASHRAE 90.1-1989 and adopted it as the Department of State Buildings Energy Conservation Standard for New and Existing State Buildings, E-1991. It applies to all state-owned buildings or buildings that receive Vermont funds. Buildings that receive local funds must comply with ASHRAE 90A-1980. CVPS's objective is to create a system and method through its DSM program for Commercial New Construction to identify appropriate measures and to promote construction of energy-efficient structures in its service territory. The ultimate purpose of the program is to provide the Act 250 applicant with good information and assistance in the permit process and to ensure that energy-efficient measures are incorporated into the constructed building. CVPS is progressing toward 1) providing the applicant with a list of typical efficiency measures specific to the applicants's project and resulting in a comprehensive review of the energy efficiency of the project, 2) hiring an Act 250 inspector to verify the installation of agreed-upon measures and supervised by DPS, and 3) developing a method of tracking the program's effectiveness by estimating $\mathrm{kWh}$ savings and lost revenues from the program.

Process Evaluation Method:

Impact Evaluation Method:

Program Findings: CVPS has moved from an individual, highly customized analysis of an Act 250 project's efficiency measures and replaced the analysis with a more efficient, comprehensive, and proactive listing of anticipated measures based on ASHRAE 90.1-1989 guidelines. CVPS has developed the program in conjunction with Act 250 District Coordinators and DPS/EED and is able to provide service to Act 250 applicants. CVPS helps them to understand the energy efficiency expectations of the law with less delay and expense in obtaining a permit. The general public is better served because more efficient buildings mean lower operating expenses leading to more competitive businesses and less demand on existing power supplies. Rather than relying on cash incentives to accomplish the implementation of cost-effective energy efficiency measures, CVPS and DPS are using Act 250 as written to achieve benefits.

Methodology Findings:

Program Recommendations:

Methodology Recommendations:

Comments: 
Document Number: 0085

Study Title: Lighting Program Design: New Opportunities for Profits

Date: 3/26/95

Study Sponsor: US DOE, PNNL

Authors: Johnson, J, C Jones

Building Type: $\mathrm{C}$

Program Type, Code (C) or Utility (U): U

Evaluation Type, Process (P) or Impact (I): $P$

Evaluation Purpose, Formative (F) or Summative (S): $F$

Part of Process Addressed: D

Stakeholders Targeted: Consumers, Utilities

Program Description: Work done by the Energy Management Committee (EMC) of the llluminating Engineering Society (IES) and the ASHRAE 90.1 Lighting Panel for the new ASHRAE Standard 90.1-1989R provides new technical bases for the development of component-based utility lighting programs. Component-based programs offer ease of marketing, higher market penetration, and the promotion of specific cost-effective technologies when compared to design assistance programs. Combining the prescriptive criteria in Standard 90.1 with the component savings is the key to designing an effective utility lighting program for new construction. IES application models allow utilities to determine baseline lighting levels for each space type using conventional technologies typically installed in their service territories. From these, savings thresholds are established using alternative technologies that are cost-effective to the utility. The program is implemented within the context of Standard 90.1.

Process Evaluation Method:

Impact Evaluation Method:

Program Findings: Lighting programs for new buildings are one of the most cost-effective new construction programs for utilities. The IES EMC models allow utility program planners to look at the impact of installing various lighting technologies on overall lighting power density levels. The models provide sales and marketing representatives with an easy to use program that protects the shareholder return on investment. The technical work to the program design phase is shifted to the design phase and customers can easily see the benefits to utilizing substitute technologies without compromising their designs.

Methodology Findings:

Program Recommendations:

Methodology Recommendations:

Comments: 
Document Number: 0086

Study Title: New Process, New Program, New Beginning

Date: $00 / 00 / 00$

Study Sponsor: San Diego Gas \& Electric Co. (SDG\&E)

Authors: Simunec, C

Building Type: $\mathrm{C}$

Program Type, Code (C) or Utility (U): $U$

Evaluation Type, Process (P) or Impact (I): P

Evaluation Purpose, Formative (F) or Summative (S): $F$

Part of Process Addressed: $D$

Stakeholders Targeted: Consumers, Utilities

Program Description: In March 1992, SDG\&E began a redesign process that took a basic approach to developing a new incentive program. It transformed two outdated incentive programs into one new construction incentive program that will evolve as the building standards and market change. The new program, Savings Through Design, has the ability to satisfy market needs over time. Three objectives lead to successful redesign: 1) to create a process where the needs of the customers and design community are addressed and integrated into the program on an ongoing basis; 2 ) to redesign the program to meet customers needs as well as regulatory requirements now and in the future; and 3 ) to enhance the effectiveness of field staff in educating customers and the design community on the new program and its benefits.

Process Evaluation Method: The process evaluation addressed SDG\&E's Title 24 Plus and Lighting Efficiency programs. The approach included focus groups with the target market (customers with new construction projects or tenant improvements, and the design community), interviews of SDG\&E staff, and examination of program records and procedures.

Impact Evaluation Method:

Program Findings: Title 24 Plus (Performance) findings were the following: 1) The performance computer analysis was difficult to understand and to explain. 2) Analysis was time consuming and, if it did not match the schedule of a project, it was considered to be a "show-stopper." 3) For many smaller projects, the performance program was too time consuming and complicated. 4) The program appeared to work well for whole building design projects with corporate or institutional owners, but not for speculative developments or build-to-lease projects. 5) Incentive amounts could not be determined up-front since the computer analysis had to be completed first. This was a source of frustration to both customers and field representatives. Findings for Lighting Efficiency (Prescriptive) were the following: 1) The simplicity of the incentives made them easy to understand and to sell. 2) Only a short list of lighting measures was available, restricting the program's success. 3) Customers with lighting and non-lighting measures had to participate in both the prescriptive and performance programs which was confusing for participants. 4) The program lacked technical guidelines to ensure overall system efficiency and was vulnerable to customers bending the rules to receive incentives.

Methodology Findings:

Program Recommendations: The redesign process must be integrated into the implementation process to create a design cycle. The key steps to implementing a design cycle are the following: 1) Maintain the Redesigning Team with the original program designer and program manager and conduct a "mini" process evaluation. 2) Continually channel all suggestions and input back into the program so that it is always evolving to reflect the ever changing new construction market. 3) Ask questions such as "Are we satisfying customer needs?" as much often as "Are we meeting our goal?" 4) Ask non-participating customers why they did not participate, as participating customers are asked why they did participate. 5) Continue to add new selling features. 6) Continue to add creative marketing techniques.

Methodology Recommendations:

Comments: 
Document Number: 0087

Study Title: Design Assistance: How Effective Is It in the Long Run?

Date: 3/26/95

Study Sponsor: Southern California Edison (SCE)

Authors: Johnson, $J$

Building Type: $\mathrm{C}$

Program Type, Code (C) or Utility (U): U

Evaluation Type, Process (P) or Impact (I): I

Evaluation Purpose, Formative (F) or Summative (S): $S$

Part of Process Addressed: I

Stakeholders Targeted: Consumers

Program Description: The targeted program was SCE's Design for Excellence (DFE) new construction program. Finished buildings in the program were surveyed to determine the degree to which utility recommendations were executed and if there were clear trends that could be used to assist in increasing the effectiveness of. such a program. Utility personnel visited the buildings to verify what energy-efficiency measures remained a part of the project throughout the entire design/construction process.

Process Evaluation Method:

Impact Evaluation Method: Twelve non-residential buildings were studied - five offices, five city buildings, a university classroom, a retail department store, and a golf course clubhouse.

Program Findings: The percentage of utility recommendations implemented ranged from $40 \%$ to $133 \%$ for the twelve projects $-67 \%$ of the projects implemented had at least the full package of recommendations. In all 12 buildings, at least part of the recommended package was retained throughout the building process. Recommended energy efficiency measures and the percentage of the times they were implemented were the following: high efficiency package units $(100 \%)$; high performance glazing $(100 \%)$; variable speed drives $(100 \%)$; optimized building envelope (100\%); EMS/controls (100\%); evaporative cooling (100\%); primary/secondary pumping (100\%); occupancy sensors (80\%); incandescent lamp upgrades $(80 \%)$; day lighting/controls $(78 \%)$; T8 lamps/electronic ballasts (75\%); high efficiency chiller (67\%); high efficiency motors $(50 \%)$. The survey found that owner interest was critical in increasing the chance of being implemented in the final building. In both cases where the owner initiated the process and the measures failed to produce the desired outcome, the reasons for shortfall were the lack of cooperation of a lighting designer and a project overburdened with setbacks. In both cases where the design assistance was initiated by a member of the design team, full implementation was not achieved. There appears to be no correlation between when the analysis was begun and how effective the assistance was in affecting design changes. Success was more dependent upon such factors as the economics of the project, the openness of the design team to outside involvement, and the commitment of the building owner to lower operating costs. Measures with relatively long paybacks and low incentive-to-cost ratios were implemented just as often as those that were more economically attractive.

Methodology Findings:

Program Recommendations: Encouraging an integrated approach to increase building performance in new construction should be used as a tool for communicating the practical benefits and investment opportunities to a building owner.

Methodology Recommendations:

Comments: 
Document Number: 0088

Study Title: Analysis of Commercial Model Conservation Standard Study

Date: 01/01/89

Study Sponsor: Bonneville Power Administration (BPA)

Authors: Schuldt, $M, J$ Romberger, J Cade

Building Type: $C$

Program Type, Code (C) or Utility (U): U

Evaluation Type, Process (P) or Impact (I): P I

Evaluation Purpose, Formative (F) or Summative (S): $F$

Part of Process Addressed: D

Stakeholders Targeted: Designers, Contractors

Program Description: BPA sponsored the study to assess the cost and energy impact of the new Model Conservation Standards (MCS) on commercial buildings in the Pacific Northwest.

Process Evaluation Method: The assessment of current practice (1989) end-use consumption for each prototype began with a review of building characteristics and end-use consumption estimates that were developed for the 1980 base year as part of previous research. The review of building physical and operational characteristics identified features that were impacted by an analysis of current design practice. The current practice (1989) baseline consumption estimates were computed with the DOE-2.1D model under Typical Meteorological Year (TMY) weather conditions. Fuel typing was based upon discussions with building operation managers and members of the building design community. The provisions of the MCS selected for analysis included all elements that saved electric energy. The incremental capital cost was estimated for the individual provisions of the new MCS using primarily vendor quotations. The lifetime of the MCS provisions was also estimated. The cost-effectiveness of the new MCS was calculated using the energy savings, incremental capital cost, incremental O\&M cost and lifetime estimates. The DOE-2.1D model was used to compute energy savings for the package including the interactive effects between provisions.

Impact Evaluation Method: The energy savings, cost, and cost-effectiveness of the provisions of the new MCS were then evaluated with respect to 1989 current practice. The study developed baseline (without MCS) end-use consumption estimates from current practice of new construction in each of the ten building classifications. The analysis of energy savings was based upon a series of computer simulations using the DOE-2.1D model. Prototypical buildings were based on real building consumption and characteristics data from a variety of data sources including End Use Load and Conservation Assessment Project (ELCAP), hourly load and audit data from over 3,000 commercial buildings.

Program Findings: The new MCS saved energy in each building classification evaluated in Seattle. The savings realized varied significantly across building classifications. The package of measures produced savings realized in a cost-effective manner in all but one building classification due to a relatively modest increase in incremental capital cost.

Methodology Findings:

Program Recommendations: More stringent provisions of the new MCS could be tolerated in many building classifications for the internal lighting end-use.

Methodology Recommendations:

Comments: 
Document Number: 0089

Study Title: Florida Building Energy-Efficiency Rating Systems: Progress and Remaining Issues

Date: 3/26/95

Study Sponsor: Florida Solar Energy Center

Authors: Vieira, R, P Fairey

Building Type: $C R$

Program Type, Code (C) or Utility (U): C

Evaluation Type, Process (P) or Impact (I): $P$

Evaluation Purpose, Formative (F) or Summative (S): F

Part of Process Addressed: A I C E

Stakeholders Targeted: Utilities, Builders, Financiers, ESCO's, Real-estate Agents, Home Buyers

Program Description: Rating systems were developed during 1994 by the Florida Solar Energy Center (FSEC) under contract with the Dept. of Community Affairs (DCA) for new and existing residential, public, and commercial buildings. One-day training courses and certification exams were developed by FSEC and offered at no charge to potential energy-eficiency raters under contract with DCA during 1994. The rating system applies to almost all Florida's new and existing building types, addresses all energy and end-use, both individually and collectively, gives energy use estimates in energy units and in dollars, compares the building directly with all other buildings of the same type, explains precisely how and where energy is used in the building, and provides specific information on energy-efficiency improvement potentials. It also gives clear and unambiguous results, educates large numbers of consumers, provides for independent evaluations by certified raters, and levels the playing field in the energy-efficient market.

Process Evaluation Method:

Impact Evaluation Method:

Program Findings: There are serious market problems: ratings are voluntary, at the discretion of the home buyer, and both the market infrastructure and the demand are weak at present. The rating system is basically a state-imposed "unfunded" mandate. Most private industry issues have not been adequately addressed, so they remain unresolved: utilities don't want to use it in their programs; home builders claim they can't sell energy-efficiency; bankers gain nothing but paperwork; real-estate agents have to deal with legal compliance; and home buyers pay, but to what end?

Methodology Findings:

Program Recommendations: The state should provide funding to support this program to provide rater certification; evaluate and maintain rater performance quality; and maintain procedures, certification exams and rating tools. User-friendly computer "tool kits" should be developed that can "attach" to official Energy Code estimation software which are designed to meet the specific needs and capabilities of the building and energy communities. A uniform standard method like the Rating System should be used to evaluate and report energy use in all of Florida's building energy-efficiency programs. Formal panels should be convened from the building and energy community who are most affected by the Rating System. The panels should be charged with two tasks: 1) resolve outstanding issues and 2) develop consensus standards for the "tool kits." Four panels should be considered including a utility panel, finance and mortgage panel, construction and real-estate panel, and energy service company (raters) panel.

Methodology Recommendations:

Comments: 
Document Number: 0090

Study Title: Measured DSM Energy Savings in New Multifamily Buildings

Date: $00 / 00 / 93$

Study Sponsor: Bonneville Power Administration (BPA), Tacoma Public Utilities

Authors: Brandis, P, M Schuldt, J Romberger

Building Type: $R$

Program Type, Code (C) or Utility (U): $C$

Evaluation Type, Process (P) or Impact (I): I

Evaluation Purpose, Formative (F) or Summative (S): $S$

Part of Process Addressed:

Stakeholders Targeted: Utilities

Program Description: BPA is conducting an evaluation of the impacts of the Model Conservation Standards (MCS) on the energy consumption characteristics of new multifamily buildings in the Pacific Northwest. BPA, in cooperation with Tacoma Public Utilities, has sponsored the Multifamily Metering Project. Continuous hourty measurements of apartment-level end-use consumption and other important energy performance parameters are being made on 84 housing units in ten buildings. The sample contains five matched pairs of test and reference buildings.

Process Evaluation Method:

Impact Evaluation Method: A comprehensive Analysis Plan was developed to guide the evaluation of the energy impacts of the conservation measures (the efficiency features of the MCS). The Plan includes a set of generic procedures that address all aspects of the evaluation from experimental design, through data collection and analysis, to the evaluation of energy savings realized by the individual conservation measures in each building pair. Emphasis is placed on the unique aspects of the Plan, which includes calibration of the DOE-2 hourly simulation model with the measured performance data under conditions with and without the MCS features. The paper provides graphical and tabular summaries of the measured performance data for the matched building pairs.

Program Findings: Lighting/appliances is the largest end use in all buildings, $36-47 \%$ of total annual consumption. This corresponds to a 2 to 1 variation in normalized annual consumption, from 2.6 to $5.2 \mathrm{kWh} / \mathrm{sq} . f \mathrm{ft}$. This range is caused by the combined effects of a large variation in average annual vacancy rates (4\% to $49 \%$ ) and differences in the consumption patterns of the tenant populations. Space heat is the smallest end use in all but two of the buildings. It represents $20 \%$ to $33 \%$ of total annual consumption. This corresponds to a large variation in normalized annual consumption, from 2.0 to $4.6 \mathrm{kWh} / \mathrm{sq} . \mathrm{ft}$. A comparison of total consumption between the building pairs indicates that the MCS buildings consumed less total energy than their non-MCS counterparts in three of the four cases where the comparison could be made. A similar comparison of measured space heating consumption between the building pairs indicated that the MCS buildings consumed less energy for this end use in two of the four cases. To illustrate the value of the hourly consumption data, 24-hour end-use consumption profiles were prepared for the two buildings in the 6-unit matched pair. The profiles reveal different consumption patterns in the two matched pair buildings. Peak consumption for the MCS building occurs between 7 and 8 a.m. and 7 and 8 p.m., caused by high hot water and lighting/appliances usage before and after the working day. These profiles are consistent with expected tenant behavior and the consumption profiles measured in previous studies. A very different trend is noted for these end uses in the non-MCS building. The consumption for both the hot water and lighting/appliance end uses increased throughout the day with peak consumption occurring between 9 and 10 p.m. This atypical pattern is caused by the combined effects of a high vacancy rate and an unusual tenant population during this time period. in both cases space heating consumption remains fairly constant throughout the day without a notable reduction in consumption from night setback in the nighttime hours. Methodology Findings:

Program Recommendations:

Methodology Recommendations:

Comments: 
Document Number: 0091

Study Title: Evaluating the Impacts of Model Conservation Standards on Single-Family Construction Practices in the Northwest

Date: 00/00/88?

Study Sponsor: Bonneville Power Administration (BPA), Northwest Power Planning Council

Authors: Brandis, P, B Cody, M Brown, M Haeri

Building Type: $R$

Program Type, Code (C) or Utility (U): C

Evaluation Type, Process (P) or Impact (I): I

Evaluation Purpose, Formative (F) or Summative (S): $S$

Part of Process Addressed: IC

Stakeholders Targeted: Home Owners

Program Description: BPA, in conjunction with the Northwest Power Planning Council, has implemented a wide range of activities to improve building practice in the Pacific Northwest. Activities include offering technical assistance, use of financial incentives, the Super Good Cents (SGC) marketing program, the Early Adopter Code Program (EAP), and even a threatened surcharge. The purpose of this study is to assess the impacts of these activities on single-family home construction. This is accomplished by comparing the energy-efficiency of 1983 pre-program homes with 1987 homes and by comparing 1987 homes built under BPA with other homes constructed in the same year.

Process Evaluation Method:

Impact Evaluation Method: The evaluation is comprised of four interrelated components: an occupant survey, billing history analysis, energy simulation modeling, and construction characteristics data from site visits including blower door tests. Metered data from the End-Use Load and Consumer Assessment Program (ELCAP), Residential Standards Demonstration Project (RSDP), and SGC are also utilized. The focus was on space heating energy use and evaluation of construction practices for four house types: SGC, GC, EAP, and non-MCS, built and occupied in 1987. A sample of homes built in 1983 provides a historical comparison. Twenty-eight SGC utility areas served as the primary sampling unit accounting for over $90 \%$ of all 1987 SGC houses built in the region. The selection of EAP houses was based on a census of all 1987 houses in three climate zones. The non-MCS sample and the GC sample were selected from the 28 SGC utility areas located in climate zones 1, 2, and 3 and four $10 \mathrm{U}$ areas in zones 1 and 3. Construction characteristics and blower door test results were collected at 205 sites across the region and 203 on-site audits were completed. The audits included measurements of building size, insulation levels, and air tightness. In a combined engineering and statistical analysis of energy use, multivariate regressions, based on data from the 203 audited homes, will be used to control for family and house size, construction characteristics and climate zones. The energy use analysis is intended to produce statistically reliable estimates of the amount of electricity consumed for space heating in the four house types for the three climate zones. As a first approximation in the analysis, the Princeton Scorekeeping Method (PRISM) is used to derive estimates of weather-sensitive loads. Using the PRISM model, estimates of weather-normalized annual consumption (NAC) and space heating were obtained using approximately 1 year of weather data. The presence of heat pumps has the potential to cause major problems in the application of PRISM. The analysis of the ELCAP data showed that the bias in PRISM estimates of NAC and heating loads for heat pump sites is within an acceptable range and no greater than that found in non-heat pump sites. Use of PRISM in the presence of air conditioning is also problematic because, where such equipment is used, temperature-sensitive loads will assume a bimodal shape. To resolve this problem, only non-summer consumption records were used to estimate the PRISM models. Like heat pumps and air conditioning, wood heating is problematic because it violates the linearity assumption of the PRISM model. In the present evaluation, all households reporting wood as their primary space heating fuel were dropped from the study. To ensure the quality of the data, consistent screening procedures were applied to all billing records before the application of PRISM.

Program Findings: The preliminary results indicate that the energy efficiency of construction practices in the Pacific Northwest progressed significantly between 1983 and 1987. Homes built in 1987 as part of MCS marketing and code adoption programs appear to require $20 \%$ to $28 \%$ less energy for space heating than other 1987 homes. Methodology Findings:

Program Recommendations:

Methodology Recommendations:

Comments: 
Document Number: 0092

Study Title: Evaluation of Performance-Based Energy Codes for Large Office Buildings

Date: 00/00/89

Study Sponsor: Seattle City Light

Authors: Katz, G, J Heller, D Baylon, D Sumi

Building Type: $C$

Program Type, Code (C) or Utility (U): C

Evaluation Type, Process (P) or Impact (I): I

Evaluation Purpose, Formative (F) or Summative (S): $S$

Part of Process Addressed: $C$

Stakeholders Targeted: Architects, Building Owners

Program Description: In 1984 the City of Seattle added a provision to the existing building energy code, the Major Projects Rule (MPR). It was designed to reduce the electrical load added by new construction by increasing the efficiency of new buildings over $50,000 \mathrm{sq}$. $\mathrm{ft}$. It requires the building designer to demonstrate through simulation a $10 \%$ reduction in energy use from the prescriptive requirement of the current city code. Buildings built under this code were compared with buildings built in adjacent urban areas under the Washington State Energy Code which is identical to the current Seattle code. Building HVAC systems and lighting systems were compared; comparisons were also made of the degree to which the performance prediction of the energy simulation corresponded to actual performance, and the energy use of the two groups of buildings. Detailed walk-through audits were conducted to review HVAC, lighting, and other energy systems. Short-term submetering of particular energy systems including lighting HVAC, computer rooms, and plug loads were conducted. This information along with total energy billings was used to assess energy end-uses.

Process Evaluation Method:

Impact Evaluation Method: The main goal of the study was to look at the impact of the code on the energy performance of the buildings. The study compared six large MPR office buildings built in Seattle under the terms of the MPR. A control group of eleven large office buildings built during the same period (1985-87) in King County and the Portland metropolitan area was used to define common practice. The following systems were examined in the computer model: interior lighting, garage lighting, HVAC system changes, cooling load reductions, high efficiency cooling, fan energy reduction, garage fan, and miscellaneous.

Program Findings: The conservation measures used to meet the MPR requirements were similar to those found in comparable buildings in adjacent jurisdictions not subject to the MPR. Many of these conservation strategies reduced construction and operation costs and were, therefore, part of common practice. In most cases, the base energy code set a standard lower than that found in standard equipment or in normal design practice. Operation and occupancy had a greater impact on building energy use than the conservation measures adopted to meet the MPR requirements.

Methodology Findings:

Program Recommendations: Although this evaluation of the MPR did not find substantial energy savings as a result of the performance-based code, it did identify several factors that can produce energy savings in large commercial buildings. The prescriptive energy code should more closely match normal design practice and standard equipment. Building operators should be educated to monitor and operate the systems installed in their buildings to provide maximum energy efficiency.

Methodology Recommendations:

Comments: 
Document Number: 0093

Study Title: Straight from the Horse's Mouth: Feedback from Design and Construction Professionals on Commercial New Construction Efficiency Programs

Date: $3 / 26 / 95$

Study Sponsor: Barakat \& Chamberlin

Authors: Brown, J, K Cosgrove

Building Type: $\mathrm{C}$

Program Type, Code (C) or Utility (U): U

Evaluation Type, Process (P) or Impact (I): P

Evaluation Purpose, Formative (F) or Summative (S): F

Part of Process Addressed: D

Stakeholders Targeted: Architects, Builders

Program Description: In October 1993, Barakat \& Chamberlin conducted four focus groups to explore current commercial building practices, the appropriate type of design and financial assistance required to encourage investment in high-efficiency technologies, and the appropriate timing of that assistance. The focus groups were part of two concurrent process evaluations for commercial new construction efficiency programs offered by sister gas and electric utilities in the Midwest. The focus groups explored the reasons for participation and non-participation in the utilities' new construction efficiency programs and the trade allies' suggestions for attracting more participants to these programs.

Process Evaluation Method:

Impact Evaluation Method:

Program Findings: Many findings were produced by the study. First, clients lack knowledge about energy efficiency. Clients are aware of energy efficiency in the abstract but do not know about specific energy-efficiency opportunities and their associated benefits. Second, building design and construction professionals lack detailed knowledge about energy-efficiency opportunities and utility programs. The focus group participants said they have little time to increase their knowledge about available efficiency options or incentives. Third, energy-efficiency is not their business. Time is money, and the participants do not see that they are compensated for the costs of the additional analyses required for energy-efficient design. The architects pointed out that energy efficiency analyses are considered "additional services" in their standard form of agreement for architectural work. Fourth, program paperwork is a barrier to participation. In most cases, the burden of paperwork falls on the construction professionals. It takes time to complete program paperwork, and they are frustrated when the time they spend on papenwork is disproportionate to the dollars or savings associated with the utility program in question. Fifth, timing is critical. The window of opportunity for affecting decisions about the efficiency of building design and equipment is small. Sixth, building design and construction professionals are skeptical about the performance of new high-efficiency technologies. The focus group participants expressed skepticism about the performance of new high-efficiency technologies. Because these technologies are unfamiliar to them, they consider their performance claims to be unproven and financially risky.

Methodology Findings:

Program Recommendations: Many recommendations resulted from this program. First, the client "pull" has to be increased. Client knowledge about energy efficiency increases the number of clients that ask for efficiency measures and improves the chances that clients will be responsive to recommendations for high-efficiency improvements. Second, knowledge of and trust in high-efficiency technologies in the building design and construction community need to be increased. They need tangible proof of performance and reliability before they can take a positive attitude toward a given high-efficiency design or technology. Third, knowledge about utility programs in the building design and construction community needs to be increased. The key to influencing building design and construction is to be present at the start, when the project is first being checked out. Fourth, participation in the utility programs should be made easier. If the potential clients perceive utility program participation as time consuming or complicated, they will be unenthusiastic about participating in a program. Thus, the more streamlined a program participation process can be made, the more likely the program is to attract participants. Fifth, clients need to be given a product. Instead of offering energy-efficiency programs, utilities could offer products and services. These products and services could include design analysis services, turnkey end-use services, equipment leases, or performance guarantees, to name a few.

Methodology Recommendations:

Comments: 
Document Number: 0094

Study Title: Making a Connection Between Commercial New Construction Codes and Utility New Construction Programs: A Means of Market Transformation

Date: $3 / 26 / 95$

Study Sponsor: Barakat \& Chamberlin

Authors: Hamilton, $M$

Building Type: $C R$

Program Type, Code (C) or Utility (U): U C

Evaluation Type, Process (P) or Impact (I): $P$

Evaluation Purpose, Formative $(F)$ or Summative $(S)$ : $F$

Part of Process Addressed: D

Stakeholders Targeted: Utilities, Building Officials, Architects, Builders

Program Description: Joint industry market transformations/opportunities - such as codes and standards - may offer utilities extremely cost-effective DSM while providing educational and marketing value for the customer. Several Washington State utility and industry associations have embarked on a joint industry market transformation effort to enhance code compliance over a three-year period. A partnership between utilities and the building community was created to provide the technical assistance and training necessary to successfully implement the new commercial code. Two non-profit organizations were created: the "Utility Code Group" and "Building and Design 2000." The Utility Code Group is made up of nine major electric and gas utilities in Washington State. Building and Design 2000 is a consortium of design, construction, building, and enforcement organizations. Both organizations seek to develop training and technical assistance for those responsible for designing and constructing structures that will meet the new code, as well as those charged with inspecting projects for code compliance. The utilities have agreed to fund a three-year training and technical assistance program to implement the code. The Building and Design 2000 consortium will implement the training and enforcement program. The approach is expected to be five times less expensive per $\mathrm{kWh}$ saved than acquiring the same energy savings through a conventional new construction incentive program. Effective code compliance allows the utilities to set higher baselines for their new construction programs, and expect increased participation due to greater market presence.

Process Evaluation Method:

Impact Evaluation Method:

Program Findings:

Methodology Findings:

Program Recommendations: Some issues arise with joint utility market transformation efforts. First is the role of code compliance in utility programs. Providing building code information and education is an opportunity for utilities to provide valuable expertise to their customers and trade allies. It also allows them to become involved in new construction projects as early as possible. The Washington State experience is an example of providing customers with value while increasing code compliance levels. Second is regional associations. Associations and industry trade groups within the business community are commonly used to address governmental issues and cultivate their respective industries in a broader sense. Creating organizations to implement specific projects, as in the Washington State experience, can bring competing utilities and interests together to achieve creative solutions. Third is establishing a process of cooperation. Natural tensions may arise due to conflicting self-interests between for-profit and non-profit organizations and between government and private entities. $A$ clearly defined and well-managed process can bring together a larger group, allowing participants to leverage support while working with organizations such as state agencies and related trade associations. Fourth is quality control and evaluation. Quality control and evaluation feedback loops can provide useful data for improving program implementation, assessing continued participation, or improving the approach to similar projects. This will aid evaluating continued participation or approaching similar projects. Fifth is utility investments. Utilities may use these programs to leverage multiple objectives, including guiding related industry efforts (such as new construction practices) and government efforts (such as code development and enforcement), and in providing customer service. Sixth is documenting energy savings. Determining energy savings or other values for a utility from joint market transformation activities includes several issues that may prove more complex than the impact measurement typically used for DSM programs.

Methodology Recommendations:

Comments: 
Document Number: 0095

Study Title: Design Assistance: What's Been Learned from the Early Years

Date: 00/00/93

Study Sponsor: Southern California Edison (SCE)

Authors: Johnson, J

Building Type: $\mathbf{C}$

Program Type, Code (C) or Utility (U): U

Evaluation Type, Process (P) or Impact (I): 1

Evaluation Purpose, Formative (F) or Summative (S): $S$

Part of Process Addressed: I

Stakeholders Targeted: Designers, Building Owners

Program Description: This program offered technical assistance and resources to design professionals involved in the design of new or renovated commercial and industrial buildings in SCE's senvice territory. To be eligible for the program a building had to be at the programming or schematic design phase, space-conditioned, and have a connected load of a least $100 \mathrm{~kW}$. Costs for each study were limited to $\$ 7,500$. Design assistance was initiated about the same time that performance-based financial incentives were introduced to support comprehensive integrated design for producing the greatest energy savings. Two groups of consultants were established to provide a broad range of senvices. The first consisted of professionals meeting SCE's technical requirements and demonstrating a knowledge of energy-efficient design techniques. The second included professionals who demonstrated a working knowledge of the DOE-2 hourly energy-use simulation program. Program promotion was accomplished principally through SCE's field representatives. A typical Design Assistance study involved an hourly energy-use computer simulation comparing energy and economic impacts of various efficiency strategies.

Process Evaluation Method:

Impact Evaluation Method:

Program Findings: Between 4 and 12 requests for design assistance were received each quarter between the second quarter of 1991 and the third quarter of 1993. These included the following: 13 office, 12 classroom, 8 recreation, 7 manufacturing, 6 library, 4 laboratory, 3 hospital, 3 retail, 3 courthouse, 3 police/fire, 2 hotel, 1 grocery, 1 restaurant, and 4 other. Customer types included a range of public and private entities. The base case for measuring energy savings is a counterpart building that just meets the minimum requirements of California's Building Energy Standards (Title 24). Buildings exceeding this baseline by $10 \%$ or more are eligible for "Performance Level" incentives; those exceeding by $25 \%$ or more are eligible for "Performance Plus" incentives. The average improvement of the Design Assistance participants was $27.4 \%$ better than Title 24 . The facilities achieving the highest savings/sq. ft. were laboratories, police facilities, and grocery stores. The average was $6 \mathrm{kWh}$ savings/sq. ft. The average demand reduction was $1.82 \mathrm{~W} / \mathrm{sq}$. $\mathrm{ft}$. The total costs of the program average less than $\$ 0.20 / \mathrm{kWh}$, and the average decreases as the program matures. Four factors are reliable guidelines for deciding whether or not a project is a good candidate for design assistance: 1) Size - the larger the facility, the greater the potential for large amounts of energy savings; 2) Climate - the more extreme the climate, the higher the energy use, and the greater the potential for savings; 3 ) Occupancy - longer operating schedules allow for greater energy reductions, and variable occupancies produce conditions that respond well to controls that can modulate the use of the equipment; 4) Energy Use Patterns - any building with a high demand for cooling, ventilation, lighting, etc. that can be varied according to the existing load is a good candidate for analysis. Also any project that requires opposite, coincident loads allowing energy recovery strategies should be investigated. The average cost of analysis was $\$ 7,450$.

Methodology Findings:

Program Recommendations: The Design Assistance analysis can be combined with other programs, but because the programs are administered differently, combining studies has been a problem. Other utilities and organizations often have design assistance programs similar in nature and intent to SCE's program. When the goals of the programs are in agreement, it can be advantageous for all involved parties to pool resources and work together. In general, it is believed that the earlier the concept of designing for energy efficiency is introduced into a project, the more strategies can be implemented, the less costly it is to integrate measures, and the more valuable design assistance will be to that project. The primary lesson learned and the key to a good design assistance program is flexibility - to provide exactly what is appropriate for a given customer, for a given project, within a given time constraint.

Methodology Recommendations:

Comments: 
Document Number: 0096

Study Title: Utility Programs: Supporting Adoption and Enforcement of Energy Codes for New Building Design and Construction

Date: $08 / 01 / 94$

Study Sponsor: DOE

Authors: Johnson, $\mathrm{J}$

Building Type: $\mathrm{CR}$

Program Type, Code (C) or Utility (U): C

Evaluation Type, Process (P) or Impact (I): I

Evaluation Purpose, Formative (F) or Summative (S): $F$

Part of Process Addressed: AIE

Stakeholders Targeted: Utilities, Code Officials, States

Program Description: Pacific Northwest Laboratory conducted a survey of utilities to find out what strategies are being used to promote energy-efficient building design and construction. Utilities offer training programs for designers, builders, code officials, real-estate agents, bankers, subcontractors, and utility staff. Technical assistance for building professionals for specific technologies is common. Utilities target their marketing strategies to increase program awareness among different audiences.

Process Evaluation Method:

Impact Evaluation Method:

Methodology Findings:

Program Findings: 1) DSM programs encourage state code adoption - utilities, through new construction DSM programs, can encourage a state to voluntarily adopt new code levels. BPA's Early Adopter Program encouraged adoption of Model Conservation Standards (MCS) by local governments. These efforts will capture between 150.5 and 163.9 MW for all electric utilities in Washington State by 2003. The Northwest Power Planning Council estimates that the electricity saved is worth between $\$ 1.2$ and $\$ 1.3$ billion. Some utilities across the country discontinued their new construction DSM programs because optional building energy standards were adopted into their respective state building energy codes. Utilities have established technical advisory groups including builders to prepare state energy code revisions, provided information and market assistance leading to stricter state energy standards for new homes construction and formed collaboratives to implement state-wide energy conservation and efficiency policies. 2) Collaboration creates bigger energy savings - utilities have established working relationships with the design and building communities to improve their programs. 3) Aggressive marketing yields big market impact - Kansas City Power and Light staff credit marketing efforts aimed at potential home buyers for the success of their DSM new construction residential program. Austin Electric publicized the names of the most energy-efficient local builders and designers with an aggressive marketing program that is driving the demand for energy-efficient housing. 4) Training and enforcement are critical to success - utility training programs are directed toward designers, builders, code officials, and building owners. Kansas City Power and Light has found that realestate agents can play a significant role in educating potential home buyers about the advantages of an energy-efficient home. The California Public Utilities Commission provides economic incentives by allowing investor-owned utility shareholders to earn a return on DSM programs. The California Energy Commission enforces energy-efficiency standards for new buildings and appliances. Florida Power and Light conducts audits of residential new construction, informs home owners if their homes fall within state guidelines, and provides information on how to improve energy efficiency. Puget Sound Power and Light staff recommend emphasizing training building code officials, especially those working for smaller cities and jurisdictions that have limited resources, and keeping energy code enforcement simple because calculations and computer simulations are rarely used by building inspectors. DSM programs can lead to more stringent and user-friendly building energy codes and standards. Utilities can work with state legislatures to promote the adoption of building energy codes. Utilities need to periodically reassess DSM programs to ensure the most cost-effective programs. Utilities can collaborate amongst themselves and with other groups to increase energy savings and share costs. Aggressive marketing to the buyer yields bigger market impact. Utilities can benefit from establishing working relationships with the building community, including lenders, realtors, and appraisers. Energy codes are of little value without implementation and enforcement. Training programs for builders, subcontractors, and code officials are the first step.

Program Recommendations:

Methodology Recommendations:

Comments: 
Document Number: 0097

Study Title: The Role of Utility DSM Programs in Promoting Building Energy Codes

Date: 00/00/94?

Study Sponsor: DOE

Authors: Sandahl, L, D Shankle, B Wise

Building Type: $\mathrm{R} C$ other

Program Type, Code (C) or Utility (U): C

Evaluation Type, Process (P) or Impact (I): $P$

Evaluation Purpose, Formative (F) or Summative (S): $S$

Part of Process Addressed: A I E

Stakeholders Targeted: Utilities, States

Program Description: Pacific Northwest National Laboratory (PNNL), under the Building Energy Standards Program (BESP), conducted a study for DOE's Office of Codes and Standards to identify new construction DSM strategies that utilities have adopted or developed to promote energy-efficient design and construction. The goal was to identify opportunities where states might collaborate with utilities to promote the adoption, implementation, and enforcement of energy-efficient building energy codes.

Process Evaluation Method: PNNL surveyed selected utilities, extrapolated lessons learned, and identified evolving trends in 27 utility new construction DSM programs. Utilities were identified by reviewing new construction DSM literature and by interviewing experts in the industry. Utilities were then contacted by phone.

impact Evaluation Method:

Program Findings: 1) DSM covers a wide range of programs for residential, commercial, and industrial customers. Incentives are offered to designers, builders, or owners. Utilities offer training for designers, builders, code officials, realtors, bankers, subcontractors, and utility staff. Technical assistance is offered. Utilities employ many marketing strategies to increase program awareness. 2) Utilities are reassessing DSM programs for more cost-effective savings. Utilities are focusing more of their DSM resources on the commercial sector because the energy savings are more predictable and dollars spent have a higher impact. 3) It is important to train code officials, architects, builders, and contractors to meet or exceed codes because codes are of little value unless they are implemented and enforced. Greater coordination between builders, designers, and owners is the key to more efficient buildings. 4) Utilities form working relationships with the design and building communities. Many utilities involve these groups early in DSM programs and have asked for and incorporated feedback into their training programs. 5) Collaborating with other utilities and organizations can help utilities increase energy savings and share costs. Utilities are looking for opportunities to work with other organizations to develop more comprehensive energy-efficient programs resulting in greater energy savings. 6) Utilities encourage state adoption of new code levels before codes become mandatory. Utilities can do this by demonstrating the feasibility of the code through their DSM programs. Some utilities have discontinued their residential new construction DSM programs because the optional building energy standards supported by the program were adopted. 7) Utilities work with their state legislature to adopt building energy standards and codes. 8) Several new construction DSM programs are using incentives as a secondary measure to encourage energy savings in buildings. Many utilities aim for aggressive marketing and education programs for the potential buyer/owner, believing this approach is critical to success. 9) Bankers and real-estate agents are important additions to the designer-builder-owner team.

Methodology Findings:

Program Recommendations: 1) Promote interaction between state energy offices and utilities through regional or state workshops or technical working meetings. Utilities should consider working with the states to support the team approach to promoting energy-efficient building standards. 2) Identify opportunities for collaborative marketing programs. States with utility new construction DSM programs may need assistance in identifying opportunities to develop collaborative programs. State energy offices could play a role in educating the home buyers on the advantages of energy-efficient homes. 3) Promote state energy office and utility collaboration on projects that combine energy efficiency and environmental concerns. Both states and utilities separately have expressed interest in linking energy efficiency to environmental issues. Utilities might senve as a resource in identifying potential state or local projects where state energy offices and utilities could collaborate. 4) Help states identify ways to encourage local enforcement of energy codes. For states that have no energy code or where the energy code falls under the purview of local jurisdictions, utility DSM new construction programs might have a role in training the current building community to adopt more energy-efficient construction practices.

Methodology Recommendations:

Comments: 
Document Number: 0098

Study Title: Issues and Results from the Evaluation of the Adoption and Enforcement of Model Conservation Standards

Date: 00/00/86

Study Sponsor: Bonneville Power Administration (BPA)

Authors: Keating, K, D Lerman, L McCutcheon

Building Type: $C R$

Program Type, Code (C) or Utility (U): C

Evaluation Type, Process (P) or Impact (I): P

Evaluation Purpose, Formative (F) or Summative (S): $S$

Part of Process Addressed: I

Stakeholders Targeted: Local Governments, Builders, Code Officials, Designers

Program Description: In 1983, the Northwest Power Planning Council formulated the Model Conservation Standards (MCS) for new residential and commercial construction. The goal was to ensure that all new construction in the region served by BPA would be built to an economically feasible and regionally cost-effective efficiency level. To encourage MCS adoption and help support enforcement, BPA set up a voluntary earty adopter program including incentives for builders and enforcement financial support.

Process Evaluation Method:

Impact Evaluation Method: The key assumption made was that current costs and building practices would have continued in the absence of the code. This allowed using current practice code enforcement costs, energy code compliance rates, and energy consumption as a baseline or control to estimate the code impacts.

Program Findings: Code adoption alone may not guarantee the desired energy savings. Effective enforcement and compliance are critical to achieve the expected energy savings. Cost Issues - The cost of the MCS enforcement was broken into three components. First is the incremental cost above enforcement of current energy codes in buildings. A simulation was conducted for each of the four states. Building code officials tracked or estimated their labor and travel costs for current practice homes and non-residential buildings. They then estimated the extra time and effort involved if they had to enforce the MCS. The median cost was $\$ 97$ per building. BPA offered a reimbursement of $\$ 125$ per building to most early adopters. The approach and analysis was different in the Tacoma area. In 14 MCS enforcement case studies from three jurisdictions, phone time logs, field visit time, office time, and average hourly wages for jurisdictions were partially integrated. Summing the activities resulted in the incremental cost estimates of $\$ 120$ per home. Second is the cost to the political entity of adopting the MCS as a code. This was fairty minimal as reported by each early adopting community. Third is the complete cost of the required measures. This was obtained from the component-by-component costs reported by the builders of 400 demonstration homes and supplemented by a survey of material and labor costs. Energy Issues - Adoption was easy to measure. Most parties concluded that the best way to enforce an energy code was a combination of plan reviews and site visits. MCS homes data were collected using inspection, thermography, and blower door tests. I was determined that no single test could predict pass/fail. If the home was found to be at least $85 \%$ of the efficiency of the MCS, it was considered compliant. Energy Savings - The cost-benefit analysis of the MCS depends on the measure of energy savings. One regional measure comes from a demonstration program (RSDP) in which 400 current practice and $400 \mathrm{MCS}$ homes were separately metered for space heating use, but the savings results from the RSDP research must be tempered with savings estimates from actual code enforcement pilots. Early adoption of the MCS in Tacoma Light provided a large-enough pilot situation to obtain meaningful results. The control group used was a sample of electrically heated homes built in the 2 years preceding MCS adoption.

Methodology Findings: The evaluation of the impact of energy codes is a new area of research. Many concepts and goals have not been clearly defined.

Program Recommendations:

Methodology Recommendations:

Comments: 
Document Number: 0099

Study Title: Commercial Building Energy Code Compliance in Washington and Oregon

Date: 00/00/91

Study Sponsor: Ecotope, Inc.

Authors: Baylon, D

Building Type: $\mathrm{C}$

Program Type, Code (C) or Utility (U): C

Evaluation Type, Process (P) or Impact (I): I

Evaluation Purpose, Formative (F) or Summative (S): $F$

Part of Process Addressed: C

Stakeholders Targeted: Architects, Engineers, Code Officials

Program Description: The study was designed to evaluate the degree to which new commercial buildings complied with the ASHRAE. 90A building standard for commercial buildings. Ecotope reviewed a random sample of 141 new commercial buildings permitted in 1990 and built in Washington and Oregon. There were 70 in Washington and 71 in Oregon. The purposes of the study were 1) to establish a baseline for new construction practices, 2) to review the degree to which these buildings complied with local energy codes, 3) to asses the attitudes of building professionals and officials toward the energy code, and 4) to suggest changes that would enhance code compliance.

Process Evaluation Method:

Impact Evaluation Method: Ecotope used 1990 historical data files from a national construction industry information service. The researchers stratified the sample into large and small buildings and chose $40,000 \mathrm{sq}$. $\mathrm{ft}$. as the cutoff point. Recruitment introduced biases: schools were over-represented and warehouses were under-represented. The researchers developed weighting factors to adjust for recruiting biases. Compliance was assessed through plan review and field audits. Compliance of the mechanical systems was based on several factors including efficiency, sizing, the presence of economizer cycles, and the air transport factor (ATF) (Washington only). Compliance of lighting systems was based on interior lighting power density (LPD), exterior lighting budgets, and the existence of controls. The researchers interviewed both design professionals and building officials. They attempted to interview the architect, principal mechanical engineer, and principal lighting engineer for each building. They also spoke with general contractors, owner representatives, and lighting and mechanical equipment installers. They focused on code compliance responsibility and enforcement problems.

Program Findings: When this sample was weighted to account for stratification, compliance was estimated to be $47 \%$. Compliance by systems averaged $75 \%$. Large buildings often had poor levels of envelope compliance because of the high levels of glazing. LPD inspections are rare. Field changes that increased lighting levels were the largest single cause of lighting non-compliance. There is little relationship between compliance and the level of construction activity. Fifty. percent $(50 \%)$ of the architects said they were not involved with establishing energy code compliance, nor did they take the code into consideration during the design process. Code compliance was generally left to the mechanical engineers. Lighting designers favored the code. Few design professionals said that code compliance issues were a major factor in determining the mechanical or lighting system design. Only $6 \%$ said they received any feedback from code officials on energy code requirements; $12 \%$ of the sample participated in utility programs which provided either design assistance or rebates. Despite poor findings for compliance, most building officials believed the compliance in their jurisdictions was "good." Officials said energy code language was complex, ambiguous, and hindered the inspection process. Other issues were having enough time or personnel to enforce the code, coordinating inspection schedules with construction, and lack of a standardized, well-defined process for review and enforcement. The average building heat loss rate for the sample was about $12 \%$ below the code maximum with about $80 \%$ of the building meeting the envelope code. In Washington, the major cause for non-compliance was failure to meet the system sizing requirements.

Methodology Findings:

Program Recommendations: 1) Compliance levels would improve if the code were simplified. 2) Improved inspection and verification procedures are essential to the enforcement of the code. 3) Either code enforcement resources should be increased or the code should be revised to make enforcement simpler and interpretation less difficult.

Methodology Recommendations:

Comments: 
Document Number: 0100

Study Title: MCS Clearinghouse for Code Officials

Date: $10 / 00 / 87$

Study Sponsor: Bonneville Power Administration (BPA)

Authors: Lerman, D, A J Block

Building Type: $\mathrm{RC}$

Program Type, Code (C) or Utility (U): C

Evaluation Type, Process (P) or Impact (I): 1

Evaluation Purpose, Formative (F) or Summative (S): $S$

Part of Process Addressed: IC

Stakeholders Targeted: Code Officials

Program Description: in 1985 BPA funded the development of a Clearinghouse to serve as a center for the Model Conservation Standard (MCS) data and as a place to which code officials could turn for information. It included a Clearinghouse operated by the International Conference of Building Officials (ICBO) and a telephone hotline for each of the four states in BPA's service area.

Process Evaluation Method:

Impact Evaluation Method: BPA contracted with International Energy Associates Limited (IEAL) to evaluate operation of the Clearinghouse. Four main issues were to be addressed: 1) How the Clearinghouse was used and by whom; 2) how users evaluated the Clearinghouse; 3) why some potential users did not use it; and 4) what the effect of the Clearinghouse was on regional orientation to the MCS. IEAL interviewed 1) code officials at 16 MCS Earty Adopter jurisdictions; 2) 20 other jurisdictions selected from among both hotline users and non-users to capture demographic variation; 3) 20 Super Good Cents (SGC) coordinators; and 4) ICBO and MCS program staff at BPA, Northwest Power Planning Council staff, program and policy staff with Early Adopter jurisdictions and SGC utilities, personnel at the state energy offices, and staff at the Association of Cities in Washington and ldaho. Program Findings: The Clearinghouse was cited as the only central source of energy code information for code officials in the Pacific Northwest. 1) Between Jan. 1986 and Mar. 1987, jurisdictions placed 1,150 calls to the hotlines. 2) Hotline users tended to be large jurisdictions with relatively high levels of building activity. 3) Jurisdictions not using the hotline in Oregon and Washington were small cities with little building activity. 4) Hottine use was restricted in Idaho to four jurisdictions and in Montana just two, probably due to the limited code enforcement in most areas of those two states. 5) User jurisdictions were very happy with the competence of the hotline staffs and with quick responses to their questions. 6) Criticism of the Clearinghouse centered on the difficulty in using the Manual of Accepted Practices (MAP). 7) Jurisdictions made little use of the Clearinghouse library because they had not heard of it, services and holdings were not publicized, and the library was not conveniently located. 8) SGC utilities reported making only infrequent use of the Clearinghouse materials because of difficulty understanding how to use the materials. 9) There was general agreement that the hotline had reduced anxieties about energy codes. Involvement of ICBO increased the credibility of the MCS.

Methodology Findings:

Program Recommendations: 1) Continue funding the Clearinghouse. 2) Distribute a brochure for code officials describing the first two years of Clearinghouse operation, and including a section on library holdings and services. 3) Disseminate knowledge about the Clearinghouse to builders by providing a flyer on the program for code officials to give to builders. 4) Provide brief, in-person Clearinghouse orientation courses for SGC coordinators. 5) Inform utilities what the interpretations are, how they may be useful to utilities, and what is to be done with them. 6) Advertise library services more to increase Clearinghouse library use.

Methodology Recommendations:

Comments: 
Document Number: 0101

Study Title: Progress Evaluation of the Washington State Energy Code Program

Date: $12 / 15 / 91$

Study Sponsor: Bonneville Power Administration (BPA)

Authors: Barton, PJ, ML Carr

Building Type: R C

Program Type, Cocle (C) or Utility (U): C

Evaluation Type, Process (P) or Impact (I): $P$

Evaluation Purpose, Formative (F) or Summative (S): $F$

Part of Process Addressed: 1

Stakeholders Targeted: Code Officials, Builders

Program Description: In January 1990, the Washington State Legislature ordered the creation of new state-wide building codes. These codes specified conservation standards for all new residential and commercial buildings and created ventilation requirements applicable to some of these buildings. The Washington State Energy Code (WSEC) Program is intended to facilitate implementation of this new code. The program provides training, technical, and financial assistance to code enforcement officials and the construction community. This document reports on a progress evaluation conducted to establish the effectiveness of the WSEC program in facilitating full and timely implementation of the new codes.

Process Evaluation Method: People involved with the program administration and implementation were interviewed. The sample was selected to reflect geographic, demographic, climatic, historical, and political diversity. Legislation, working documents, contracts, and literature produced in support of the code program were reviewed. WSEO provided participant lists, data on building activity in the jurisdictions, and documentation on the office's activities to date. This information served to focus the inquiry and complement primary data collected through telephone surveys, field visits, and informal communication. Surveys were developed for each class of respondents. When possible, open-ended questions were used and respondents were encouraged to share their experiences with the new codes and impressions about how well program activities served their needs. Information was gathered by telephone and in-person interviews.

Impact Evaluation Method:

Program Findings: 1) The WSEC program appears to be successful in general. 2) There is not enough information available to draw definitive conclusions. 3) The existence of two energy codes - the Northwest Energy Code (NWEC) and the WSEC - has the potential to create confusion and delays in implementing the new code. 4) Confusion about the evolving role of the Bonneville Area Offices may adversely affect code implementation. Methodology Findings: The information contributed by participants, non-participants, and others involved with the WSEC provides insights on the important implementation activities of the program. The data suggest a set of steps necessary for full implementation of the code and a framework for identifying means to improve the program's operation. Since this is a preliminary evaluation of the early activity of the program, it excludes information about penetration, efficiency for enforcement, and performance of the structures built to the code. Focus is on the development of the human capital and institutional relationships necessary for full implementation and long-term sustainability of the code.

Program Recommendations: 1) A process evaluation should be conducted in approximately six months. 2) The WSEO should develop contingency plans to meet a potential increase in demand for its services between now and the end of December 1990. 3) Material lists need to be updated. 4) WSEO should focus on training goals, not program participation goals. 5) Training could be fine-tuned. 6) A formal role should be defined for the Area Offices. 7) Definitive code interpretations should be available through the hotlines. 8) Bonneville should quickly and clearly set policy for extending NWEC Program contracts.

Methodology Recommendations:

Comments: 
Document Number: 0102

Study Title: Implementation and Enforcement or Bonneville's Model Conservation Standards within Earty Adopting Jurisdictions

Date: $02 / 01 / 90$

Study Sponsor: Office of Energy Resources, BPA

Authors: Brown, M, S Cohn, J Kolb

Building Type: $R$

Program Type, Code (C) or Utility (U): C

Evaluation Type, Process (P) or Impact (I): I

Evaluation Purpose, Formative (F) or Summative (S): $S$

Part of Process Addressed: IE

Stakeholders Targeted: Code Officials

Program Description: This report evaluates the implementation, enforcement methods, and costs of BPA's Early Adopter Program (EAP). EAP was initiated in 1986 to help jurisdictions in the Pacific Northwest adopt energy-efficient, residential Model Conservation Standards (MCS).

Process Evaluation Method:

Impact Evaluation Method: Objectives of this phase II evaluation are to 1) further document the strategies used by Early Adopters to implement the MCS in their jurisdictions, 2) more accurately estimate the incremental time and cost associated with enforcing the MCS, and 3) identify changes in the implementation and enforcement activities that have resulted from learning on the part of builders and enforcement personnel. Using classification developed in the previous evaluation, each of the eight jurisdictions was categorized as using either an "interactive" (with a high level of interaction between code officials and builders) or "code-enforcement" (with only limited assistance and interaction) strategy to implement the MCS. The phase $1 /$ study includes four of the jurisdictions previously evaluated in phase I. Four 1988 Early Adopters were added to the evaluation to expand the variety of jurisdictions represented in the study and to document the experiences of jurisdictions implementing the MCS more recently. An accounting cost approach is used to estimate the incremental time and cost of the MCS enforcement. The incremental time of the enforcement personnel is measured and then multiplied by the cost of an energy-code specialist. Because of limited resources available for this study, opportunity costs are not quantified. Evaluation forms were the primary data gathering tools. The forms included 1) data forms for determining incremental time and cost and 2) an interview protocol for collecting additional information from each jurisdiction. Supplemental information was in the quarterly financial reports submitted to BPA by the sampled Early Adopters.

Program Findings: The code-enforcement strategy was found to dominate. Three of the eight jurisdictions use the interactive strategy. The total incremental time spent by interactive jurisdictions is almost twice that of code-enforcement jurisdictions. For each single-family (SF) home, interactive jurisdictions devoted approximately 9 hours on MCS-related enforcement activities, excluding travel time; code enforcement jurisdictions spent 5 hours. None of the four jurisdictions studied in phase I changed their implementation strategies between 1987 and 1989. There was some evidence of decreased implementation costs due to "learning" effects. Two of the four Phase I jurisdictions decreased their technical assistance time - one by $20 \%$ and the other by $50 \%$. Two of the four Phase l adopters showed a decrease between 1987 and 1989. Two reported no change in plan review times. Inspection times decreased for two of the Phase l adopters, increased for two adopters, and remained constant for the other three jurisdictions from 1987 to 1989. Total incremental time did not change significantly between 1987 and 1989 indicating that the overall magnitude of any learning effects was relatively small.

Methodology Findings:

Program Recommendations: 1) Measures should be taken to prevent duplication of efforts, inconsistent plan review, and inspection activities when an SGC utility co-exists with a jurisdiction administering the MCS; 2) BPA should consider the development and implementation of computer software as a mechanism for recording plan review and inspection activities; 3) BPA should encourage the use of the plan review and inspection data forms through financial penalties or incentives. Code officials mentioned four compliance areas where improved training and education is needed: 1) Better education packages are needed for owner-builders; 2) Increased radon monitoring and training is needed; 3) Window specifications need better identification; 4) Special training is needed for trades people - insulators, sheet rockers, and others; and it should be provided after regular business hours. BPA has instituted measures that address all but the last need. A training program for trades people is currently under development.

Methodology Recommendations:

Comments: 
Document Number: 0103

Study Title: New Residential Construction Compliance: Evaluation of the Washington State Energy Code Program

Date: 07/01/93

Study Sponsor: Bonneville Power Administration (BPA)

Authors: Warwick, M, A Lee, L Sandahl, D Durfee, E Richman

Building Type: $\mathbf{R}$

Program Type, Code (C) or Utility (U): C

Evaluation Type, Process (P) or Impact (l): P

Evaluation Purpose, Formative (F) or Summative (S): $S$

Part of Process Addressed: C

Stakeholders Targeted: Code Officials

Program Description: In 1990 the Washington State Legislature passed a residential energy efficiency code to be effective July 1,1992 . BPA supported passage and implementation, and contracted with the Washington State Energy Office (WSEO) to provide code implementation support to the building industry and code enforcement jurisdictions through the Washington State Energy Code (WSEC) program. The WSEC program was initiated in 1992 prior to the effective date of the WSEC. A previous evaluation by Pacific Northwest Laboratory (PNL) found that systems were in place to accomplish the training and other support planned under the WSEC program. However, few buildings had been constructed to the WSEC at the time and there was no basis for drawing conclusions about the success of the WSEC program in achieving code compliance. Those conclusions are the subject of this report. The objective was to assess the components of the program and determine the effectiveness of the WSEC program in terms of code compliance. Although implementation of the WSEC program is mandatory, participation in the program is voluntary.

Process Evaluation Method: Code compliance is difficult to measure and is rarely the subject of evaluation. This evaluation employed methods that relied on field data collected by WSEO to assess compliance. The WSEO data were drawn from a "construction" checklist used by WSEO to identify areas of code implementation that may require specific support in the training they provide. Using the checklist, data were collected for major construction activities and graded on compliance. Compliance was measured at the time of inspection, not at completion. Final levels of compliance were not checked. Therefore, conclusions drawn in this report may underrate final levels of compliance. PNL developed a method that translated these categorical measures of compliance into measures of heat transfer that could be used in a standard engineering model of heat loss. The model was developed to represent three common home designs and sizes. The WSEO data were translated into indices that reflected the fraction of savings achieved for each construction element in terms of whole heat loss. Local code officials, the BPA program manager, BPA area office cognizant program personnel, and the WSEO program manager were interviewed with both open-ended and closed-ended questions.

Impact Evaluation Method:

Program Findings: There is some level of non-compliance with the code. However, this is estimated to have little impact on the thermal performance of typical homes. Near complete achievement of the energy savings objectives of the WSEC was projected based on homes inspected in the first full year after implementation of the code. WSEC's role in achieving the result is unclear because it was not the first energy efficiency code in Washington, nor did it require a significantly different way of home building. In addition, BPA was promoting similar energy efficiency standards through voluntary adoption of enhanced codes by local jurisdictions and through building standands administered by utilities. As a result, differences in code compliance between jurisdictions that participated in the WSEC program and those that did not were not significant.

Methodology Findings:

Program Recommendations: 1) Training should be continued to ensure high levels of compliance. 2) Participation of builders and sub-contractors in training needs to be increased. A certification process might increase participation. 3) The WSEC needs to be revised to simplify implementation and to adapt it to building code revision cycles. 4) BPA should review the role of energy efficiency codes as resource acquisition mechanisms and adopt a clear policy regarding this role. 5) Energy efficiency should continue to be promoted to ensure market demand for energy-efficient homes and high levels of code compliance. 6) Code compliance can be evaluated and savings projected using qualitative measures.

Methodology Recommendations:

Comments: 
Document Number: 0104

Study Title: An Evaluation of the New York State Energy Construction Code Program

Date: 08/01/93

Study Sponsor: New York State Energy Office

Authors: NCSBCS

Building Type: $R$

Program Type, Code (C) or Utility (U): C

Evaluation Type, Process (P) or Impact (I): I

Evaluation Purpose, Formative (F) or Summative (S): $S$

Part of Process Addressed: I, C

Stakeholders Targeted: Code Officials, Architects, Engineers, Builders, Contractors, Suppliers

Program Description: The 1978 New York State Energy Conservation Construction Code Act set energy efficiency requirements for building construction including the design, selection, and installation of mechanical, electrical, and lighting systems and equipment. The New York State Energy Office (NYSEO) conducts energy code training workshops and provides technical assistance and binding interpretations of energy code requirements to ensure compliance. The NYSEO periodically reviews the energy code and develops amendments to ensure that it is cost-effective and responsive to changing design and construction practices, new industry standards, and improved equipment and materials.

Process Evaluation Method:

Impact Evaluation Method: This evaluation sought to 1) assess the extent to which energy code program goals and objectives had been achieved, 2) assess the general level of awareness and understanding of energy code requirements and compliance methods among design professionals and code enforcement officials, 3) determine the level of compliance with various energy code requirements, and 4) compare the estimated design heat loss of post-1987 one- and two-family residences with that of pre-1987 one- and two-family residences Two mail-administered surveys were used to determine the opinions, knowledge, and practices of design professionals and code officials regarding the energy code program. The surveys asked design professionals how they implemented the energy code and asked enforcement officials how they enforced it. They examined personal characteristics (title, job experience, jurisdiction), opinions of NYSEO services, and knowledge of specific energy code provisions. They asked each group to assess their colleagues' understanding of key provisions. On-site inspections were undertaken to see how the energy code was being implemented in the field. This research was considered the most effective method of determining the degree to which actual construction reflected energy code requirements.

Program Findings: 1) Code officials and design professionals rely heavily on energy office technical staff, seminars, and literature for energy code information and assistance and more assistance is needed. 2) Insufficient information on submitted plans is a major obstacle to determining code compliance. 3) Supplier/manufacturer information is a major tool design professionals use to judge residential HVAC and DHW compliance. 4) The majority of post-1987 homes inspected comply with the energy code's overall heat loss requirement. 5) The progressively more stringent energy code has increased the efficiency of residential structures throughout New York. On-site inspections show that over three-quarters of new one-and two-family residences meet higher standards than the energy code requires, suggesting an upward movement of the energy-efficiency baseline.

Methodology Findings:

Program Recommendations: 1) The NYSEO should continue its efforts to simplify and explain the code; increase emphasis on thermal rating, acceptable practice, alternate design, residential HVAC, etc.; and increase its energy code-related training efforts. 2) Investigate methods to improve submitted plans to permit more effective compliance evaluation. Designers and code officials should be required to use a standardized form for documenting equipment and building specifications, which could help code officials determine compliance. 3) The NYSEO should continue to promote its appliance directories. It also should consider additional ways to help suppliers and manufacturers provide energy savings information about their products and increase efforts to inform suppliers and manufacturers about code requirements. 4) Increase training activities and provide additional implementation tools. The NYSEO should also investigate possibilities for an increased role in enforcement of the energy code. 5) Continue to expand the scope of the energy code and strengthen its requirements as more effective energy conservation techniques become widely available and economically reasonable.

Methodology Recommendations:

Comments: 
Document Number: 0105

Study Title: A Study of Compliance with the Lighting Provisions of the Minnesota State Building Code for Small Commercial Buildings

Date: $10 / 01 / 94$

Study Sponsor: Minnesota Department of Public Service

Authors: Gentilini, L, D Bohac, T Dunsworth, M Hewett

Building Type: $\mathrm{C}$

Program Type, Code (C) or Utility (U): C

Evaluation Type, Process (P) or Impact (I): I

Evaluation Purpose, Formative (F) or Summative (S): $S$

Part of Process Adidressed: IE

Stakeholders Targeted: Lighting Designers, Contractors, Code Officials

Program Description: In May 1991, the state of Minnesota implemented an energy code that required the lighting power budget of commercial buildings to comply with the Code of Federal Regulations (CFR) Title 10, part 435.103. The CFR contains minimum requirements for lighting equipment and two alternative compliance procedures, prescriptive and system performance, for the design of building lighting and lighting control systems. In 1992, the Minnesota Department of Public Service (DPS), supported by the U.S. Environmental Protection Agency, contracted the University of Minnesota to develop a series of educational seminars geared toward groups involved in ensuring that building codes are implemented. The goals of this study include an evaluation of the effectiveness of the workshops as well as the results of a comprehensive study to determine the following: 1) the effectiveness of the implementation and enforcement of the Minnesota Energy Code lighting standards; 2 ) the influence of previous knowledge, training, enforcement, market conditions, and other variables on the energy efficiency considerations in the design and installation of lighting systems; 3 ) the resources that would be required to ensure that lighting installations meet minimum energy efficiency criteria; and 4) the costs and benefits of adequate training of people who design, install, and inspect lighting systems.

Process Evaluation Method: There were two surveys of lighting designers and contractors and code officials. In addition, plan reviews and site visits were conducted to determine compliance.

Impact Evaluation Method:

Program Findings: The estimated compliance rate for the buildings was $50 \%$. There was a $42 \%$ compliance rate from site visits, but when including the lighting standard, compliance dropped to the range of $10 \%-14 \%$. Each survey group said that there was a need for more uniform enforcement supported by adequate funding. The code needs to be modified to make it simpler and clearer. There was no demonstrable effect on the buildings reviewed, and the designers and contractors generally gave the seminars fairly low marks in terms of actually bringing about changes in their behavior.

Methodology Findings:

Program Recommendations: It appears the seminars with this particular type of content and marketing approach are not the most promising approach. General changes in industry practices, utility rebate programs, adoption of revisions to the code, and active enforcement of these are the major factors leading to increased compliance. These aspects should be investigated more as opposed to seminars. Other types of conservation programs are possible as well, but their development will require innovative thinking about program contents, delivery mechanisms, and funding. To make them succeed it will be necessary to cultivate support from key parties that may be resistant to suggestions. These parties include regulators, electric utilities, code officials, and trade allies at all levels.

Methodology Recommendations:

Comments: 
Document Number: 0106

Study Title: Evaluation Results for MCS Code Adoption Demonstration Project, Vol. I

Date: $12 / 01 / 85$

Study Sponsor: Bonneville Power Administration (BPA)

Authors: McCutcheon, L, G Cullen, S Scott, C Snow, C McDonald, D Hussey

Building Type: R C

Program Type, Code (C) or Utility (U): C

Evaluation Type, Process (P) or Impact (I): $P$

Evaluation Purpose, Formative (F) or Summative (S): $F$

Part of Process Addressed: I

Stakeholders Targeted: Code Officials

Program Description: BPA has been conducting research to evaluate the new Model Conservation Standards (MCS) directed toward reducing electrical energy consumption of new electrically-heated residential and commercial buildings. The objectives of this study were 1) to recommend a testing method that can be used in the field to monitor compliance with MCS, and 2) to estimate incremental time and cost for enforcing compliance among jurisdictions which are early adopters of MCS.

Process Evaluation Method: Four types of testing techniques were available for measuring compliance: inspections during the construction process, audits, blower door tests, and infrared thermography tests. The decision was made to concentrate evaluation efforts on the last three methods. In-depth field testing of all three post-construction methods was carried out on a small sample of MCS homes. The data collected provided the basis for evaluating the methods. It was decided to generate one measure of pass/fail by coding and reducing all the information and modeling the home with the WATT-SUN model, a steady-state thermal transmittance program capable of simulating energy consumption of residential buildings. A comparison of space heating load results would determine whether the building was in "true" compliance or not. For measuring the incremental time and cost of enforcing MCS, building department personnel of early adopter communities were asked to maintain logs of all time spent specifically on MCS enforcement. This included desk time explaining the codes, time spent reviewing plans, and inspection time. The data were collected at the end of eleven weeks. Estimates of incremental time and cost due to MCS enforcement were derived from these data.

Impact Evaluation Method:

Program Findings: The results of the analysis were inconclusive in terms of providing a single recommended method for spot-checking compliance. Fewer than $60 \%$ of WATT-SUN based compliance assessments were correctly predicted by any of the three tests. This is not surprising since each of the three tests measures different, mutually exclusive MCS code requirements. On the basis of WATT-SUN runs, the average home's space heating load was very close to code requirements. The average home consumed $9.6 \%$ more than the code required. Results showed that the total time spent on enforcement per house was approximately seven hours. At a rate of $\$ 14.48 / \mathrm{hr}$., and considering the average fully burdened rate of building inspectors involved, the incremental cost of MCS is approximately $\$ 120 /$ home.

Methodology Findings: The subjectivity in evaluating thermography results is one area in which the reliability of the testing and analysis methods used in this project might be improved.

Program Recommendations: The results of this research should be viewed with some caution because the sample sizes were very small.

Methodology Recommendations:

Comments: 
Document Number: 0107

Study Title: Getting to Code: Economic Costs and Benefits of Developing and Implementing Washington State's Residential Energy Code

Date: $07 / 01 / 93$

Study Sponsor: Washington State Energy Office (WSEO)

Authors: Schwart, H, R Byers, and A Mountjoy-Venning

Building Type: $R$

Program Type, Code (C) or Utility (U): C

Evaluation Type, Process (P) or Impact (I): I

Evaluation Purpose, Formative (F) or Summative (S): $S$

Part of Process Addressed: I

Stakeholders Targeted: Home Builders, Building Officials, Local Government Officials

Program Description: In 1986, the Washington legislature passed a law requiring upgrading the Washington State Energy Code (WSEC) about halfway from the 1980 code to the proposed Model Conservation Standards (MCS) level and requiring further studies to determine the cost effectiveness of the MCS. In 1990 the legislature passed a law requiring WSEC to be raised to MCS levels. Other provisions of the legislation required BPA to provide owners of new buildings with payments to offset the incremental costs associated with the new code.

Process Evaluation Method:

Impact Evaluation Method: The analysis consisted of three steps: 1) compiling data about BPA expenditures, 2) estimating energy savings, and 3) analyzing the cost per $\mathrm{kWh}$. To determine BPA expenditures the following were considered: relevant programs and expenditure data, estimated expenditures, and future expenditures for each project. The BPAWSEO programs considered were those to move the state toward adoption of the code or to implement it successfully. Energy savings were estimated using the baseline efficiency, the number of efficient housing units built, and the energy savings per unit. Two methods were developed to calculate energy savings. The two methods provided a range of probable savings. First is the WSEO/NPPC method. It uses the 1980 WSEC as a baseline. Annual energy savings are accumulated through the year 2003 by using actual housing starts data and forecasts. To calculate annual energy savings, savings were calculated per unit per year first. The BPAOak Ridge National Laboratory (ORNL) method was the second one used. It did not compare prototypical 1986 WSEC and MCS/1991 WSEC houses to a single baseline of the 1980 WSEC. Instead it compared actual energy consumption for a sample of houses built to MCS to energy consumption in a sample of 1987 non-MCS houses. Therefore, this method compares MCS with current practice. Estimating the cost per $\mathrm{kWh}$ was done using three criteria: cost to BPA, total societal cost, and value of conserved energy. The value of conserved energy was estimated by running the Integrated System for Analysis of Acquisitions (ISAAC) model.

Program Findings: Using data from the 1989 WSEO study (Cost-Effectiveness of Residential Building Energy Codes), it was estimated with the WSEO/NPPC method that the 1986 energy code saved $1.7 \mathrm{kWh} / \mathrm{sq}$. ft./year in Western Washington (climate zone 1) and $2.39 \mathrm{kWh} / \mathrm{sq}$. ft./year in Eastern Washington (climate zone 2). The same study estimates additional savings from the 1991 code at 1.17 and $1.84 \mathrm{kWh} / \mathrm{sq}$. $\mathrm{ft} /$ /year for climate zones 1 and 2 respectively. Based on average unit sizes, cumulative savings through 2003 were calculated for all electrically heated units built each year. Total savings were estimated at 163.9 aMW. The ORNL method estimates that MCS homes consume $0.9 \mathrm{kWh} / \mathrm{sq}$. $\mathrm{ft}$. less electricity than non-MCS homes. Total savings are estimated to be 150.5 aMW. The cost to BPA using the high and low energy savings estimates ranges between $2.7 \mathrm{mills} / \mathrm{kWh}$ and $2.9 \mathrm{mills} / \mathrm{kWh}$. Total resource cost was found to be between 18.6 and $20.3 \mathrm{mills} / \mathrm{kWh}$. The value of conserved energy was estimated to be $31.2 \mathrm{mills} / \mathrm{kWh}$. The program is estimated to save between 150.5 aMW (BPAORNL method) and 163.9 aMW (WSEO/NPPC method) for all electric utilities in Washington state through 2003.

Program Recommendations:

Methodology Findings: Savings that houses will provide beyond 2003 or savings attributable to houses built after 2003 were not included in the estimation of total savings from implementing the MCS/1991 WSEC so the benefits are underestimated.

Methodology Recommendations:

Comments: 
Document Number: 0108

Study Title: Evaluation of the Enforcement Costs of the Washington State Commercial Energy Code

Date: 01/01/87

Study Sponsor: Bonneville Power Administration (BPA)

Authors: O'Neill \& Company, Inc.

Building Type: $C$

Program Type, Code (C) or Utility (U): C

Evaluation Type, Process (P) or Impact (l): IP

Evaluation Purpose, Formative (F) or Summative (S): $S$

Part of Process Addressed: I C E

Stakeholders Targeted: Local Jurisdictions

Program Description: In 1979, the Washington legislature passed legislation to develop a state energy code. The Washington State Energy Code (WSEC) is designed to provide minimum standards for new or altered commercial buildings and structures for the efficient use of energy. The code provides three methods of meeting the minimum energy-efficiency standards: the prescriptive design path, the component performance design path, and the energy budget design path.

Process Evaluation Method: The purpose of this study was twofold: to better understand the enforcement practices of local jurisdictions and to estimate the costs of enforcing the commercial energy code in Washington. This study excluded jurisdictions that enforce any other commercial code. Twenty jurisdictions were chosen in the state based on location, enforcement method, commercial building activity, and population. Twenty jurisdictions were retained for the study after the selection process. The first phase in the study was the development of an overall evaluation design and methodology. Procedures for data collection were defined as well as the format and content of the reports to obtain data on the costs incurred by local jurisdictions to enforce the code. The second phase in the study was data collection. Enforcement practices of the energy code and costs of implementation were evaluated. Tasks included administering a survey through the mail, follow-up telephone calls, and key informant interviews. The work was coordinated closely with the Association of Washington Cities (AWC). Impact Evaluation Method: See Process Evaluation Method.

Program Findings: The study made major findings classified in three categories. (A) Amount, location and type of commercial building activity. 1) The large counties in Washington had $50 \%$ more commercial building activity than the large cities while medium-size cities' building levels outpaced the counties with similar populations. 2) Because of the poor economy in rural Washington, many counties did not have any commercial building activity in the year prior to this report. 3) Almost $80 \%$ of the commercial buildings were under 10,000 sq. $f t$. and had simple mechanical and lighting systems. (B) Characteristics of people who enforce the commercial energy code: 1) Most people who were responsible for the commercial energy code did not feel adequately trained or educated to enforce it. 2) Most people involved in code enforcement had been in position a long time and planned to stay until they retired. 3) Most building enforcement personnel had had some college education but only half completed a degree. 4) Most building code enforcers had come from the construction trades. 5) Enforcement officials code were a dedicated group who felt a great deal of responsibility towards their jobs. (C) Code enforcement. 1) Except for the insulation and glazing requirements, the commercial energy code was not being well enforced. 2) Most jurisdictions reviewed the commercial building plans themselves. 3) The quality of the plans submitted was the most important factor in determining the amount of review time needed. 4) The costs of the current energy code enforcement averaged approximately $5 \%$ of the overall cost of enforcing all building codes. 5) More on-site training for officials would improve code compliance. 6) Most officials liked the Energy Hotline.

Methodology Findings: A few jurisdictions were extremely hard to contact or simply did not have time to fill out the survey or offer an interview. A few smaller areas had no commercial construction during 1986. Due to these circumstances, other jurisdictions were added.

Program Recommendations: 1) Training of code officials should be continued, targeting jurisdictions with large amounts of commercial buildings for intensive one-on-one training. 2) A central plan review service should be offered. 3) An index system for the energy code should be developed. 4) Easy enforcement tools for building officials should be developed. 5) Training should be provided to engineers and architects. 6) One code enforcement reimbursement level should be established.

Methodology Recommendations: The study suggests that follow-up telephone calls combined with key informant interviews are a strong strategy to supplement data previously collected by mail surveys.

Comments: 
Document Number: 0109

Study Title: Capturing Lost Opportunities in Residential New Construction

Date: 01/01/95

Study Sponsor: Georgia Power Company (GPC)

Authors: Gunel, I, R Moe of Synergic Resources Corporation (SRC) and M Stewart of GPC

Building Type: $R$

Program Type, Code (C) or Utility (U): $U$

Evaluation Type, Process (P) or Impact (I): I

Evaluation Purpose, Formative (F) or Summative (S): $S$

Part of Process Addressed: I

Stakeholders Targeted: Utilities

Program Description: GPC has been actively promoting energy efficiency in new homes since the 1970's. By 1993 program efforts had been expanded, through a comprehensive approach under the Residential Energy Efficiency Program (REEP) consisting of the Super Good Cents (SGC) program, the Good Cents (GC) program, and the Individual Measures (IM) program. SGC promotes the highest energy efficiency levels in new construction through specific efficiency measures. GC promotes and educates builders on a package of energy-efficiency features that exceed the building code requirements. IM provides incentives for installation of specific energyefficiency features in homes that do not meet all of the $G C$ requirements.

Process Evaluation Method:

Impact Evaluation Method: GPC's 1993 RNCP was evaluated using conditional demand analysis to estimate gross energy impacts, load analysis methodology to estimate gross load impacts, and builder survey analysis to estimate free rider and free driver rates for the program. Data came from a 300 home program participant sample and $\mathbf{3 0 0}$ home non-participant sample. Program participants were stratified by program, housing type, HVAC system type, and weather zone. Strata sample size were proportional to the engineering estimate of savings in each stratum. A random sample was selected within each stratum. The sample of non-participants was selected using a list of new accounts in GPC's billing system and they were stratified. Telephone surveys of participants and non-participants provided structural, equipment and occupant demographics information. Monthly billing data and hourly outdoor temperature data were also obtained. To estimate load shape impacts, a sample of 60 program participants was selected and stratified and the load data recorders were installed, collecting data for 9 months. Additional data were collected by on-site surveys. SRC conducted telephone surveys of a sample of builders to analyze free ridership and free drivership in the program. The average unit gross energy impacts of the program were estimated econometrically. A participant model was estimated using discrete choice methods and it was used to compute self-selectivity corrections. Then, a conditional demand model was estimated. Annual gross energy impacts were estimated by combining the conditional demand model parameters with estimates of typical weather data. Initial estimates of the average annual load shapes were developed in an econometric analysis. Final estimates of the average unit load shape impacts of the program were developed by calibrating the initial estimates to be consistent with estimates of average full-year gross unit energy savings. The load shape impacts were estimated as the difference between the final load shape estimates for participants and non-participants. Rebound effects and persistence were estimated based on previous studies.

Program Findings: 1) Gross Energy Impacts. Aggregating across HVAC system type gives unit savings of 3,752 $\mathrm{kWh}$ per year for SGC homes. The unit gross energy impact estimates for typical GC participants range from 712 $\mathrm{kWh}$ (multifamily with split systems), to $3,298 \mathrm{kWh}$ (single family, heat pumps). Percentage savings ranged from $18 \%$ to $20 \%$ for a typical GC participant. Across all housing and system types the estimated average GC savings is 2,576 kWh. 2) Gross Load Shape Impacts. Unit savings are typically about $45 \%$ of the non-participant load. 3) Other Effects. (a) Free rider rates for the GC and SGC programs were estimated to be $75 \%$ and $20 \%$ respectively. (b) Although free driver effects were possible, they were estimated to be zero for both programs. (c) Rebound effects of both programs are zero. Program homes built in 1993 saved about 5,400 MWh of net energy and $2.2 \mathrm{MW}$ of net demand in a normal weather year. Without including administration costs, the SGC, the $G C$, and the IM programs had a benefit/cost ratio of 1.34, 2.01, and 1.52, respectively, under the Total Resource Cost (TRC) test. Including the overall program delivery costs, however, the 1993 Residential New Construction Program fails the TRC test with a benefit/cost ratio of 0.67 .

Methodology Findings:

Program Recommendations:

Methodology Recommendations:

Comments: 
Document Number: 0110

Study Title: Reviewing the Past and Refining the Future: Evaluations in Resource Planning

Date: 01/01/95

Study Sponsor: Northwest Power Planning Council (NPPC)

Authors: Gardner M, F Gordon and M Quaid

Building Type: $C R$ other

Program Type, Code (C) or Utility (U): $U$

Evaluation Type, Process (P) or Impact (I): P I

Evaluation Purpose, Formative (F) or Summative (S): $F$

Part of Process Addressed: D

Stakeholders Targeted: NPPC, Utilities, State Energy Offices, Bonneville Power Administration (BPA)

Program Description: The NPPC has the responsibility to develop a least-cost plan for electricity for the Pacific

Northwest region. Prior estimates of conservation resources have relied on information in the region's utility program evaluations. Since evaluations have become numerous, the NPPC began creating a database of evaluation reports for the region. Almost 400 evaluations from the Northwest were collected; these were primarily sponsored by utilities, state energy offices, and BPA. From the 400 evaluations collected, 100 were selected to be included in the database, which is a module of the Northwest Utility Conservation and Tracking System (NU-Trak). The evaluations were selected because they focused on resource planning studies.

Process Evaluation Method: The methodologies used varied across the studies.

Impact Evaluation Method: The methodologies used varied across the studies.

Program Findings: A range of programs was covered by the evaluations.

Methodology Findings: Most of the 100 evaluations tended to be impact rather than process evaluations. In general, they failed to meet the needs and desires of resource planners due to limited study budgets. All the impact evaluations reviewed included savings data, but many presented results in one lump amount, which was not useful for planning. Where available, unit savings were not always in the units most useful for planning. Cost data were not always presented in the evaluations, were sometimes listed per unit, and were not always in the most useful units for resource planning. Cost data were often presented in the evaluations in terms of utility cost, but not overall measure cost, which is important for planning entities using the societal cost test. Data on program penetration were sometimes in the process evaluation, sometimes in the impact evaluation, and sometimes in neither. When present, estimates of free ridership were in either the process or impact evaluation, depending on whether the estimate was based on a survey or comparison study. Program goals, constraints, and maturity were often described in process evaluations. Where no process evaluation was conducted with an impact evaluation, it was sometimes difficult to understand the context for impact studies. Data on building or facility types were presented more frequently in recent studies. Residential evaluations often described measure type, while commercial and industrial evaluations usually described only end-uses where conservation took place. Evaluations based on engineering.estimates can be quite useful for calibrating end-use forecasting models, but the evaluations often failed to publish the critical details. The data from the evaluations revealed some patterns regarding information availability. While many evaluations presented data in a useful form for planning, absence of context, unclearly defined units and, in some cases, absence of fundamental information, limited the usefulness of many other evaluations. However, very recent evaluations are escaping these pitfalls.

Program Recommendations:

Methodology Recommendations: Evaluators would be of better service to planners if the following basic precepts were followed: 1) document the context for the program; 2) document the context for the market, even if it sometimes requires borrowing data from customer surveys, resource studies, etc.; 3) where practical, synchronize process and impact evaluations; 4) where engineering analysis is part of an evaluation summarize and show the detailed performance parameters; and (5) in process evaluations, describe the success of the program in effectively delivering technologies.

Comments: 
Document Number: 0111

Study Title: PG\&E's 1992 Residential New Construction Program (RNC) Impact Evaluation

Date: 01/01/95

Study Sponsor: PG\&E

Authors: Caulfield, TO, AG Lee, and F Harrison

Building Type: $\mathbf{R}$

Program Type, Code (C) or Utility (U): U

Evaluation Type, Process (P) or Impact (I): 1

Evaluation Purpose, Formative (F) or Summative (S): $S$

Part of Process Addressed: I

Stakeholders Targeted: PG\&E, Builders

Program Description: PG\&E's RNC program consisted of two components - the California Comfort Home (CCH) and High Performance Window (HPW) programs. The RNC program was designed to deliver significant summer energy savings and peak reduction. The program offered incentives to builders for installing energy-efficient features exceeding California's Title-24 (cooling budget) efficiency standards by at least $10 \%$.

Process Evaluation Method:

Impact Evaluation Method: The evaluation (by Quantum Consulting Inc. (QC)) integrated engineering estimates, load data, and billing analysis to estimate program savings. The evaluation uses three analysis steps: 1) the engineering analysis, which estimates energy and demand impacts in the absence of participants' behavioral responses, 2) the statistical billing analysis, which estimates $\mathrm{kWh}$ realization rates and accounts for participants' occupancy patterns and behavioral responses to program measures and changes in baseline energy usage through use of a comparison group, and 3) the load analysis, which produces end-use-specific estimates of demand ( $\mathrm{kW}$ ) impacts and diversity factors. These estimates were used to calibrate the engineering models. The integrated analysis combines outputs of the intermediate analyses. Five key data sources were used in the evaluation: the PG\&E tracking system, customer survey data, builders survey data, builders surveys, PG\&E billing data, and load data. Participants were segmented by climate, building type, and program component.

Program Findings: Overall, the 1992 RNC program resulted in substantial net electrical $(7.0 \mathrm{GWh}$ and $6.5 \mathrm{MW})$ and gas (613 kTherms) savings with an estimated Total Resource Cost (TRC) ratio of 1.4 and 1.7, respectively. The most prominent single finding was the dominant effect that air conditioner SEER improvement had on electric energy and demand impacts. SEER improvements accounted for $67 \%$ to $72 \%$ of the cooling energy savings, and $44 \%$ to $51 \%$ of the demand savings. The demand impact evaluation indicated a total adjusted gross peak demand impact of $6.5 \mathrm{MW}$, which is higher than the $5.7 \mathrm{MW}$ projected. The off-peak demand impact is estimated to be about $2.0 \mathrm{MW}$. The evaluation estimate of winter gas savings exceeds the program estimate, while evaluation estimates of summer electrical energy savings are less than the projected impact. The higher heating energy impact is mainly attributable to the HPW program component. The differences in impacts between climate zones illustrate the variety of home construction practices used by builders. The 1992 RNC program's net-to-gross ratio provides an indication of how the program changed builders' compliance with the standards. The 1992 PG\&E RNC program appears to have greatty influenced builders to construct more energy-efficient homes than they had built historically.

Methodology Findings: The difference between the pre-program and evaluation estimates of gas savings may be partially attributable to the methodology.

Program Recommendations:

Methodology Recommendations: Future research efforts should focus on tracking heating differences resulting from upgraded equipment - furnaces, insulation, and windows - since the combination of these factors appears to have produced an unrealistically low initial therm savings estimate.

Comments: 
Document Number: 0112

Study Title: Moving the New Construction Baseline? A Regional Approach to Assessing the Market Impacts of the Energy Crafted Home Program

Date: 01/01/95

Study Sponsor: Unknown

Authors: Gondek, C, H Powell, A Sorrentino, R Wirstshafter

Building Type: $C R$

Program Type, Code (C) or Utility (U): $U$

Evaluation Type, Process (P) or Impact (I): I

Evaluation Purpose, Formative (F) or Summative (S): $F$

Part of Process Addressed: D

Stakeholders Targeted: Electric Utilities, Builders, Architects, Home Buyers

Program Description: In June 1995, five New England electric utilities completed a comprehensive analysis of the regional residential new construction market. The research assessed current market conditions, detailed building practices, and attempted to isolate factors influencing energy-efficiency choices by builders, architects, home buyers, and others. A major interest in the study was to establish a link between the Energy Crafted Home $(E C H)$ program and possible spillover of program-stimulated efficiency techniques and building practices into the regional residential market. The ECH program was initiated by four of the five project sponsors in 1991. This program has the objective of transforming the regional new-home market.

Process Evaluation Method:

Impact Evaluation Method: The research methodology established a common ground for meeting the needs of the sponsoring utilities and achieve the three major objectives of the study: 1) estimate current residential baseline practices, 2) characterize the regional residential new construction market and identify infiuences that shape it, and 3) estimate past, current, and future impacts of residential DSM construction programs. Four complementary approaches were utilized to address the primary research objectives: 1) a telephone survey of regional builders; 2) extensive on-site audits of 195 homes (fossil and electrically heated) built between 1991 and 1995 ; 3 ) a home owner/renter survey completed concurrently with the on-site audits; and 4) in-depth interviows with architects, financial institutions, building material manufacturers and distributors, and building code regulators. Program Findings: (1) For the electric heat market, the study had two main findings: First was the existence of two unique market segments characterized by distinct building practices, technologies, and priorities. In the first segment - smaller homes and apartments - electric resistance heat is installed to minimize initial construction costs. The second sub-market consists of larger, often custom homes with numerous amenities. These homes often use ground source heat pumps. The second critical finding was the identification of the low penetration of electric heat in the regional new construction market. The average electric heat share for the entire study area was found to be $4.15 \%$. Surveyed builders, real-estate agents, subcontractors, and other market participants shared the perception that electric heat was increasingly unpopular. Consumers and most market players had the perception that operating costs of electric heat were much higher than those of fossil-fuel systems. Some attributed this perception to poor construction practices and inefficient electric heating systems installed during the mid-1980s. (2) The study made two major findings regarding code compliance. First, building codes are a good proxy for baseline building practices for all fossil-fuel homes and electrically heated homes under 1,900 sq. $\mathrm{ft}$. Second, code compliance was fairty good. (3) Home buyers vastly overestimate the costs of efficiency measures. The survey confirmed that buyers rank energy efficiency relatively low in the hierarchy of desirable home characteristics. Buyers perceived energy-efficiency measures to be very costly. They are more aware of efficient windows and ceiling and wall insulation than any other energy-efficient measures. However, there is little relationship between customer demand and the measures that net the greatest savings. Demand for installed energy-efficiency measures is driven more by the home buyers than the builders or architects

Methodology Findings: This study produced solid information regarding the current building practices against which changes can be measured. To assess the impact of program spillover, it is necessary to track changes in construction practices and the cause for the changes on a regular basis.

Program Recommendations: Utilities must increase home buyer awareness of actual measures and efficiency benefits of $\mathrm{ECH}$ program certification.

Methodology Recommendations: A time series approach should be used. Quick builder surveys should be implemented that address how current practices are changing and the motivations for these changes.

Comments: 
Document Number: 0113

Study Title: The Demise of Residential New Construction Programs: Is there Life After Death?

Date: 01/01/95

Study Sponsor: Assistant Secretary for Energy Efficiency and Renewable Energy, Office of Utility Technology (DOE)

Authors: Vine, EL.

Building Type: $R$

Program Type, Code (C) or Utility (U): U

Evaluation Type, Process (P) or Impact (I): I

Evaluation Purpose, Formative (F) or Summative (S): $S$

Part of Process Addressed: I

Stakeholders Targeted: Investor-owned Utilities

Program Description: This project under the Database on Energy Efficiency Programs (DEEP) evaluated 10 residential new construction programs (RNCPs) sponsored by investor-owned utilities in the United States. DEEP's goal is to compile and analyze the measured results of energy-efficiency programs in a consistent and comprehensive fashion.

Process Evaluation Method:

Impact Evaluation Method: A literature review and consultations with DSM program experts on RNC programs were conducted.

Program Findings: When weighted by energy savings, it was found the average Total Resource Cost (TRC) of the 10 RNC programs in the sample is $\$ 0.07 / \mathrm{kWh}$; the median is $\$ 0.25 / \mathrm{kWh}$. All costs are expressed in 1994 dollars. The standard deviation of the TRC was large, reflecting the diverse performance of these programs. Overall the RNCPs were not found to be cost-effective. Several utilities in the DEEP project terminated their programs, significantly modified their programs (e.g., eliminating incentives and focusing on information and design assistance), or reduced their program budgets. Based on interviews with program managers and evaluators, DEEP project staff found three significant reasons that explain the low cost-effectiveness of RNCPs: 1) increased tightening of state building standards and national appliance standards have improved the baseline; 2 ) inadequate marketing strategies have reduced impacts; and 3) energy savings calculations have failed to include induced savings by nonparticipants and from non-program activities undertaken by participants.

Methodology Findings:

Program Recommendations: Utilities must take advantage of opportunities for improving the economics of RNC programs, including the incorporation of energy savings from program spillover. The results of DEEP suggest four strategies for improving the cost-effectiveness of RNCPs: (1) reduce program marketing costs and develop more effective marketing strategies, (2) promote technologies and advanced building design practices significantly exceeding state and federal standards, (3) recognize these programs' role in increasing compliance by participants with existing state building codes, and (4) obtain "energy-savings credit" for program spillover impacts.

Methodology Recommendations:

Comments: 
Document Number: 0114

Study Title: A Cross Sectional Analysis of Commercial New Construction Impact Evaluations

Date: 01/01/95

Study Sponsor: Unknown

Authors: Alereza, T and C Chappell

Building Type: $C$

Program Type, Code (C) or Utility (U): U C

Evaluation Type, Process (P) or Impact (I): I

Evaluation Purpose, Formative (F) or Summative (S): $S$

Part of Process Addressed: D I C E

Stakeholders Targeted: Utilities

Program Description: During 1993 and 1994, four utilities' commercial new construction programs were evaluated to explore the effect of program design features, baseline building codes, and service territory on building code compliance, program effectiveness, and free-ridership. The four programs evaluated were 1) San Diego Gas \& Electric's (SDG\&E) Title 24 Plus Incentive Program, 2) Southern California Edison's (SCE) Design For Excellence Incentive Program, 3) British Columbia Hydro's (B.C. Hydro) New Building Design Program, and 4) Portland General Electric's (PGE) Energy Smart Design Program.

Process Evaluation Method:

Impact Evaluation Method: The studies examined closely the energy savings for the program participants and estimated the realized gross program savings. The components of each study were building a sample, conducting telephone surveys, collecting site data, validating an energy model, calculating gross savings, and conducting a net-to-gross analysis. For the SCE and B.C. Hydro evaluations, the authors used a stratified sampling scheme. For the SDG\&E and PGE evaluations, they used a census. The site data collection was done through a high-resolution survey process with an in-depth interview with building operators to obtain operating schedule and management data. Building simulation were performed to estimate energy usage and demand under different assumptions about equipment, building construction and operating conditions. Gross energy savings were obtained as differences in energy use calculated from parametric simulation runs. The lack of a "before" condition with new construction projects necessitated creation of a suitable energy-use baseline for comparison with the energy use with the program measures. For the four evaluations, two alternative baselines were defined. One was the level of energy efficiency established by building energy efficiency standards. The second used participant and non-participant buildings to determine characteristics of new buildings in the utilities' service territory.

Program Findings:

Methodology Findings: lissues such as baseline selection, isolation of individual measure impacts, and free-ridership rate estimation were explored in this research. The lack of a "before" condition with new construction projects necessitates the creation of a suitable energy-use baseline for comparison. As the baseline for a new construction program, building standards are useful for several reasons: 1) program planners use the standards as a way to estimate the energy efficiency of typical new construction by assuming that new buildings are generally built to just meet the code; 2 ) program designers can use the standards to describe the basic level of energy efficiency legally required in a building and can also use code mechanisms to determine efficiency levels that exceed the standards; 3 ) implementers and building designers are familiar with code requirements and compliance procedures and therefore have a common language to understand the incentive program's efficiency recommendations; 4) builders, designers and building owners can identify the costs and benefits of the incremental measures to improve energy efficiency because they know basic code requirements. Disadvantages to using the building code to define baseline conditions include the following: 1) the assumption that buildings are built to just meet the code may be flawed - buildings can either be built better than the code or be constructed so that they do not meet the code; 2 ) the building code offers building designers several compliance approaches, but these approaches do not necessarily produce the same efficiencies when applied to a particular building; and 3) certain building types may be exempt from the standards.

Program Recommendations:

Methodology Recommendations: Efforts must be made to persuade nonparticipants to participate in the evaluation studies. To accomplish this, the benefits of the data collection and the program analysis must be explained carefully to the customers. Educating customers on the program evaluation will increase program awareness, energy-awareness, and the long-term success of the program.

Comments: 
Document Number: 0115

Study Title: Process Evaluation of the Non-Integrated Areas Pilot Program

Date: $09 / 01 / 92$

Study Sponsor: B.C. Hydro

Authors: Resource Management International, Inc. (RMI); B.C. Hydro's Evaluation Department

Building Type: $R$

Program Type, Code (C) or Utility (U): U

Evaluation Type, Process (P) or Impact (I): $P$

Evaluation Purpose, Formative (F) or Summative (S): $S$

Part of Process Addressed: I

Stakeholders Targeted: Home Owners

Program Description: From March 1990 to March 1992, B.C. Hydro implemented its Non-Integrated Areas Pilot Program (NIA Pilot Program) for its Zone II service territory, which relies on diesel-generated electricity due to difficulties of integrating the area into the Zone I provincial grid. The NIA Pilot Program had two components: the Retrofit Home Demonstration and the New Construction component. Under the program, B.C. Hydro offers Zone II residents an incentive for converting from electric space and water heat to propane or oil. Existing home owners receive an additional incentive of a full insulation package. Both program components rely on trade allies (builders, developers, and contractors) for program delivery and implementation. The NIA Pilot Program served as a testing ground for the full-scale program planned to start November 1992.

Process Evaluation Method: In early 1992, RMI and B.C. Hydro Evaluation Department staff conducted a process evaluation through interviews with B.C. Hydro/Power Smart staff, trade allies, and related parties, and a review of NIA Pilot Program documents. Two samples were used for the New Construction component: the participant sample and the non-participant sample. The New Construction participant sample consisted of 55 residential and 8 developer participants. The non-participants were drawn from a random sample of Zone II new home owners (44) and developers who did not participate in the pilot. Participants and non-participants in the New Construction component were surveyed by telephone, and participants in the Retrofit Demonstration Home component were surveyed in person and by telephone to assess customer attitudes and perceptions of the pilot program.

Impact Evaluation Method:

Program Findings: Two differences distinguished this pilot program from other Zone II programs: the consideration given to the remote location and the attention given to price and cost considerations related to diesel-generated electricity. The NIA Pilot Program helped reduce diesel-generated electric load. Annual energy savings were projected over a six-year period. For New Construction the estimates were $2.6 \mathrm{GWh} / \mathrm{yr}$ for the 1990-1992 Pilot Program, 1.8 GWh/yr for the 1992-1993 fiscal year, and $10.9 \mathrm{GWh} / \mathrm{yr}$ cumulative savings for the 1992-1998 period. For the Retrofit Demonstration Home Program energy savings were estimated at $0.134 \mathrm{GWh} / \mathrm{yr}$ for the 1990-1992 period, $0.3 \mathrm{GWh} / \mathrm{yr}$ for the second period, and 10.1 GWh/yr for the cumulative 1992-1998 period. The NIA Pilot Program was launched without a strong evaluation component. in addition, a disparity was found in program benefits allocated under the NIA Retrofit Home and New Construction components.

Methodology Findings: The New Construction participant sample was unusually small because implementation of the NIA pilot was just beginning. For the Retrofit Home customer survey, it was noted that the five respondents quickly chose to convert from an electric to propane clothes dryer. This was explained by the fact that remotely located Zone II residents tended to be more self-sufficient and familiar with home repair.

Program Recommendations: The B.C. Hydro Planning and Evaluation Division should play a stronger role in ensuring that evaluation data are integrated into program design. The program manager should define criteria to distinguish an "existing home" and a "new home" under the NIA Program so that disparities of incentives could be reduced or eliminated. Both NIA Program components should reflect B.C. Hydro/Power Smart's commitment to promoting energy efficiency and improving the environment by, for example, developing a marketing tool. Training and education should be included because of the technical complexity of the program. The B.C. Hydro staff should be briefed on program history, purpose, and goals prior to launching this program full-scale. The program marketing should be improved by developing a program marketing strategy to reflect Native cultural values. The contractor bidding process should be reviewed by the program manager to ensure that it was cost-effective. Auditor and contractor training should be provided. Reporting and cost tracking should be strengthened. Trade ally support should be increased.

Methodology Recommendations:

Comments: 
Document Number: 0116

Study Title: Energy Code Compliance

Date: 08/01/95

Study Sponsor: American Council for an Energy-Efficient Economy

Authors: Smith, LA and S Nadel

Building Type: C R

Program Type, Code (C) or Utility (U): C U

Evaluation Type, Process (P) or Impact (I): $P$

Evaluation Purpose, Formative (F) or Summative (S): S F

Part of Process Addressed: C EI

Stakeholders Targeted: Code Officials, Consumers, State and Local Governments, Utilities, Homebuilders, Home Owners

Program Description: This study reviewed numerous studies of code compliance. Energy code compliance is of concern to consumers, state and local governments, and utilities. Energy savings from energy code compliance benefit building owners and occupants directly, while indirectly reducing reliance on non-renewable energy sources, cutting utilities' peak electricity demand, and reducing pollution associated with energy use. Codes also influence manufacturers of building products and equipment. However, energy codes have been traditionally considered less important than health, safety, and fire codes or the aesthetic and financial considerations of home owners and builders. A key study concern was to find ways for improving energy code compliance.

Process Evaluation Method: Compliance studies were reviewed to expand the body of knowledge on code compliance and to capture critical factors that affect energy code compliance. Only a few studies of compliance have been conducted. Case studies from California, Florida, Oregon, Washington, Minnesota, Georgia, and Massachusetts were reviewed and factors affecting energy code compliance were discussed and lessons were drawn to improve code compliance.

Impact Evaluation Method:

Program Findings: Lack of energy code understanding is a major enforcement barrier. Architects and engineers often give energy code requirements a low priority and say they seldom have the resources to address energy issues during design. Where familiar with energy codes, architects and engineers generally found them understandable but cumbersome to use. Even when designers complied with the code, builder field changes due to price concerns and/or ignorance of energy code requirements undermined compliance. Code officials often had insufficient education and technical backgrounds to understand all code provisions. Lack of training and attention to energy issues led code officials to treat the energy code as "optional" rather than as a minimum standard. Code officials needed better tools, including computer software and simple checklists. They cited lack of resources as a barrier to improved compliance and enforcement. Between building process stages (plan reviews, calculations, and field inspection) many changes could occur that might affect previous compliance levels. Code officials considered health, fire, and safety aspects of the building code to be more important than energy aspects. Manufacturers and wholesalers can play an important role in code compliance because they provide energy-efficient products. Financial constraints contributed to low compliance. Residential builders and purchasers emphasized aesthetics over energy conservation. Commercial builders gave cost control a higher priority than energy efficiency. Procedural issues related to permitting requirements, enforcement responsibilities with state and local jurisdictions, and enforcement activity schedules impeded effective energy-code implementation. Defining compliance was an issue because the overall compliance by a "pass-fail" criterion versus compliance by building component could make a difference in the overall compliance for an area. Energy code complexity leads to poor compliance. An irregular update process and short interval between standards updates creates confusion among builders and enforcement officials, thus reducing compliance rates. Field inspection is a key component in ensuring compliance. Compliance rates varied substantially among jurisdictions, usually ranging between $50 \%$ and $\mathbf{8 0} \%$. Understanding of energy-code technical components and benefits is lacking.

Methodology Findings:

Program Recommendations: Energy code compliance can be improved through simpler codes, education of members of the building community and code officials, development of improved compliance and enforcement tools, development of improved methods for analyzing compliance and enforcement, and coordination of energy code enforcement with other building activities such as mortgages, Home Energy Rating System (HERS) programs, and utility DSM programs.

Methodology Recommendations:

Comments: 
Document Number: 0117

Study Title: Evaluation of Commercial Code Enforcement Costs, Current Practices within the State of Oregon Date: $1 / 29 / 88$

Study Sponsor: Bonneville Power Administration (BPA)

Authors: Portland Energy Conservation, Inc. \& Ross Econometrics

Building Type: $\mathrm{C}$

Program Type, Code (C) or Utility (U): C

Evaluation Type, Process (P) or Impact (I): $P$

Evaluation Purpose, Formative $(F)$ or Summative (S): $F$

Part of Process Addressed: IE

Stakeholders Targeted: Commercial Building Owners, Bonneville Power Administration (BPA), Local Jurisdictions

Program Description: Chapter 53 is the Energy Conservation portion of the 1986 State of Oregon Structural Specialty Code and Fire and Life Safety Regulations for commercial structures. The purpose of this study is to assess the administration of Chapter 53 to evaluate implementation practices and associated costs for Chapter 53 implementation. Prior to this study, BPA funded the Early Adopter Program as part of its effort to promote Model Conservation Standards (MCS) throughout the region. This study was needed to assist BPA in determining how much MCS-related activities might add to the cost of commercial code enforcement.

Process Evaluation Method: The evaluation methodology had four major components: building file review and interview, employee salary information, overhead and expenses information, and survey of code officials. Data were collected from the state Building Code Agency.(BCA) and from four large, three medium, and three small jurisdictions, with the size of the jurisdictions based on city and county population. This data collection was accomplished by reviewing building files and by interviewing code officials, plan reviewers, and inspectors.

Impact Evaluation Method:

Program Findings: Two general conclusions were made regarding Chapter 53 administration. First, the lack of plan review in Chapter 53 for commercial facilities caused lighting efficiency to be neglected. Second, the jurisdictions studied appeared to do an excellent job in administering Chapter 53 insulation requirements for commercial buildings. The lack of plan review was due to the fact that many architects and engineers seemed unfamiliar with Chapter 53. Therefore, code officials used the certification provision of Chapter $\mathbf{5 3}$ instead of administering the code in its entirety. In the Chapter 53 review of energy conservation for a commercial building, structural integrity is the most important element followed by fire, life, and safety considerations. Energy conservation is perceived as the least important issue.

Methodology Findings:

Program Recommendations: Efficient lighting systems can have the greatest impact on energy conservation within new commercial buildings, yet this is the most neglected portion of Chapter 53 administration. This study recommends that BPA fund three lighting specialists for the State of Oregon to assist in the review of lighting system plans and in the inspection of installed lighting systems. Implementing this recommendation would ensure that in the city of Portland alone, an estimated $375 \mathrm{~kW}$ of unnecessary lighting would not be installed each year. The projected cost of this resource would be approximately 3 mills per $\mathrm{kWh}$. Some options were suggested to deal with Chapter 53 issues. First, training on energy conservation and familiarity with Chapter 53 Energy Conservation should be given to architects, engineers, and electrical contractors. Second, requiring Lighting Budget Worksheets for each jurisdiction would increase compliance with Chapter 53 significantly without substantially increasing the time required by the jurisdiction staff. Third, in addition to the inspections required by Section 305 , the building owner should employ a special inspector during the following types of work: concrete, ductile moment-resisting frame, reinforcing steel and pre-stressing steel, welding, high-strength bolting, structural masonry, reinforcing gypsum concrete, insulating concrete fill, spray-applied fireproofing, piling, drilled piers and caissons, special grading-excavation-and filling, and special cases of work involving hazards. Fourth, several officials expressed the desire to simplify Chapter 53 to make it more understandable. This would aid the effectiveness of Chapter 53 implementation and enforcement. Fifth, staff should be increased to include enforcement officials with experience in building trades, mechanical systems, electrical and plumbing systems.

Methodology Recommendations:

Comments: 
Document Number: 0118

Study Title: Cost-Effectiveness of the 1986 Washington State Energy Code: Report to the Legislature

Date: 01/15/88

Study Sponsor: Washington State Energy Office (WSEO)

Authors: WSEO

Building Type: R

Program Type, Code (C) or Utility (U): C

Evaluation Type, Process (P) or Impact (I): I

Evaluation Purpose, Formative (F) or Summative (S): $S$

Part of Process Addressed: 1

Stakeholders Targeted: Electric Utilities, Home Owners, Homebuilders

Program Description: In 1985, the Washington legislature passed SHB 1114 (Chapter 19.27A RCW), establishing new energy building standards and directed the implementation of an energy code (WSEC 1986) consistent with those standards. The legislation requires in-situ testing of the thermal transmittance of individual construction components and conservation measures proposed by the Northwest Power Planning Council (NPPC). This testing is referred to as the University of Washington Component Test Program (UWCTP). The UWCTP addresses the fact that the "steady-state" engineering method to determine building energy performance does not well represent its overall energy performance, which is influenced by the behavior of its inhabitants and the interaction between the environment and the building. This report describes the program as of 1988 . It also describes the Residential Standards Demonstration Program (RSDP) and data from that program, and analyzes the cost-effectiveness of the 1986 Washington State Energy Code (WSEC) based on RSDP data.

Process Evaluation Method:

Impact Evaluation Method: The UWCTP was an extremely detailed case study of four test houses on the University of Washington campus. Two of the houses were built to energy standards approximating the 1977 WSEC and two were built to standards approximating the NPPC Model Conservation Standards (MCS). The houses were occupied by student families. The houses were extensively instrumented with approximately 1,150 sensors to measure interior and exterior air and surface temperatures, heat fluxes, occupant actions, overall energy use, and other characteristics. The data collected were to be used to calibrate computer simulation models of whole-house thermal performance. In contrast to UWCTP, the RSDP involved monitoring of $165 \mathrm{MCS}$ and 171 1980 baseline houses located in 22 of Washington's 39 counties. The houses encompassed a wide range of sizes, architectural styles, heating system types, orientations, climatic conditions, occupant characteristics, and builder characteristics. Instrumentation of the RSDP homes was simple and consisted of electric meters to measure the space heating energy use, water heating energy use, and overall energy use.

Program Findings: The RSDP monitoring results showed that on a temperature-corrected basis, the MCS homes used an average of $40 \%$ and $43 \%$ less heating energy per sq. $\mathrm{ft}$. of floor space than the 1980 baseline houses in climate zones 1 and 2, respectively. The MCS homes were also found on average to have $53 \%$ less air leakage. Overall ventilation in the MCS houses, was comparable to that in the 1980 baseline houses. The cost of the 1986 WSEC efficiency measures were estimated from the component costs reported by the builders for Washington's 228 RSDP homes. A markup of $36 \%$ was used for builder overhead, profit, fees, and taxes. These costs were estimated to add an average of $\$ 0.98$ to $\$ 1.11$ per square of floor to the cost of electrically heated buildings, depending on climate zone. For gas-heated buildings, the additional costs were estimated at $\$ 0.46$ per square foot. Costeffectiveness of the 1986 WSEC was evaluated from the perspectives of the home buyer and society. To evaluate home buyer cost-effectiveness, two methods were used: annual cash flows and life-cycle costs. These methods utilized key cost parameters typical of Washington. The 1986 WSEC houses exhibited positive cash flows and reduced life-cycle costs when electricity was used for heating. When heated with natural gas, the 1986 WSEC houses exhibited reduced life-cycle costs, but yielded small negative cash flows during the first five to seven years. From a societal perspective, the 1986 WSEC houses exhibited costs that were significantly less than those of the alternative new generating resources or sources of supply.

Methodology Findings:

Program Recommendations: WSEO recommended no changes to WSEC when this report was presented to the legislature. The analysis indicated that the WSEC was cost-effective from both a home buyer and societal perspective. Lack of UWTCP data prevented WSEO from making a final analysis of cost-effectiveness for another year. Until that analysis was completed, WSEO believed recommending changes would b premature.

Methodology Recommendations:

Comments: 
Document Number: 0119

Study Title: A Plan for Evaluating Alternative Approaches to Financing Energy Improvements in Housing

Date: 08/01/94

Study Sponsor: National Renewable Energy Laboratory (DOE)

Authors: Collins, NE, BC Farhar, WM Babiuch, and J Eckert

Building Type: $C R$

Program Type, Code (C) or Utility (U): Other

Evaluation Type, Process (P) or Impact (I): P I

Evaluation Purpose, Formative (F) or Summative (S): $F$

Part of Process Addressed: D A

Stakeholders Targeted: DOE, HUD/FHA, DVA, USDA FmHA, State and Local Governments

Program Description: Since the mid-1980s, energy-efficiency mortgages (EEMs) and home energy rating systems (HERS) have been developing along parallel, but not necessarily coordinated, pathways. The result was that different rating systems were being developed in different parts of the country and were not widely used by the mortgage industry to determine the eligibility of homes for EEMs. In an effort to begin to tie the two closer together, to standardize HERS, and to convince the mortgage industry that EEMs are a good idea, the Department of Energy (DOE) and the Department of Housing and Urban Development (HUD) initiated the National Collaborative on HERS and EEMs, composed of members from 25 stakeholder organizations. Among the recommendations of the group was that participation in HERS and EEMs programs remain voluntary and that linkages be formed between HERS and EEMs products. The Collaborative was instrumental in contributing to the inclusion of provisions on financing energy improvements in housing in several 1992 legislative actions: (1)The National Energy Polity Act of 1992 (EPAct) requires DOE to formulate, in consultation with agencies, HERS providers, builders, utilities, and others, voluntary guidelines that encourage uniformity in HERS; (2)The Housing and Community Development Act of 1992 requires that the Federal Housing Administration (FHA) conduct EEMs pilot programs in five states (Alaska, Arkansas, California, Vermont, Virginia); (3) The Veterans Home Loan Program Amendments of 1992 require that the Department of Veteran's Affairs (DVA) conduct a demonstration EEMs program in 50 states for veterans; (4) Farmers Home Administration (FmHA) and HUD must use the Council of American Building Officials' Model Energy Code (CABO-MEC) 1992 standards for loans covering new construction.

Process Evaluation Method: The overall evaluation strategy was the following. DOE would designate an organization to be responsible for the national-level evaluation. This designated national evaluation entity (DNEE) would collect information about program implementation and data about program impacts, conduct analyses, summarize progress of programs, and prepare reports for Congress and others, as required. Each pilot state would designate an organization to be responsible for state-level evaluation activities. The designated state evaluation entity (DSEE) would have responsibility for collecting necessary information and data from organizations and agencies involved in the state program. The DNEE will develop information requirements "protocols" and data collection forms to be used by the DSEEs.

Impact Evaluation Method: In response to the requirements of EPAct and the Clinton Administration's Climate Change Action Plan (CCAP), DOE assigned to the National Renewable Energy Laboratory (NREL) responsibility for monitoring the activities of state programs in the HUD EEMs pilot program and designing a plan for evaluating the impacts of alternative financing approaches. This evaluation plan on the alternative approaches to financing energy improvements in housing was designed by members of the EEMs Evaluation Working Group (EWG) in 1994. This evaluation design is intended to ensure consistency of data collected across programs and to explain where state-level database maintenance and analysis can be eased by having some of the burden managed at the national level. Three types of evaluations are covered in this plan: 1) short-term process evaluation and feedback to identify implementation barriers and learn how they can be overcome; 2) traditional process evaluation; and 3) impact evaluation. Thirty-six evaluation questions are described in this plan. For each one, a hypothesis or expected outcome is stated, variables are listed, and the proposed method of analysis is summarized.

Program Findings:

Methodology Findings:

Program Recommendations:

Methodology Recommendations:

Comments: This report is an evaluation plan and does not address a specific program. Rather the suggestions are based on different programs across states. 
Document Number: 0120

Study Title: New Home Construction Research Project: Findings, Results \& Recommendations

Date: 06/01/95

Study Sponsor: Florida Power \& Light (FPL)

Authors: Florida Power \& Light

Building Type: $\mathbf{R}$

Program Type, Code (C) or Utility (U): U C

Evaluation Type, Process (P) or Impact (I): I.P

Evaluation Purpose, Formative (F) or Summative (S): $S$

Part of Process Addressed: I

Stakeholders Targeted: Home Owners and Renters, Homebuilders, Developers, Architects

Program Description: In March 1993, FPL began a two-year new home construction research project to identify, investigate, and quantify the impact and determine the cost-effectiveness of conservation opportunities in residential, single-family detached (SFD), new homes. Total expenditures for the research project were estimated at $\$ 5,900,000$. The project explored potential conservation opportunities in three segments of the new construction market: pre-construction, construction, and post-construction. FPL encouraged the construction of new homes with efficiency levels exceeding those associated with the minimum code requirements. FPL developed the BuildSmart residential new construction program (RNC) to incorporate the activities addressed in the pre-construction and construction markets. BuildSmart was introduced in April 1994. It offers three certification levels to builders and home buyers - gold, bronze, and silver - based on the energy-efficiency requirements of the code. These levels are determined by a home's energy performance index (EPI), indicating the efficiency level. Process Evaluation Method: See impact evaluation method discussion.

Impact Evaluation Method: Seven evaluations were conducted: two for the BuildSmart program (impact evaluation, market evaluation), an inspection evaluation, a code/rating-tool evaluation, a cooling upgrade ovaluation, a heating upgrade evaluation, and a domestic hot water (DHW) evaluation. For the BuildSmart program impact evaluation models were developed to estimate program impacts based on pilot program participation and a thorough evaluation of baseline home features. The DOE-2 model was used to estimate cooling and heating impacts, adjusted using statistical analyses of end-use metering (EUM) data. DHW impacts were analyzed to identify heat recovery unit (HRU) energy and demand effects. For the market evaluation, 134 SFD home builders were surveyed to gather baseline information on building practices. Surveys were conducted with 950 occupants of new non-BuildSmart homes to assess awareness of energy-efficiency options and how this affected home purchase decisions. To conduct the inspection evaluation, two data sets describing building characteristics were assembled from code compliance forms and the data were used to establish baseline building features. For the code/rating-tool evaluation baseline models were developed to accurately represent typical SFD RNC in FPL's service territory.

Program Findings: The BuildSmart program was cost-effective, using Florida's approved methodology. Factors influencing cooling are primarily customer behavior, home energy features, and weather. No cooling impact from ceiling fan usage was supported by the research. Additional study is necessary to verify the lack of impacts. Heating is highly concentrated during brief periods. Homes with heat pumps had an average peak hour demand about half that for homes with strip heaters. DHW energy consumption averaged $2,468 \mathrm{kWh}$ for sites with electric resistance water heaters. For electric-resistance water heaters, peak summer coincident demand was $205 \mathrm{~W}$, about one-fourth the winter coincident demand. The first year of the pilot BuildSmart program resulted in annual energy savings of $267,000 \mathrm{kWh}$ and a summer demand reduction of $130.4 \mathrm{~kW}$. The south climate provides larger annual energy impacts than the other two climates. Summer BuildSmart demand impacts for cooling, heating and DHW are between $15 \%$ and $32 \%$ of baseline coincident peak demand. Winter demand is reduced between $11 \%$ and $16 \%$. Code compliance was tied primarily to the building permit process, with only weak enforcement during the construction process. The submitted EPI alone cannot be used effectively to determine the energy efficiency of the inspected home; some homes' construction features were not accurately recorded on the forms. The compliance gap in the central climate was found to be larger than in the north and south climates.

Methodology Findings:

Program Recommendations: The BuildSmart pilot program and associated research should be continued through 1995 , so that additional information obtained from the sample of houses could add confidence to the program assumptions and recommendations. FPL recommended several technical revisions and analysis steps.

Methodology Recommendations:

Comments: 
Document Number: 0121

Study Title: Utility Residential New Construction Programs: Going Beyond the Code

Date: 08/01/95

Study Sponsor: U.S. DOE

Authors: Vine, $\mathrm{E}$

Building Type: $R$

Program Type, Code (C) or Utility (U): U

Evaluation Type, Process (P) or Impact (I): I

Evaluation Purpose, Formative (F) or Summative (S): $S$

Part of Process Addressed: I

Stakeholders Targeted: Electric Utilities

Program Description: In 1995 Lawrence Berkeley National Laboratory conducted the Database on Energy Efficiency Programs (DEEP) project to evaluate the cost-effectiveness of 10 DSM utility programs in the United States. The programs were the Manufactured Housing Acquisition Program sponsored by BPA, the Super Good Cents Program (BPA), the Energy Crafted Home Program (Boston Edison Company), the Good Cents Home Program (Central Maine Power Company), the Energy Crafted Home Program (New England Electric System), the NYSE-Star Program (New York State Electric and Gas Company), the Good Cents Home Program (Orange and Rockland Company), the Comfort Home Program (Pacific Gas and Electric Company), the Excellence in Energy Efficiency Program (PECO Energy Company), and the Welcome Home Program (Southern California Edison Company).

Process Evaluation Method:

Impact Evaluation Method: Two perspectives were used to evaluate the residential new construction programs: a resource acquisition perspective and a market transformation (program spillover) perspective. Programs were selected based on four objectives. First, a focus was put on programs that promoted the design and construction of energy-efficient residences, with particular emphasis on the building envelope. Second, full-scale programs were selected. Third, adequate information had to be available to estimate the total resource cost (TRC) of energy efficiency including direct annual energy savings, total utility cost of the program, total cost of the program to participating customers, and economic lifetimes of measures installed. Fourth, programs that offered rebates to builders, home buyers, or manufacturers were preferred. Based on the literature, consultations with DSM program experts, and preliminary telephone screening of candidate programs, data were collected in a standardized way on the selected programs. Utility staff were contacted to verify the information and to obtain missing information. Program Findings: The 10 programs were found to be either not cost-effective, in danger of being discontinued, or already terminated. It was concluded that the poor cost-effectiveness of residential new construction programs stemmed from the following: 1) increased tightening of state building standards and national appliance standards which have improved the baseline; 2) inadequate marketing strategies; and 3) savings calculations that excluded savings by nonparticipants and savings from non-program measures by participants as a result of the program (the "market transformation" perspective). When weighted by energy savings, the average TRC was found to be 5.7 \&/kWh; the median was $20.8 \mathrm{k} / \mathrm{kWh}$; and the TRC ranged from a low of $3.4 \mathrm{\phi} / \mathrm{kWh}$ to a high of $725.1 \phi / \mathrm{kWh}$ (in 1994 dollars). From the TRC perspective, the performance of these programs was generally poor. The TRC of only two programs was below $5 \% / \mathrm{kWh}$ and $70 \%$ of the programs were above $15 \% / \mathrm{kWh}$.

Methodology Findings: Due to the small sample size, a statistical analysis could not be conducted to determine key determinants of program performance. A larger data set could help to learn more about the differences in results.

Program Recommendations: To improve cost-effectiveness of residential new construction programs, the following steps should be taken: 1) promote technologies and advanced building design practices that significantly exceed standards; 2) reduce program marketing costs and developing more effective marketing strategies; 3) recognize the role of these programs in increasing compliance with building codes; and 4) allow utilities to obtain an "energy-savings credit" for program spillover (market transformation) impacts. Utilities should form strong and trusting partnerships with the building community and with local and state government.

Methodology Recommendations: For data collection activities, a market baseline must be accurately measured by assessing attitudes and values and tracking sales. For data analysis, the following steps were recommended: 1) model market processes; 2) analyze the relationship between attitudes and behavior; 3) compare pre-program and post-program market survey and billing data; 4) perform multivariate regression with control groups from outside the service area; 5) simulate market transformation; and 6) compare multiple methodologies.

Comments: 